NBER WORKING PAPER SERIES

\begin{abstract}
THE LIMITS OF MERITOCRACY: SCREENING BUREAUCRATS UNDER IMPERFECT VERIFIABILITY
\end{abstract}

\author{
Juan Carlos Suárez Serrato \\ Xiao Yu Wang \\ Shuang Zhang \\ Working Paper 21963 \\ http://www.nber.org/papers/w21963 \\ NATIONAL BUREAU OF ECONOMIC RESEARCH
1050 Massachusetts Avenue
Cambridge, MA 02138
}

February 2016, Revised May 2019

\begin{abstract}
Previously circulated as "The Limits of Political Meritocracy: Screening Mayors in China Under Imperfect Verifiability." We thank the editor and two anonymous referees for very useful suggestions. We are also grateful to Douglas Almond, Kehinde Ajayi, Attila Ambrus, Abhijit Banerjee, Pat Bayer, Charlie Becker, Prashant Bharadwaj, Allan Collard-Wexler, Julie Cullen, Esther Duflo, Pascaline Dupas, Erica Field, Raquel Fernandez, Fred Finan, Rob Garlick, Bob Gibbons, Gopi Goda, Cynthia Kinnan, David Lam, Danielle Li, Hugh Macartney, Matt Masten, Michael Powell, Nancy Qian, Debraj Ray, John van Reenen, Orie Shelef, Erik Snowberg, Duncan Thomas, Chris Udry, Daniel Xu, Xiaoxue Zhao, and participants in the NBER/BREAD Fall Development Meetings, the Duke Labor/Development seminar, the Colegio de Mexico seminar, the 2015 World Congress of the Econometric Society, the 2015 Society for the Advancement of Economic Theory, NEUDC Brown, the Stanford GSB PE seminar, the NYU Development seminar, and the MIT Sloan Organizational Economics seminar for helpful comments. This paper was previously circulated under the title "The One Child Policy and Promotion of Mayors in China." Suárez Serrato and Zhang thank the Stanford Institute for Economic Policy Research (SIEPR) for financial support. Suárez Serrato gratefully acknowledges support from the Kauffman Foundation. We thank Pawel Charasz, Stephanie Karol, Han Gao, Matt Panhans, and Victor Ye for providing excellent research assistance. The views expressed herein are those of the authors and do not necessarily reflect the views of the National Bureau of Economic Research.
\end{abstract}

NBER working papers are circulated for discussion and comment purposes. They have not been peerreviewed or been subject to the review by the NBER Board of Directors that accompanies official NBER publications.

(C) 2016 by Juan Carlos Suárez Serrato, Xiao Yu Wang, and Shuang Zhang. All rights reserved. Short sections of text, not to exceed two paragraphs, may be quoted without explicit permission provided that full credit, including $\odot$ notice, is given to the source. 
The Limits of Meritocracy: Screening Bureaucrats Under Imperfect Verifiability

Juan Carlos Suárez Serrato, Xiao Yu Wang, and Shuang Zhang

NBER Working Paper No. 21963

February 2016, Revised May 2019

JEL No. D23,D73,D86,M12,M51,O12,O15,O53,P23,P26,P48

\section{ABSTRACT}

Does bureaucratic ability predict promotion in governments? We show that self-reported performance in enforcing the One Child Policy predicts mayoral promotion in China. However, misreporting handicaps screening-a non-manipulated performance measure does not predict promotion. We show that this is consistent with a model where a government has a meritocratic objective but underestimates the imperfect verifiability of performance, rather than a model where a government is only interested in the illusion of meritocracy. Thus, despite meritocratic intentions, we challenge the notion that a successful promotion system effectively substituted for democratic institutions in explaining Chinese growth.

Juan Carlos Suárez Serrato

Department of Economics

Duke University

213 Social Sciences Building

Box 90097

Durham, NC 27708

and NBER

jc@jcsuarez.com

Xiao Yu Wang

Department of Economics

Duke University

213 Social Sciences Building

Box 90097

Durham, NC 27708

and NBER

xy.wang@duke.edu
Shuang Zhang

Department of Economics

University of Colorado Boulder

UCB 256

Boulder, CO 80302

shuang.zhang@colorado.edu 


\title{
The Limits of Meritocracy: Screening Bureaucrats Under Imperfect Verifiability*
}

\author{
Juan Carlos Suárez Serrato \\ Duke University \& NBER \\ Xiao Yu Wang \\ Duke University \& NBER
}

\author{
Shuang Zhang ${ }^{\dagger}$ \\ University of Colorado Boulder
}

May 22, 2019

\begin{abstract}
Does bureaucratic ability predict promotion in governments? We show that self-reported performance in enforcing the One Child Policy predicts mayoral promotion in China. However, misreporting handicaps screening - a non-manipulated performance measure does not predict promotion. We show that this is consistent with a model where a government has a meritocratic objective but underestimates the imperfect verifiability of performance, rather than a model where a government is only interested in the illusion of meritocracy. Thus, despite meritocratic intentions, we challenge the notion that a successful promotion system effectively substituted for democratic institutions in explaining Chinese growth.
\end{abstract}

JEL Codes: D23, D73, D86, M12, M51, O12, O15, O53, P23, P26, P48.

\footnotetext{
${ }^{*}$ We thank the editor and two anonymous referees for very useful suggestions. We are also grateful to Douglas Almond, Kehinde Ajayi, Attila Ambrus, Abhijit Banerjee, Pat Bayer, Charlie Becker, Prashant Bharadwaj, Allan Collard-Wexler, Julie Cullen, Esther Duflo, Pascaline Dupas, Erica Field, Raquel Fernandez, Fred Finan, Rob Garlick, Bob Gibbons, Gopi Goda, Cynthia Kinnan, David Lam, Danielle Li, Hugh Macartney, Matt Masten, Michael Powell, Nancy Qian, Debraj Ray, John van Reenen, Orie Shelef, Erik Snowberg, Duncan Thomas, Chris Udry, Daniel Xu, Xiaoxue Zhao, and participants in the NBER/BREAD Fall Development Meetings, the Duke Labor/Development seminar, the Colegio de Mexico seminar, the 2015 World Congress of the Econometric Society, the 2015 Society for the Advancement of Economic Theory, NEUDC Brown, the Stanford GSB PE seminar, the NYU Development seminar, and the MIT Sloan Organizational Economics seminar for helpful comments. This paper was previously circulated under the title "The One Child Policy and Promotion of Mayors in China." Suárez Serrato and Zhang thank the Stanford Institute for Economic Policy Research (SIEPR) for financial support. Suárez Serrato gratefully acknowledges support from the Kauffman Foundation. We thank Pawel Charasz, Stephanie Karol, Han Gao, Matt Panhans, and Victor Ye for providing excellent research assistance.

${ }^{\dagger}$ Juan Carlos Suárez Serrato: Department of Economics, Duke University, and NBER, jc@jcsuarez.com. Xiao Yu Wang: Department of Economics, Duke University, and NBER, xy.wang@duke.edu. Shuang Zhang: Department of Economics, University of Colorado Boulder, shuang.zhang@colorado.edu.
} 
Bureaucracies play a central role in providing goods and services to people around the world, and the selection of bureaucrats has enormous impacts on welfare and inequality (Acemoglu, 2005, Besley and Persson, 2010, Rasul and Rogger, 2016). Scholars argue that political meritocracies - incentive systems explicitly designed to identify able leaders - may supplant democratic institutions by effectively screening for bureaucratic ability. ${ }^{1}$ We provide a new assessment of the screening power of meritocratic incentives by recognizing the fact that bureaucrats are often evaluated on the basis of imperfectly observed and unverifiable measures of performance. How effective are political meritocracies when performance metrics are manipulable?

We answer this question by analyzing the promotion patterns of mayors responsible for the implementation of China's One Child Policy (OCP). We find that, while provincial governments used promotion incentives to screen for mayoral ability, manipulation of reported birth statistics weakened the screening power of the meritocracy to the extent that promoted mayors were not ultimately of higher ability.

Answering this question is hampered by several challenges. First, output may be rewarded with promotion even in cases where there is no screening motive. This underscores the need to first establish whether a set of incentives is driven by an objective to identify high-ability leaders. Second, unobserved factors that can lead to cadre advancement (e.g. political connections, unobserved ability, economic growth) may be correlated with observed performance and may confound the relation between performance and compensation. Third, it is often not possible to detect manipulation in performance metrics, which is essential to evaluating the screening efficacy of any incentive system.

We overcome these challenges by combining theoretical insights with institutional features of Chinese mayoral promotion. First, we formalize the incentive design of a government that compensates mayors who differ in privately-known ability on the basis of manipulable performance measures. The model captures our empirical setting and connects the equilibrium incentive structure with the strength of the government's screening motive (i.e. meritocracy). We show that screening is costly for the principal, in the sense that incentives that prioritize screening reduce total output. Intuitively, a principal that prioritizes screening over production will provide incentives that separate the effort exerted by agents of differing abilities, as this increases the chance that agents with higher output are also the ones with higher ability. However, these incentives reduce the effort of lower-ability agents as well as total production. We characterize this trade-off between extracting information and maximizing production, and derive testable comparative statics describing how the impact of increased output on the probability of being promoted varies with respect to features of the environment, such as promotion competitiveness and output variability. These theoretical insights enable us to establish empirically whether observed incentives are consistent with a screening (meritocratic) motive.

We apply these insights to the promotion of Chinese mayors and provide empirical evidence that provincial governments used the implementation of the OCP to screen for high-ability cadres. We focus on the $\mathrm{OCP}$ as it is broadly recognized as one of the top three priorities in cadre evaluation (Birney 2014), and as this setting provides a unique opportunity to evaluate whether imperfect

\footnotetext{
${ }^{1}$ Bell (2015) defines political meritocracy as "the idea that a political system is designed with the aim of selecting political leaders with above average ability to make morally informed political judgments." Bell and Li (2012) provide an overview of meritocracy in the Chinese political system from the point of view of political science.
} 
verifiability limited the system's effectiveness at screening bureaucrats. First, we find that mayors with better self-reported OCP performance are more likely to be promoted. ${ }^{2}$ On average, reducing the reported rate of natural increase by 1 in 1,000 people increases the probability of promotion by $13 \%$ and is equivalent, in its effect on promotion, to an $10 \%$ increase in GDP. ${ }^{3}$ Second, we find that promotion patterns are consistent with the comparative statics of a system of meritocratic incentives. We show that OCP performance is more predictive of promotion in provinces where OCP is a more informative signal of mayoral ability. We also show that OCP performance is less predictive of promotion in provinces where promotions are more competitive, as it is more difficult for any given mayor to achieve the maximum output-and thus be promoted-when the pool of competitors is larger. ${ }^{4}$ These results suggest that, beyond implementing the OCP, promotion incentives were used deliberately to screen for high-ability mayors.

Finally, we study whether the meritocracy succeeded at identifying high-ability mayors. Since mayors are evaluated on the basis of self-reported data, mayors may misreport. We use population auditing surveys and employ a retrospective measure of performance based on census microdata to analyze potential cheating behavior. We find that mayors adjust their manipulation of data on the rate of natural increase. This is consistent with our model's prediction that mayoral effort increases and misreporting decreases when audits increase the probability of detection.

Our model shows that the scope for manipulation limits the power of the screening mechanism to select high-ability mayors: the expected ability of the promoted mayor is a combination of the expected ability under a random promotion scheme and a scheme where OCP performance is perfectly verifiable. Our results show that provincial leaders attempted to use promotions as a meritocratic screening device, and that mayors respond to these incentives by working harder in years when audits are stronger. While provincial governments were not able to evaluate the extent of misreporting in real time, our retrospective analysis shows that, in practice, mayor manipulation rendered the meritocracy ineffective as actual OCP performance using census data is not predictive of promotion.

We explore the robustness of our results to a number of potential concerns. We assuage concerns that our conclusions are the spurious byproduct of unobserved measures of performance or political connections (Shih et al. 2012, Jia et al. 2015). By focusing on the comparative statics of the model, the finding that OCP incentives are consistent with a meritocratic objective relies on non-trivial patterns that are unlikely to result from spurious correlations. In particular, any story of potential confounders that may explain the effect of OCP performance on promotion must also account for

\footnotetext{
${ }^{2}$ Throughout, we use the demographic concept of the rate of natural increase, which is defined as the crude birth rate minus the crude death rate. Targets for the rate of natural increase are set every five years in Five-year Plans. We measure mayors' performance in implementing the OCP by the gap between the centrally-set target of natural increase and the rate they report achieving.

${ }^{3}$ In particular, we show that OCP matters for promotion beyond meeting the target, providing empirical evidence for Wong (2012), who reports that officials are penalized in promotion for poor population control, regardless of their performance in other categories.

${ }^{4}$ These results are robust to alternative measures of noisiness and competitiveness. We use three measures of noisiness: the province-level variance in birth rates, the province-level variance in gross migration, and the average of both measures. We use the average tenure of provincial officials as a first measure of competitiveness. Intuitively, provinces with higher average tenure are more competitive, since this means slots for promotion open up less frequently for aspiring mayors. We also use the average promotion rate as a second measure of competitiveness as well as the average of both measures.
} 
the comparative statics on noise and competitiveness. ${ }^{5}$ Nonetheless, we pursue several alternative strategies to allay these concerns. First, we use the panel structure of our data and include mayor fixed effects. ${ }^{6}$ Second, we control for alternative, non-manipulable measures of economic growth. ${ }^{7}$ Third, we pursue an identification strategy to isolate variation in OCP performance that is exogenous to time-varying political connections. We use changes in the targets set by the central government in five-year plans as an instrument for OCP performance. ${ }^{8}$ Finally, we show the robustness of our results to other potential concerns, including measurement error, prefecture-level incentives, and alternative specifications. In all cases, we find that OCP performance has economically and statistically significant effects on promotion, that the comparative statics are consistent with a system of meritocratic incentives, and that actual OCP performance is not predictive of promotion.

Rather than attributing these results to corruption or to an aversion to meritocracy in the Chinese government, our results show that provincial governments attempted to use the OCP to identify and promote high-ability leaders. However, the imperfect verifiability of birth rates limited the efficacy of the meritocracy and resulted in a promotion rule that effectively promoted mayors at random. Counter to common belief (e.g., Wong, 2012), the use of the OCP as a screening tool may have lowered the human cost of the policy, since incentives that did not prioritize screening would have resulted in higher overall effort in controlling population growth. Overall, our results form a counterpoint to the argument that the success of the Chinese authoritarian government can be attributed to a successful system of meritocratic promotions (Bell and Li, 2012).

Our model makes three innovations that are at the core of our results. First, in contrast to the career concerns model of Holmstrom (1999), we analyze a setting where multiple agents with private abilities compete. This feature gives rise to the trade-off between signal separation versus production. ${ }^{9}$ Second, our model extends the classic literature on tournaments (e.g. Lazear and Rosen 1981) by enriching the principal's objective to allow for an unobserved value for meritocracy. The possibility that the government values the screening motive beyond ability's role in production is crucial for studying political meritocracy. Finally, we allow for imperfectly-verifiable performance metrics to show how misreporting limits the screening power of meritocracies. These theoretical

\footnotetext{
${ }^{5}$ We also derive alternative comparative statics on noise and competitiveness whenever promotion is based on an unobserved metric that is correlated with OCP performance. We show that if OCP performance is correlated with connections or with an unobservable measure of performance, we would not expect to see the empirical comparative statics that are revealed by the data.

${ }^{6}$ Our regressions also include prefecture fixed effects, year fixed effects, prefecture-year characteristics, and potential determinants of the targets.

${ }^{7}$ These measures include the $\log$ of economic output, economic growth rate, and non-manipulable measures of output such as railway cargo volume and electricity usage.

${ }^{8}$ We show that the instrument is not correlated with economic growth, indicating that the effect of OCP performance on promotion is not a spurious byproduct of economic development. We also provide evidence for the validity of this strategy by showing that new province targets are not set to favor particular mayors, and that mayors are not strategically promoted to help them avoid toughened targets.

${ }^{9}$ Our focus on the relation between government objectives and equilibrium incentives is more closely tied to research on organizational forms (e.g., Maskin et al. 2000) than to the career concerns literature. In contrast to the current literature that expands on the career concerns model of Holmstrom (1999) (see, e.g., Persson and Zhuravskaya 2015, Jia 2014, and Jia et al. 2015), this paper allows for strategic interaction between agents in their effort choice and misreporting behavior, which is crucial for analyzing the principal's objective. For example, Jia et al. (2015) analyze single-agent promotion where the agent is non-strategic - her ability is exogenously-given and she takes no actions. In this setting, there is no role for the principal to use incentives, like promotion, to influence agents' efforts, and it is not possible to infer the principal's objective from equilibrium incentives.
} 
innovations open the door to studying a variety of new questions. In our setting, they enable us to use observed patterns of compensation to learn about the underlying objectives of the government, and to evaluate how effective the government is at achieving those objectives.

Our model simplifies some features of the environment that are not critical for our purposes. First, we focus on a single performance measure, in order to isolate the trade-off between production and signal extraction, while allowing for a manipulable measure of performance. In contrast, the standard multi-tasking model is single principal-single agent, and there is no misreporting of output by agents. Strategic misreporting from multiple mayors on multiple tasks complicates the analysis beyond the scope of this paper, leads us away from our main research questions, and is unlikely to affect our main results. ${ }^{10}$ Similarly, we do not directly model the role of political connections. Instead, our model derives testable predictions for the case where the measure of performance is related to an unobserved margin, such as a political connection. We find that the predictions go against the case of meritocracy, which implies that we may empirically separate the two cases. Regardless of these abstractions, our model shows that treating the structure of incentives as an equilibrium object and understanding the underlying objectives that determine them is essential to a complete understanding of meritocracy, its effect on incentives, and its efficacy in selection.

Given the wide-ranging policies that are implemented through promotion incentives in China, the economics literature is just starting to recognize the importance of this mechanism for the effective implementation of economic policy. ${ }^{11}$ In particular, the literature on political selection is not able to empirically distinguish incentives designed for screening from those designed for output production, or to identify screening made ineffective by misreporting. This paper provides a fundamental reassessment of the empirical relation between promotion and reported performance by combining a rich empirical environment with a model that is suited to the empirical setting. Our model shows that identifying a truly meritocratic objective requires tracing out the principal's trade-off between screening for ability and maximizing output, and that meritocratic policies may fail to select high ability mayors in the presence of misreporting.

While there is evidence to suggest that the implementation of the One Child Policy was used to screen mayoral ability beyond other measures such as GDP (e.g. Birney (2014); Scharping (2003); Wong (2012)), this is ultimately an empirical question. We test the rich predictions from our model and show that the implementation of the world's largest population control program in history was significantly affected by the use of promotion incentives. ${ }^{12}$ We provide evidence both that performance measures are manipulated, ${ }^{13}$ and that this weakens the efficacy of the screening mechanism

\footnotetext{
${ }^{10}$ We know from Holmstrom and Milgrom (1991) that, in multi-tasking settings, noisiness in one performance measure may depress the power of the optimal, linear wage for all tasks. Even if this multi-tasking intuition generalizes to multiple agents and imperfectly verifiable output, our main result relating the principal's trade-off between signal extraction and production should remain unchanged. The key insight that the principal moves from a piece rate to a tournament as her value of screening grows should not change since the power of both schemes would be reduced.

${ }^{11}$ See, for example, Shih et al. 2012, Li and Zhou 2005, Zheng et al. 2014, Landry 2008, and Fisman and Wang 2015.

${ }^{12}$ Our results thus add to the literature on incentive design by taking theory to a unique dataset in an interesting Chinese setting. While papers in contract theory explore incentive structures given noisy signals of effort or ability ( Lazear and Rosen 1981, Baker et al. 1994, Holmstrom 1999, Rochet and Stole 2003), the body of empirical evidence testing these theoretical mechanisms is relatively small (Baker et al. 1994, Prendergast 1999, Chiappori and Salanie 2000).

${ }^{13}$ Our paper is also related to forensic economics, a literature which uncovers evidence of hidden behaviors and
} 
in identifying high-ability individuals. ${ }^{14}$

The enforcement of the OCP is uniquely suited to our analysis for several reasons. First, the central government audits population figures by conducting fertility surveys. ${ }^{15}$ The timing of the audits generates variation in audit probabilities, which are a central part of our model. Second, data from auxiliary population surveys can be used to measure misreporting and to evaluate the screening efficacy of promotion incentives. Third, changes in directives from five-year plans generate identifying variation in incentives. Finally, enforcing the OCP is recognized as the most difficult task among local officials (Scharping, 2003); thus, an official's proficiency in controlling births is likely an effective signal of a mayor's ability. In addition, we deepen the understanding of the OCP (e.g., Qian 2009, Ebenstein 2010, Wei and Zhang 2011, Choukhmane et al. 2014). Our findings suggest a mechanism for the persistence of the $\mathrm{OCP}$ - in addition to caring inherently about reducing births, the meritocracy-minded government, unable to accurately evaluate the strength of its audits, erroneously believed that reported success at implementing the OCP was informative of mayors' ability.

The rest of the paper is organized as follows. Section 1 describes institutional details of the OCP and its implementation. Section 2 develops a model of optimal compensation for mayors and discusses testable predictions. We describe our data in Section 3. Section 4 tests the theoretical predictions on the promotion rule and Section 5 provides evidence of data manipulation in response to audit risk and analyzes the efficacy of the promotion mechanism in selecting high-ability mayors. Section 6 concludes by discussing the role of manipulation in analyzing equilibrium promotion rules.

\section{Institutional Details of the One Child Policy}

In 1979, soon after China's Cultural Revolution and after a decade-long economic crisis, Deng Xiaoping expressed the fear that "without birth planning, economic growth will be consumed by population growth." Since then, all economic planning has presupposed success in population control. At the national level, a specific target on population growth was set so that the total population would not exceed 1.2 billion in 2000. Chinese scientists working for the government further developed a projection that showed that, in order to achieve the population target, the optimal fertility level should be one child per woman (Scharping 2003). This recommendation was incorporated into the family planning policy in the same year and the policy was thereafter known in the West as the One Child Policy (OCP). ${ }^{16}$

corruption, and which studies the role of audits in limiting corruption. See Zitzewitz (2012) for a review of recent papers in forensic economics, as well as studies that use audits to detect corruption, including Olken (2006), Ferraz and Finan (2008), Ferraz and Finan (2011), and Bobonis et al. (2013).

${ }^{14}$ Whether screening mechanisms successfully select high-ability agents for promotion is still an open question in many areas. For example, recent studies find empirical evidence of incentive distortions, including teacher manipulation of test scores (Jacob and Levitt 2003) and of student composition in test-taking pools (Cullen and Reback 2006). However, these studies do not investigate the impact that manipulation has on the quality of teachers hired.

${ }^{15}$ In contrast, it is difficult to evaluate the accuracy of local GDP figures and no formal auditing is used by upper-level government to verify these reported measures of performance.

${ }^{16}$ The OCP was intended to end by 2000. Amendments have relaxed this policy for single children, and it was further relaxed to a universal two-child policy in 2015. However, birth planning remains a 基本国策 (i.e., "a fundamental national policy") of the government (http://news.sina.com.cn/c/2016-01-11/doc-ifxnkkuy7874744.shtml). 
Under the OCP, a limit of one child per family was strictly enforced in urban areas, and secondchild permits were issued for special exemptions in rural areas and for ethnic minorities. Some other exemptions were also granted, for example, to couples who were disabled or who lived in remote areas. Provinces with a tight policy restricted themselves to common norms for exemptions, while regions with a more relaxed policy may include other criteria. The national policy was relaxed in 1984 to allow rural couples to have a second child if their first-born was a girl.

\subsection{Enforcement Mechanisms}

A variety of birth control methods have been used to enforce the OCP. Sterilization and insertion of an intrauterine device (IUD) after the first or second birth were implemented on a large scale. Between 1979 and 1999, the percentage of women of reproductive age who underwent sterilization rose from $21 \%$ to $35 \%$ (Scharping 2003). Meanwhile, coerced abortions of unauthorized pregnancies have been used as a "remedial measure making up for contraceptive failures." For above-quota births, financial sanctions are the main instrument for enforcing the OCP. Depending on the location and time period, the birth of an extra child can cost a family $10 \%-25 \%$ of their annual income for $7-14$ years. Other punishments widely used include denial of bonus payments, health and welfare benefits, denial of job promotions or even demotions in urban work units, as well as the confiscation of family farmland in rural areas.

Strong resistance and non-compliance at the grassroots level, especially in rural areas, made it very challenging to enforce the OCP. As documented by Scharping (2003), internal reports issued within the party in the 1980s and 1990s acknowledged that assaults on local birth-planning cadres were frequently provoked by coercive abortions, sterilizations, and the administration of penalties.

\subsection{Mayoral Promotions and the OCP}

“计划生育是天底下最难的一项任务!"

"Birth planning is the hardship number one under heaven!"

-A Chinese cadre (Scharping, 2003)

The central government controls the appointment, evaluation, promotion, and demotion of subnational officials in China, and the career paths of these officials are determined by the performance of their jurisdictions (Xu 2011). The central government directly controls the key positions at the province level and grants the provincial government the power to appoint key officials at the prefecture level. The provincial government stipulates a set of performance criteria for mayors.

Economic growth, social stability, and enforcement of the One Child Policy are consistently among the highest priorities (Birney 2014). In a published list of performance indicators of 104 prefectures in 2000, GDP per capita was used to evaluate economic growth and the birth rate was used to evaluate enforcement of the OCP (Landry 2008). However, despite the consensus that the OCP is among the highest priorities of the Chinese government, we are not aware of empirical evidence on the role of enforcing the OCP in the evaluation of officials. This is the first study to 
present a bigger picture by considering the role of the OCP, in addition to economic growth, in determining promotion of officials.

A centrally-controlled planning system has monitored the local enforcement of the OCP since the 1980s. At the highest level, the State Planning Commission sets birth plan targets as part of five-year plans, with the original goal of meeting the national population goal of 1.2 billion by the year 2000. Thus, the annual province-level targets for population and birth rate are set every five years. Only national and provincial targets are set; these targets are assigned to prefectures and further distributed to lower levels (Hardee-Cleaveland and Banister 1988). Prefectures are responsible for local implementation and submit the population and birth data to provinces. Provinces then transmit these numbers to the central government.

Birth control performance is directly linked to cadre evaluation. Hardee-Cleaveland and Banister (1988) document the following:

In Shaanxi in March 1987, the provincial party committee deputy secretary and acting governor "demanded that leaders at all levels should simultaneously grasp two kinds of production - economic production and reproduction - and take measures to do this work well and firmly. Otherwise, they are not qualified leaders."

\subsection{Data Collection and (Mis)reporting by Chinese Mayors}

Data for the evaluation of mayoral OCP performance are gathered by a birth planning commission (Scharping 2003). The birth planning commission is in charge of workers in villages (rural), neighborhood committees (urban), and industrial enterprises (urban), who file cards on women of reproductive age, and keep track of their births. Prefectures do random checks twice a year to verify these numbers, while the birth planning commission does random checks more frequently. These local workers have no direct incentive to deviate from their assigned task, since their incomes and careers do not explicitly depend on these numbers, in contrast with the mayor. The prefecture then aggregates these local numbers and sends a prefecture-level number to province. The data manipulation (misreporting) is most likely to occur through the mayor (either directly or indirectly), since her performance evaluation depends explicitly on this number.

In addition to the birth rate, the birth planning rate, which is the percentage of total births that are authorized, is also reported from lower level governments. In practice, lower level authorities often report very high birth planning rates of 98-99\%, which are extremely unrealistic and unreliable. This is because it is much more difficult for the central government to verify whether a birth is authorized than whether a birth occurred. For this reason, the birth planning rate is not used in the evaluation of mayor performance (Scharping 2003).

The leadership has been aware that, even for birth rate numbers, there are potential problems with data quality since the data are reported by officials whose evaluations depend on these data. Population census data are ideal as a systematic comparison with reported numbers, but are only conducted approximately every ten years $\left(1982,1990\right.$, and 2000). ${ }^{17}$ A mini census for $0.1 \%$ of the

\footnotetext{
${ }^{17}$ Census data are collected independently by the City Bureau of Statistics (organized by the National Bureau of Statistics (NBS)). They survey every household to gather birth and population information. It is viewed as the best data on birth and population counts.
} 
population was conducted in 1995. To further investigate the credibility of reported birth numbers, the State Birth-Planning Commission was charged with conducting national fertility surveys for $0.1 \%$ to $0.2 \%$ of the population in 1988,1992 , and 1997 . These census and national fertility surveys were organized at the province level, where they serve as the main instrument for data validation. As an example, the 1992 fertility survey uncovered an underreporting of 18\% in reported birth rates. A particularly striking case of underreporting was found in Guangxi province and the leadership was forced to deliver a written self-criticism (Scharping 2003).

Figure 1 displays an official document from Fujian province that links OCP performance to promotion outcomes and details guidelines for local officials with respect to the implementation of the OCP. The first highlighted section states that local officials are responsible for reporting accurate birth rates and other OCP statistics. The second highlighted section states that local officials should ensure the accuracy of the reported numbers and avoid underreporting, misreporting, faking, and failing to report birth rate statistics. Finally, the third highlighted section states that the province government is responsible for investigating violations of these guidelines. If these guidelines are violated, the responsible officials are denied positive credits in their annual evaluation and their records are sent to the personnel department of the province government.

\section{A Tournament Model with Non-Contractible Output}

We are interested in whether self-reported and actual OCP performance predict mayoral promotion, and what we can learn from any discrepancy or parity. Because we cannot observe the government's true objective, or the compensation schemes that bureaucrats actually faced, we write a model that yields a relationship between promotion patterns and the government's objectives. In particular, we show that different objectives correspond to differences in how the marginal impact of self-reported output on promotion probability varies in competition and noise. The key theoretical insight is that a tournament with one prize generates more "separation" in output across agents with different ability and convex effort costs, while an incentive structure which applies more continuous pressure, such as a piece-rate, generates more total output. The principal's relative value of screening (i.e. meritocracy) determines whether she designs incentives to magnify differences in the output of highability versus low-ability agents (a tournament), at the cost of total output, or to generate as much output as possible, which reduces what individual output reveals about the underlying ability of the agent (a piece-rate). We also characterize the degree to which imperfect verifiability of performance affects the efficacy of a tournament as a screening mechanism for ability.

\subsection{The Model}

The world is populated by a risk-neutral principal and $N \in\{2,3,4, \ldots\}$ risk-neutral agents. Agents are heterogeneous only in their privately-known ability, $a_{i}$. Utility for all agents is described by $u_{i}(x)=x$ for $x \in \mathbb{R}$. In our setting, the principal is the provincial governor and the agents are the mayors competing for promotion. 
Figure 1: Official Document From Fujian Province

福建省人口和计划生育工作

责任考核奖惩办法(试行)

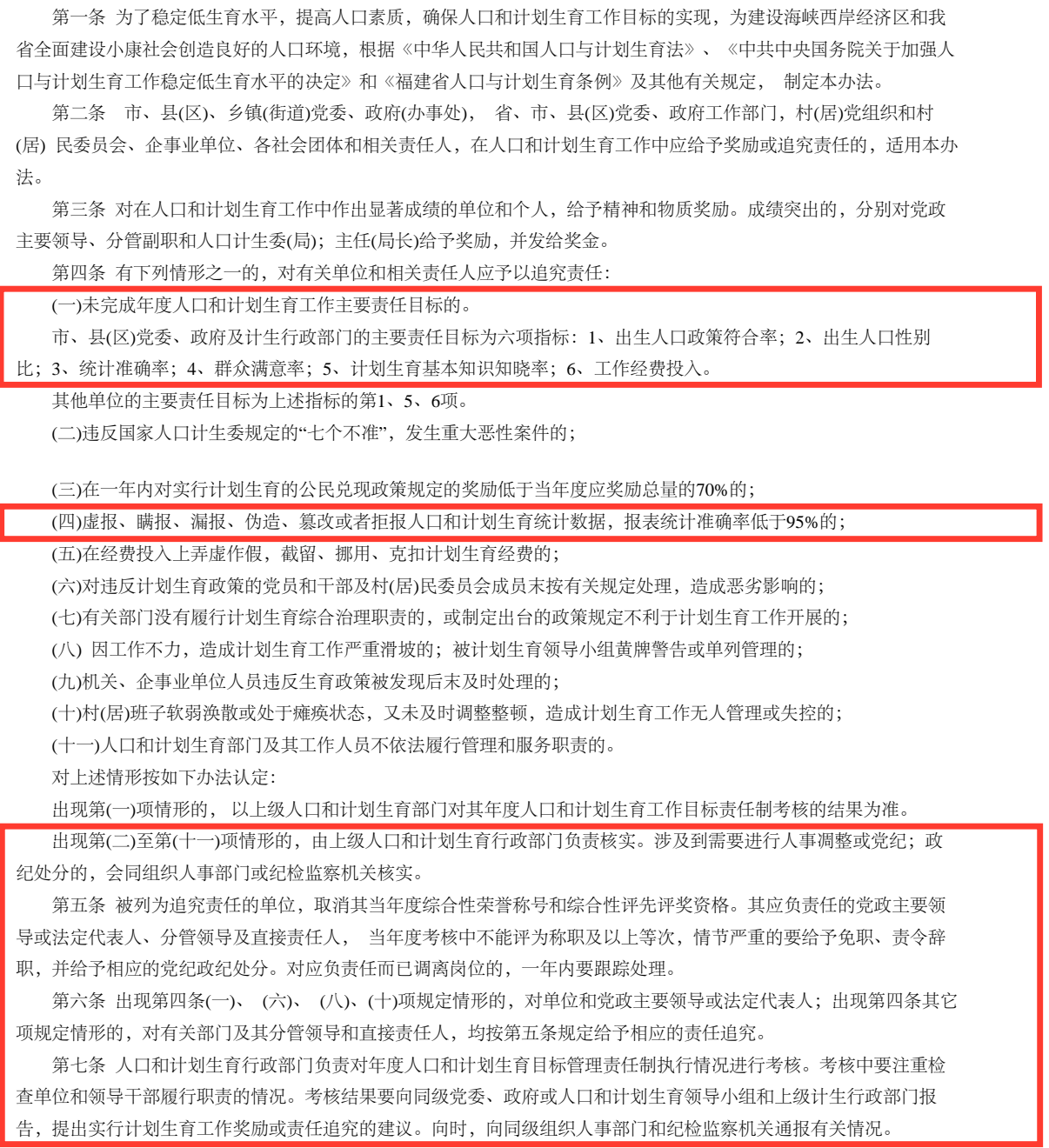

Note: This document from Fujian Province outlines guidelines for local officials on the One Child Policy and links performance to promotion outcomes. The first highlighted section states that local officials are responsible for reporting accurate birth rates and other OCP statistics. The second highlighted section states that local officials should ensure the accuracy of the reported numbers and avoid underreporting, misreporting, faking, and excluding birth rate statistics. Finally, the third highlighted section states that the province government is responsible for investigating violations of these guidelines. If they are violated, the responsible officials are denied positive credits in their annual evaluation, and their records are sent to the personnel department of the province government. Source: http://yz.zfxxgk.gov.cn/ShowArticle. asp?ArticleID $=75204$ 
The governor chooses a compensation scheme and which single mayor to promote in order to maximize the following weighted sum of total output produced and the expected ability of the promoted mayor:

$$
\omega E\left[\sum_{i=1}^{N} y_{i}\right]+(1-\omega) E\left[a_{i} \mid i \text { is promoted }\right] .
$$

In our setting, output $y_{i}$ is the birth rate achieved by mayor $a_{i} .{ }^{18}$ The weight $\omega$ may capture the trade-off between output maximization and an inherent value of meritocracy, between maximizing short-run versus long-run output, and between maximizing output in one task versus maximizing output across several tasks, to name a few interpretations. If $\omega=1$, the governor focuses only on maximizing output. If $\omega=0$, the governor focuses only on promoting the mayor with the highest ability. $\omega$ is determined by the central government in our empirical setting and is held constant across regions.

Mayor $a_{i}$ produces output $y_{i}=e_{i}+\varepsilon_{i}$, where $e_{i}$ is unobservable and non-contractible effort, and $\varepsilon_{i} \sim \exp (\lambda)$ is noise with mean $E(\varepsilon)=\frac{1}{\lambda}$, variance $V(\varepsilon)=\frac{1}{\lambda^{2}}$, and is iid across agents. ${ }^{19}$ The effort cost to $a_{i}$ is $c\left(e_{i}\right)=\frac{1}{a_{i}} \exp \left(e_{i}\right)$. These assumptions ensure that a given level of effort is less costly and that marginal cost of effort is lower for higher-ability mayors, that higher levels of effort are more costly for all mayors, and that effort cost increases at an increasing rate. Assume for notational convenience that $a_{1}>a_{2}>\ldots>a_{N} \geq 1$; a mayor with a higher $i$ index has lower ability. The governor and the mayors know the average ability in the population, $\bar{a}=\frac{1}{N} \sum_{i=1}^{N} a_{i}$.

Output is not observable or contractible, but the governor can compensate mayors based on their self-reports $\hat{y}_{i}{ }^{20}$ Suppose the governor audits mayors' reports, but these audits are limited in their scope. The governor commits to firing any mayor who can be proven to be over-reporting (the mayor incurs disutility $F<<0$ from being fired), but proving this is difficult. In particular, the audit is sufficient proof with certainty if and only if $\frac{\hat{y}_{i}}{y_{i}}>\delta$ : the mayor exaggerates by a lot. If the mayor only slightly exaggerates, that is, $\frac{\hat{y}_{i}}{y_{i}} \in(1, \delta]$, then the audit is sufficient proof with only probability $p \in(0,1)$. That is, given that a mayor is over-reporting, the audit generates sufficient proof with probability $p$ and the mayor is fired, but generates insufficient proof with probability $(1-p)$ and the mayor is not fired. In other words, even if a governor knows a mayor is lying, if she cannot prove it, she cannot fire him. The strength of the audit is captured both by $p$ and $\delta$. Both $\delta=1$ and $p=1$ capture the case where output is contractible. ${ }^{21}$

The governor chooses between two compensation schemes: a tournament based on reported outputs where one mayor is promoted, or a piece rate. Note that mayors can still be observed to be promoted while facing a piece rate on OCP performance, as their promotion can depend on their performance in non-OCP tasks.

\footnotetext{
${ }^{18}$ The principal prefers a lower birth rate, and agents must exert more effort to achieve a lower birth rate. "Higher $y$ is better" is standard, but in the case where output is the birth rate $b$, we can define output $y \equiv \frac{1}{b}$.

${ }^{19}$ Assume that $\lambda \in(0,1)$, a parametric assumption for objects to be well-defined: this ensures that $V(\varepsilon) \in(1, \infty)$.

${ }^{20}$ See Appendix A.5 for the case where output is contractible.

${ }^{21}$ Punishing liars is both an actual feature of our empirical setting (mayors are told explicitly they will incur demerits in their performance review if they are caught lying), as well as strategic for the principal. Suppose instead that the principal did not commit to punishing detected and proven liars, believing that she can correctly back out true output from reported output, because she knows the degree of inflation. Then any mayor could profitably deviate by inflating even further. This leads to unraveling, since mayors will all pool on reporting infinity.
} 
The timing of the game is as follows:

1. Each mayor observes her own private ability $a_{i}$ and chooses effort level $e_{i}$, which is nonobservable and non-contractible by the governor.

2. Each mayor's output $y_{i}$ is realized. Output remains private information.

3. Each mayor submits a private report of output to the principal: $\hat{y}_{i}$.

4. The governor audits each mayor. If the mayor reported $\hat{y}_{i}=y_{i}$, she is truthful and will not be wrongfully charged with lying. If the mayor reports $\hat{y}_{i}>y_{i}$, audits detect and are sufficient proof with probability 1 if $\frac{\hat{y}_{i}}{y_{i}}>\delta$, and with probability $p$ if $\frac{\hat{y}_{i}}{y_{i}} \in(1, \delta]$. Mayors proven to be lying are fired.

5. The governor promotes one mayor based on any criterion of her choice, and compensates mayors who are not fired based on their self-reported output. ${ }^{22}$

There are three "types" of pure strategy equilibria: ${ }^{23}$

1. "All lie": all the mayors misreport their output.

2. "All truth": all the mayors truthfully report their output.

3. "Partial lie": some mayors misreport and some mayors report truthfully.

We characterize the partial lie/partial truth equilibrium in Appendix A.6. In particular, when audits are weaker, such that most or all agents misreport in equilibrium, the lowest-ability (and lowestperforming) agents have the smallest incentive to misreport. This is because the lowest-performing agents need to misreport more in order to win the tournament. In order to avoid punishment, the lowest-performing agents simply tell the truth, which decreases the likelihood that they are promoted even further. The remaining mayors are likely to be promoted and all misreport. Since the mayors that are likely to be promoted all misreport, the rest of our analysis focuses on the "all lie" equilibrium. ${ }^{24}$

\subsection{Equilibrium Promotion Patterns}

We show that if the governor sufficiently values meritocracy, then tournaments are preferred over piece rates. We characterize the relationship between self-reported OCP performance and probability of promotion when the tournament is chosen and when the piece rate is chosen, as well as how this

\footnotetext{
${ }^{22}$ Note that the principal is not allowed to promote zero mayors (although she is allowed to set a bonus of zero). This would be an extra incentive tool for the principal to induce effort. Ruling this out is realistic (when a slot opens up, some agent does get promoted to fill it), and also "works against us" in the sense that this makes the tournament a less potent tool. Since one of our key goals in constructing this model is to show that there exists an intuitive subset of the parameter space, specifically, a screening motive, for which the principal's equilibrium choice of compensation scheme is a tournament, showing that the principal chooses to use a weakened tournament when she cares about screening implies that a more flexible tournament would be even better.

${ }^{23} \mathrm{We}$ focus on pure strategies as it is unclear how to empirically interpret mixed strategies in OCP enforcement effort and reporting in a static game.

${ }^{24}$ We test this assumption empirically in Table A.21 and Table A.22, which show that low-performing mayors (those who do not reach the target) misreport less and are also less likely to misreport at all.
} 
relationship varies with different degrees of competition between mayors and different degrees of noisiness in production. Our final result characterizes the extent to which a tournament mechanism based on self-reported performance selects mayors who are actually of high ability as performance becomes less and less verifiable.

\section{The Relationship between Compensation Scheme and the Government's Objective}

We first characterize the compensation scheme set by the governor, depending on the relative importance of meritocracy.

Proposition 1. There exists an $\tilde{\omega} \in(0,1)$ such that, if $\omega>\tilde{\omega}$ (the governor values output for production relatively more than for screening), the governor uses a piece rate mechanism. If $\omega<$ $\tilde{\omega}$ (the governor values output for screening relatively more than for production), the tournament mechanism is chosen.

Please see Appendix A.2 for a detailed proof. ${ }^{25}$

The intuition behind this result is the following. When the governor's sole concern is output maximization, continuous incentive pressure is the cheapest way to induce total effort. The convexity of effort costs makes it less costly to smooth effort across agents of all ability levels. On the other hand, if the government's objective is to use observed output to identify the highest-ability agent, then tournaments are preferred. Since the reward for output is discontinuous, and the marginal cost of effort is decreasing in ability, the differences between the effort exerted by lower- and higher-ability mayors will be greater than under the continuous piece rate. ${ }^{26}$ This "effort separation" across the heterogeneously-able individuals reduces total output produced but enables the governor to infer mayors' abilities from output observations. When the governor sufficiently values promoting the highest-ability mayor, the tournament mechanism becomes optimal as it induces bigger differences in effort exerted by mayors of different ability, thereby increasing the expected ability of the promoted mayor. However, the manipulability of output limits informativeness, as the governor can only contract on reported output and detects lies imperfectly. ${ }^{27}$

Figure 2 clearly illustrates the intuition. Mayors are ordered by ascending ability along the $\mathrm{x}$ axis. The chosen parameters are provided at the bottom of the figure. Given those parameters, we solve for the best piece rate and the best tournament bonus for the governor. The dark-grey bars indicate effort exerted under the piece rate scheme, and the light-grey bars indicate effort exerted under the tournament. Both the "effort separation" and the lower total effort generated by the tournament are evident.

\footnotetext{
${ }^{25}$ If we allow for a combination of tournament and piece rate, we see that a mechanism with both elements (e.g. a tournament with bonus $B$ and piece rate payments for individual outputs) weakly dominates pure tournament or pure piece rate. However, as $\omega \rightarrow 0$, the optimal mechanism converges toward pure tournament, and as $\omega \rightarrow 1$, the optimal mechanism converges toward pure piece rate, so we can still compare tournament-heavy with piece rate-heavy mechanisms and our results continue to apply.

${ }^{26}$ Note that the governor cannot condition compensation directly on ability, as it is private information.

${ }^{27}$ This result survives allowing the governor to choose a scheme which includes both piece rate and tournament components. A scheme with both components always weakly dominates pure piece rate and pure tournament; however, as $\omega \rightarrow 1$, the pure piece rate again becomes optimal, and as $\omega \rightarrow 0$, the pure tournament again becomes optimal.
} 
Figure 2: Numerical Example of Effort Separation

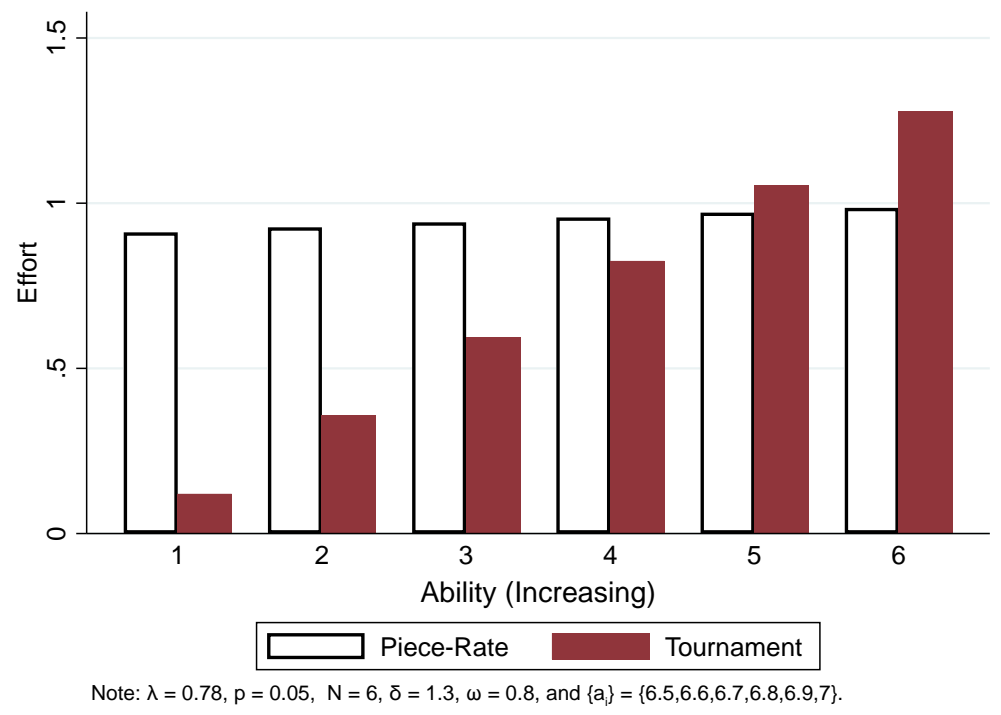

Note: This figure plots equilibrium effort levels under the optimal piece rate and tournament compensation mechanisms given a set of parameter values. The figure shows that tournaments lower overall effort but increase effort separation across mayors of different abilities.

\section{Equilibrium Properties of Promotion under a Pure Production Objective $(\omega=1)$}

When $\omega=1$, so the governor cares about the OCP for population control and not as a means to screen mayoral ability, the governor compensates self-reported output (lower birth rate) with a piece rate. Thus, conditional on agent ability, the promotion rule is independent of OCP performance.

Proposition 2. If $\omega=1$, mayors are compensated with a piece rate and, conditional on ability, increasing self-reported OCP output does not increase mayor $a_{i}$ 's probability of promotion. This is true regardless of the noise $(\lambda)$ and the competitiveness $(N)$ of the environment.

Proposition 2 guides the econometrician to compare promotion outcomes for mayors with higher and lower reported output. However, the results of Proposition 2 no longer hold when this comparison is not conditional on a given agent's ability, which requires additional tests.

Corollary 1. If $\omega=1$ and the governor bases promotions on a task other than OCP performance that is positively correlated with ability, mayors are compensated via a piece rate on self-reported OCP performance. In addition, unconditional on ability and conditional on performance in the promotion task:

(i) Self-reported OCP performance increases mayor $a_{i}$ 's probability of promotion.

(ii) Self-reported OCP performance has a larger effect (increase) on the probability of promotion in noisier environments (smaller $\lambda$ ).

(iii) Self-reported OCP performance does not have a differential effect (increase) on the probability of promotion in more competitive environments (larger $N$ ). 
The proofs of Proposition 2 and Corollary 1 are presented in Appendix A.3.

Given that the governor compensates mayors with a piece rate when $\omega=1$, it can be shown that, in noisier environments, higher-ability mayors exert differentially higher effort compared to lower-ability mayors. This is because, in noisier environments, the governor sets a lower piece rate (the slope of the wage in reported output is flatter). Lower-ability mayors decrease their effort differentially more than higher-ability mayors in response to this lower piece rate, since their marginal cost of effort is higher. Since ability is positively correlated with the dimension on which promotion is based, it must be that the impact of having higher ability on the probability of promotion in noisier environments is larger. But we know that ability is also positively correlated with output. Hence, it must be that the observed impact of increasing output on probability of promotion in noisier environments is also larger.

Conditional on performance in the task on which promotion is based, the impact of self-reported OCP performance on probability of promotion cannot vary by competitiveness, since it is rewarded with a piece rate. Thus, Corollary 1 guides the econometrician who may be concerned that she is unable to separate variation in mayor's self-reported OCP performance from variation in ability.

Equilibrium Properties of Promotion under Screening and Production Objectives $(\omega<1)$

Proposition 3. If $\omega<\tilde{\omega}$, mayors are compensated with a bonus in a tournament where the mayor with the highest reported OCP performance who is not caught lying is promoted. Further, in the equilibrium where all mayors misreport:

(i) Self-reported OCP performance increases mayor $a_{i}$ 's probability of promotion

(ii) Self-reported OCP performance has a larger effect (increase) on the probability of promotion in less noisy environments (larger $\lambda$ )

(iii) Self-reported OCP performance has a larger effect (increase) on the probability of promotion in less competitive environments (smaller $N$ )

The technical details of the proof of Proposition 3 are presented in Appendix A.4.

Result (i) is clear, since the principal has no reason to discourage higher output, beyond firing mayors who are caught lying. Result (ii) holds because output is more informative of mayor ability in less noisy environments. Thus, the governor has more confidence that the high production mayor she is promoting is indeed of higher ability. Result (iii) holds because increasing output increases the probability of achieving the maximum output by a larger amount when there are fewer competitors. That is, there are fewer outputs a mayor has to beat in order to have the maximum output in a less competitive environment.

We take the contrasting predictions of Corollary 1 and Proposition 3 to the data as they allow us to empirically differentiate between the case where promotions are driven by a meritocratic objective, and the case where, despite the lack of a meritocratic motive, the correlation between OCP performance and promotion is driven by an omitted variable. 
The Predictive Power of Self-Reported versus Actual Output for Promotion when Output is Non-Contractible

Our final result characterizes the degree to which mayor manipulation decreases the screening ability of the tournament mechanism when governments wish to use OCP to learn about mayor ability.

Proposition 4. If $\omega<\tilde{\omega}$, so that the tournament compensation is optimal in the "all lie" equilibrium with all mayors misreporting output:

(i) The expected ability of the promoted mayor when output is not contractible is a weighted average of the expected ability of the promoted mayor when output is contractible and the expected ability of a randomly-drawn mayor, where the weight depends on audit strength $p$ :

$$
E^{\text {non-contract }}\left[a_{i} \mid i \text { promoted }\right]=\tilde{p} E^{\text {contract }}\left[a_{i} \mid i \text { promoted }\right]+(1-\tilde{p}) \bar{a}
$$

(ii) The weaker the audit (lower $p$ ), the closer the expected ability of the promoted mayor is to a random draw: $\tilde{p}^{\prime}(p)<0$.

(iii) When audits are completely uninformative, the expected ability of the promoted mayor is exactly the population average: $\tilde{p}(0)=0$.

See Appendix A.4 for details.

Typically, researchers studying audits have analyzed experiments (see, e.g., Olken 2006). In practice, the treatments raise the audit risk from near non-existent to near certainty. Proposition 4 gives us insight into interior audit risks, which are likely to be more realistic and feasible as long-run policies. This contribution of our model can be applied to questions beyond promotions in China.

\section{Measuring Promotion and OCP Performance}

The system that monitors and sets birth targets was built in the 1980s with the ultimate goal of containing population growth by year 2000. Our study focuses on the time period 1985-2000 since it is ideal for studying the relationship between mayoral promotions and the implementation of the OCP, and since systematic prefecture-level data became available starting in 1985.

\section{Sample of Mayors}

We collected Chinese mayoral data by digitizing a complete list of mayors in office from 1985-2000 from two series of hard copy records: City Gazetteers, published by the gazetteer office of each city, and the City Development Yearbook, published by the Chinese Urban Development Research Council. The list includes the mayor's name, as well as the year and month at the start and end of her term. We obtained data on 967 mayors in 258 prefectures and 28 provinces between 1985 and 2000. While data on Chinese political leaders at the provincial level are more commonly accessible, to our knowledge there are no such comprehensive data for Chinese mayors before 2000. Landry (2008) is the only other example we know of that uses mayor data in years 1990-2000. 


\section{Promotion}

Promotion is defined as an upward move in the political career. The most natural upward move for a mayor is becoming the party secretary in the same or a different prefecture, which is the definition of mayor promotion in the existing literature (Landry, 2008). ${ }^{28}$ This measure, though convenient, ignores other possible moves above the prefecture level, including provincial governor or vice-governor, minister of central ministries, etc. We define a mayor as being promoted if there is an increase in her bureaucratic rank to any of the following positions at the end of her term:

1. Prefecture: party secretary in the same or a different prefecture.

2. Province: provincial governor or vice-governor, party secretary or vice-secretary, party committee member, chairman or vice-chairman of the People's Political Consultative, chairman or vice-chairman of the People's Congress. ${ }^{29}$

3. Central: minister or vice-minister of central ministries.

A mayor is not promoted if she continues as mayor, moves to positions of the same bureaucratic rank, or exits politics. First, one could continue as mayor in the same or a different prefecture. In our data, forty mayors served in two prefectures. If one is transferred from the first city to the second, she is not promoted in the first city and her promotion status in the second city depends on her move after serving the second time. Second, one could be promoted to positions in the provincial government that have the same bureaucratic rank as mayor: director or vice-director of provincial departments, assistant to the provincial governor, etc. Finally, while one could leave politics by working in industry, we only observe this for three mayors in our data. See Appendix B for details on the measurement of promotion in the data.

\section{OCP Performance}

Targets for the rate of natural increase are set every five years in Five-year Plans. The rate is the crude birth rate minus the crude death rate. We digitized the targets for the rate of natural increase from Provincial Five-year Plans in 1985, 1990, and 1995. For example, a province's 1985 plan sets the target for annual rate of natural increase in 1986-1990.

We use two measures of the birth rate to compare the reported OCP performance with actual performance: (1) the official rate of natural increase from published data that are reported to provincial governments, and recorded in City Statistical Yearbooks, and (2) a retrospective birth rate from microdata of 1990 and 2000 population censuses that are not observed by the provincial government on a yearly basis, and the rate of natural increase is measured by the crude birth rate

\footnotetext{
${ }^{28}$ In Landry (2008), promotion is defined as being promoted to the party secretary in the same prefecture or elsewhere. This definition underestimates the likelihood of promotion because mayors could move to higher-ranked positions at the province or central level. We use the most complete definition of promotion based on the bureaucratic rank. In Table 1, we show that $15 \%$ of promotion of mayors in 1985-2000 was above the prefecture level.

${ }^{29} \mathrm{An}$ alternative is to define promotion to province-level positions based on administrative division, i.e., province is a higher administrative division than prefecture. However, this is more controversial than the definition based on bureaucratic rank. In our definition, if a mayor becomes the director of a department in the provincial government that has the same bureaucratic rank as mayor, she is not defined as being promoted. In our data, only 40 out of the 967 mayors serve in multiple prefectures.
} 
from census minus the crude death rate in City Statistical Yearbooks. A mayor's reported OCP performance is measured by comparing the reported rate of natural increase with the target from the corresponding five-year plan. The lower the reported rate relative to the target, the better the mayor's OCP performance. ${ }^{30}$ Unfortunately, not all prefectures publish data on the rates of natural increase consistently in 1985-2000. On average, $80 \%$ of prefectures report yearly data, except in 1988, when no prefectures published birth rate data. ${ }^{31}$ In our sample of mayors, 697 out of 967 are matched with the reported rates. ${ }^{32}$

We measure actual OCP performance by the gap between the target and the rate using census data. Census data are collected independently by the City Bureau of Statistics (organized by the National Bureau of Statistics (NBS)). They survey every household to gather birth and population information. ${ }^{33}$

We compute the crude birth rate retrospectively using microdata from the 1990 and 2000 censuses; these data are observed by provincial government only in census years. Crude birth rates in 1986-1989 come from the 1990 census and those in 1990-2000 come from the 2000 census. The main concern with census data is the potential for internal migration, since prefecture of birth is not observed for migrants in all years. Migration was tightly restricted under the Hukou system until its relaxation in the 1990s. Figure A.1 shows the percentage of migrants in 1982-2000 from census and population surveys. The migration rate of the entire population remained under $2 \%$ in the 1980 s and slowly increased to $4 \%$ in 1995. In our estimations, we allow for year-specific effects of these average migration measures for years 1990-1994 and 1985-1990. The most significant increase in migration occurred between 1995 and 2000, with the migration ratio reaching $11 \%$ in 2000. Since we observe the prefecture of origin for migrants from 1995-2000, we use information on out-migration and in-migration by prefecture and year when constructing birth rate measures. We find that ignoring migration leads to very small underestimation of birth rate by 0.2 (per 1000 population) in 1995-2000. In Appendix B, we discuss in greater detail how we measure the crude birth rate from census data and how we account for migration.

\footnotetext{
${ }^{30}$ To the best of our knowledge, prefectures face a common province-level target. Our main specification controls for potential determinants of targets at the prefecture-level, including the percentage of childbearing-age women, the percentage of Han population, and the percentage of rural population. In addition, in Section 4.2.3, we estimate the effects of these determinants on province-level targets and use prefecture-level variation to compute prefecture-level targets. Our results are robust in these specifications.

${ }^{31}$ Table A.1a summarizes the number of prefectures that report birth rate data by year in our analysis sample.

${ }^{32}$ Note that when prefectures do not report yearly data, these data include birth rate, economic growth, and population statistics. The difference between our initial sample of 967 mayors and our final sample of 697 is due to changes in administrative boundaries that prevent us from linking prefectures across Censuses. Importantly, this change in sample size is not due to selected reporting by mayors.

${ }^{33}$ The NBS organizes a quality control survey after each census to check for unreported people (for example, hidden children). The survey sample for the 1990 census is around 170,000 people. The NBS finds 1 unreported birth per 1,000 births. It is viewed as the best data on birth and population counts. An interesting set of papers evaluates the quality of the 1990 census data. There is no consensus about underreporting in the census: Banister (1992) and Johansson and Nygren (1991) argue that there is no underreporting, while Zeng et al. (1993) argues the opposite. The latter paper backs out "actual births" by counting children in the mid-1990s and accounting for deaths. They find that births of female children are underreported in the 1990 census. We do not think this is a problem for our results, since we find that mayors underreport even relative to a potentially underreported census, our estimates are a weak lower bound on cheating. We also find that the extent of cheating decreases in audit years. This result would be overturned by an underreported census only if the census is particularly underreported in audit years, which seems very unlikely. Finally, we find that promoted mayors do no better in the census than non-promoted mayors. This would be overturned by an unreported census only if the census over-reported births especially for promoted mayors.
} 
Table 1: Summary Statistics

\begin{tabular}{|c|c|c|c|c|c|c|}
\hline \multirow[b]{3}{*}{ Promotion } & \multicolumn{3}{|c|}{ (1) Mayor } & \multicolumn{3}{|c|}{ (2) Mayor-year } \\
\hline & Mean & Std. Dev. & Obs & Mean & Std. Dev. & Obs \\
\hline & & & & & & \\
\hline Promoted & 0.53 & 0.5 & 697 & 0.15 & 0.35 & 2058 \\
\hline Prefecture party secretary & 0.45 & 0.5 & 697 & 0.12 & 0.33 & 2058 \\
\hline Province government or party leaders & 0.06 & 0.24 & 697 & 0.02 & 0.13 & 2058 \\
\hline Central ministries & 0.02 & 0.13 & 697 & 0 & 0.07 & 2058 \\
\hline Tenure (year) & 3.79 & 2.03 & 697 & 2.76 & 1.86 & 2249 \\
\hline \multicolumn{7}{|c|}{ Rate of natural increase (RNI, per 1,000 population) } \\
\hline Recorded rate & 7.66 & 3.29 & 697 & 7.63 & 3.71 & 2058 \\
\hline Rate from census & 8.28 & 5.52 & 675 & 8.43 & 5.74 & 1895 \\
\hline Target rate & 10.57 & 2.32 & 697 & 10.53 & 2.51 & 2058 \\
\hline \multicolumn{7}{|l|}{ OCP performance } \\
\hline $\mathbb{I}[$ Reported RNI is below target $]$ & 0.8 & 0.31 & 697 & 0.8 & 0.4 & 2058 \\
\hline Target RNI - reported RNI & 2.91 & 3.19 & 697 & 2.9 & 3.7 & 2058 \\
\hline $\mathbb{I}[\mathrm{RNI}$ from census is below target $]$ & 0.74 & 0.4 & 675 & 0.74 & 0.44 & 1895 \\
\hline Target RNI - RNI from census & 2.27 & 5.16 & 675 & 2.14 & 5.42 & 1895 \\
\hline Real GDP (million RMB) & 8517 & 11359 & 697 & 9348 & 12255 & 2058 \\
\hline $\log ($ GDP) & 3.89 & 1.04 & 697 & 3.99 & 1.06 & 2058 \\
\hline \multicolumn{7}{|l|}{ Prefecture-year controls } \\
\hline Population $(1,000)$ & 5383 & 49415 & 697 & 6132 & 114802 & 2058 \\
\hline Percentage of urban population & 0.31 & 0.17 & 697 & 0.32 & 0.17 & 2058 \\
\hline Investment (million RMB) & 3973 & 9187 & 697 & 4382 & 10463 & 2058 \\
\hline
\end{tabular}

Notes: Please refer to Section 3 for details on data sources.

\section{Summary Statistics}

Our main analysis sample includes 697 mayors in 211 prefectures and 28 provinces. ${ }^{34}$ Table 1 reports the summary statistics at both the mayor level and mayor-year level. $53 \%$ of mayors were promoted to a higher-ranked position, with $45 \%$ promoted to party secretary in the same or a different prefecture, $6 \%$ to leadership at the province level, and $2 \%$ to central ministries. Among all promotions, $15 \%$ moved above the prefecture level, suggesting a substantial underestimation of mayor promotion by the definition in previous studies. On average, mayors spent 3.8 years in office. Figure 3a shows the distribution of years in office. Most mayors were in office from two to five years. The turnover rates are especially high in the second and third years. Tenure at promotion has similar properties and is graphed in Figure 3b. ${ }^{35}$

\footnotetext{
${ }^{34}$ Column 1 of Table A.1a summarizes the number of mayors by year in our analysis sample.

${ }^{35}$ Our results are robust to excluding mayors that were only in service for less than three years, as we show in Table A.24. Note that the number of prefectures in a province varies from 1 to 21. Figure A.2 plots the histogram of the number of cities per province. We also show in Table A.15 that our results are robust to excluding mayors that represent large cities within a province as well as provinces where population is concentrated in few cities.
} 
Figure 3: Histogram of Years in Office

(a) Histogram of Years in Office

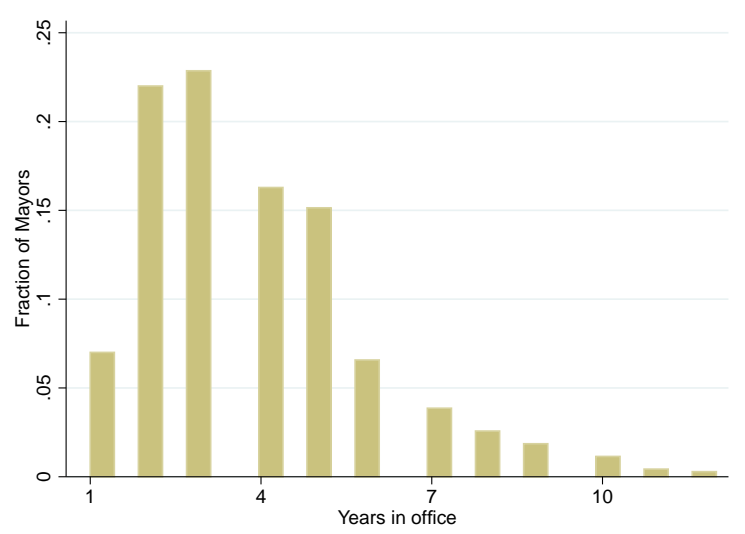

(b) Tenure at Promotion

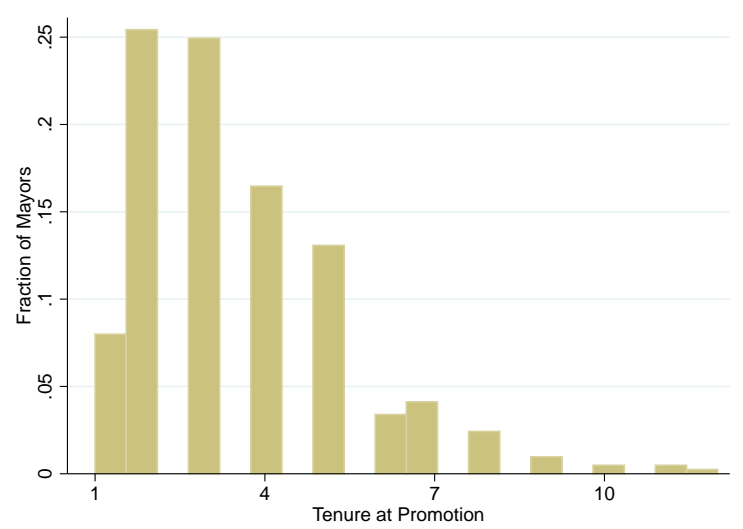

Notes: Figure 3a shows the distribution of years in office per mayor. Figure 3b shows the distribution of tenure at promotion of mayors who were promoted.

A key variable of interest is OCP performance, which is measured by the gap between the birth rate target and a given measure of birth rate. The average reported rate of natural increase is 7.7 per 1,000 people, while the rate computed using census data is 8.3. Both are lower than the target average of 10.6. On average, the reported rates are 3 births per 1,000 people below target. $80 \%$ of mayors reported the rates lower than their assigned target. In comparison, the rates from census data suggest that only $74 \%$ of mayors were below their specified target. In our analysis, we use changes in targets as instruments for OCP performance. Figure 4 presents (a) the average target across provinces, as well as (b) the number of provinces that experienced a decrease in the target in each of the five-year plans. In addition, Table A.13 reports correlations between the targets and province characteristics. This table shows targets are not set to favor mayors in more concentrated provinces or those that represent a larger share of a province's population. Moreover, Table A.13 shows that the rate of mayoral promotion does not affect how targets are set. 
Figure 4: Birth Rate Targets

(a) Birth Rate Target

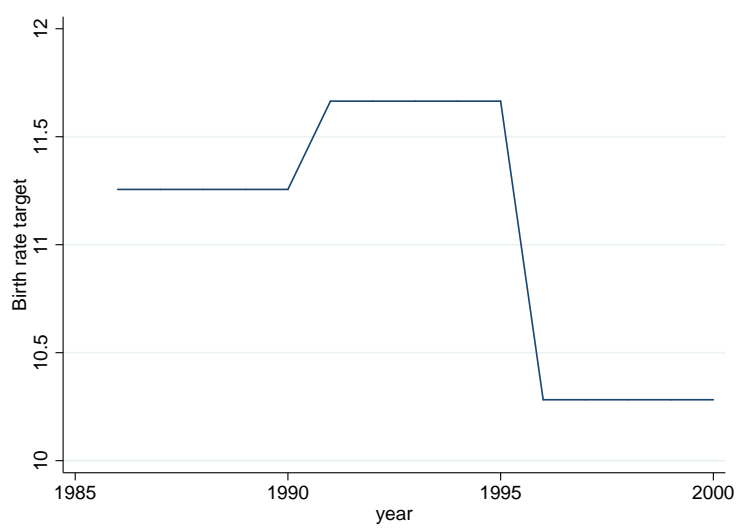

(b) Number of Provinces with a Decreased Target

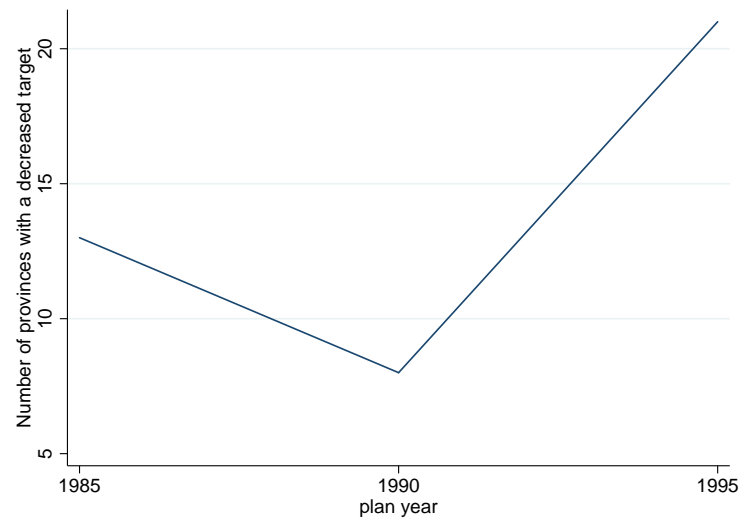

Notes: Figure 4a shows the average target for the rate of natural increase across provinces set in five-year plans. Figure $4 \mathrm{~b}$ presents the number of provinces that experienced a decrease in the target in each of the five-year plans in 1985, 1990 and 1995.

Data on annual nominal GDP at the prefecture level in 1985-2000 come from City Statistical Yearbooks. We use the nominal GDP and national current price index (CPI) to compute real GDP. The average real GDP in the mayor-year sample is 9348 million RMB. Landry (2008) shows a published list of performance indicators of 104 prefectures in 2000, where GDP per capita is listed as the measure to evaluate economic performance of mayors. Therefore, in our main specification, we follow the official evaluation metrics and use log GDP to measure economic performance while controlling for population. Finally, we compiled prefecture-year controls from City Statistical Yearbooks, including population, percentage of urban population, and government investment.

\section{Mayoral Promotion and OCP Performance}

We now analyze whether reported OCP performance affects the promotion of mayors. Our first specification tests this prediction by examining whether reported OCP performance increases a mayor's probability of promotion using a linear probability model:

$$
\text { Promoted }_{i c p t}=\beta_{1} O C P_{c p t}^{\text {reported }}+X_{i c p t} \gamma+\mu_{i}+\eta_{c p}+\lambda_{t}+\varepsilon_{i c p t},
$$

where $i$ denotes the mayor, $c$ the prefecture, $p$ the province, and $t$ the year. $\mu_{i}$ are mayor fixed effects, $\lambda_{t}$ are year fixed effects, and we also include prefecture fixed effects, $\eta_{c p}$, as some mayors served two different prefectures. The dependent variable, Promoted Prpt $_{\text {, }}$ is a binary outcome that is equal to 1 if mayor $i$ in prefecture $c$ of province $p$ is promoted in year $t$ and 0 otherwise. $X_{i c p t}$ is a vector of time-varying attributes of mayor $i$ or prefecture $c$ in year $t$, including the mayor's tenure, and prefecture-year log of real GDP, log of population, percentage of urban population, log of investment, and migration controls. We also control for $O C P_{c p t}^{C e n s u s}$ in this regression. Finally, we allow for errors to be correlated at the province level. 
The key regressor of interest is reported OCP performance. Superior performance in implementing the OCP corresponds to a lower reported rate of natural increase compared to the target: $O C P_{c p t}^{\text {reported }}=$ Target $_{p t}-$ Birth Rate $_{c p t}^{\text {reported }}$. From conversations with local officials, we know that these targets have been used as a benchmark for expectation. That is, while meeting the expectation does not guarantee rewards, local officials are rewarded if they exceed the expectation. For this reason we allow $O C P_{c p t}^{\text {reported }}$ to have differential effects on promotion depending on whether the target was met (i.e., $O C P_{c p t}^{\text {reported }}>0$ ).

The identifying assumption of Equation 2 is that OCP performance is uncorrelated to other factors that may drive mayor promotion. We address this concern in three ways. First, the panel nature of our data allows us to include mayor fixed effects, $\mu_{i}$, which control for time-invariant ability that may affect the initial placement or political connections to province-level officials. Second, in Section 4.1 we use predictions from our model that characterize the comparative statics of OCP performance across provinces with different degrees of noisiness and competitiveness. As a third strategy, in Section 4.2 we use an instrumental variables approach that elicits variation in OCP performance using changes in targets from five-year plans. This strategy exploits variation in reported OCP performance that is uncorrelated with either changes in connections or other changes in unobserved margins. ${ }^{36}$ In addition, we perform a battery of robustness checks in Section 4.2.

We begin by showing the correlation of reported OCP performance and promotion in Figure 5. The x-axis represents the residualized OCP performance and the y-axis represents residualized promotion probability, where we control for person, city, and year fixed-effects. Panel (a) of Figure 5 shows the relation in the sub-sample where the reported rate of natural increase is above target (negative OCP performance); we do not observe any correlation between reported OCP performance and promotion. Panel (b) of Figure 5 plots the relation when the reported rate is equal to or below target (non-negative OCP performance). In this case, OCP performance is positively correlated with probability of promotion. Note that while beating the OCP target increases a mayor's probability of promotion regardless of GDP performance, these findings also show that OCP performance matters for promotion beyond simply meeting the target. ${ }^{37}$

Table 2 reports estimates of Equation 2. We start by showing in column (1) that reported OCP has no effect on promotion when we look at the full sample of mayors. As we show in Figure 5, the effect of reported OCP on promotion depends on whether or not a mayor is below the target. In columns (2)-(5), we focus our regression analysis in the sub-sample with non-negative OCP performance. ${ }^{38}$ Consistent with the graphical presentation, estimates from column (2) through (5) all show that mayors with better reported OCP performance are more likely to be promoted. In this and other tables, we focus on the results from the richest specification in column (5). Decreasing the rate of natural increase by 1 per 1000 increases the chance of promotion by 1.7 percentage points, or around $13 \%$ of the probability of promotion. To gauge this magnitude, consider that the interquartile

\footnotetext{
${ }^{36}$ In particular, this strategy assuages concerns that time-varying political connections (as in Jia 2014) confound the effect of OCP performance on promotion.

${ }^{37}$ Evaluation costs often cause principals to set targets to weed out non-contenders, such as admissions committees which ignore students with low GRE scores or hiring committees which ignore candidates with low GPAs.

${ }^{38}$ This restriction is consistent with the model in Section 2.1. In particular, recall that the lowest-performing mayors are not likely to misreport. Moreover, they are not likely to be relevant for promotion decisions. In our data, there is always at least one mayor that reaches the target for every province in every five-year-plan period.
} 
Figure 5: OCP Performance and Promotion
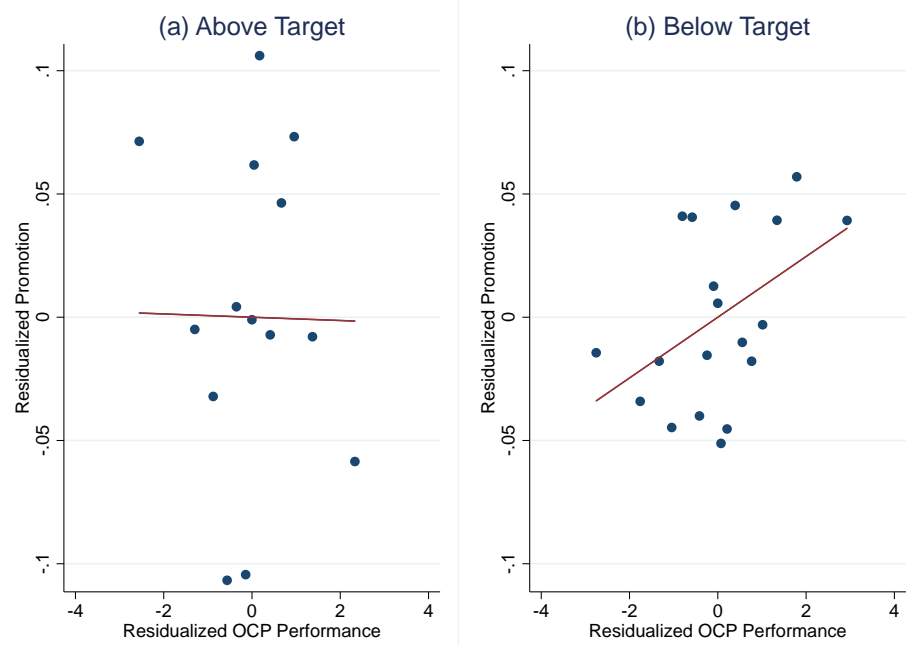

Notes: In Figure 5, the x-axis represents the residualized OCP performance and the y-axis represents the residualized promotion probability where we control for person, city, and year fixed-effects. OCP performance reported is the target for the rate of natural increase minus the reported rate of natural increase. Panel (a) shows the relation in the sub-sample where the reported rate is above target (negative OCP performance). Panel (b) plots the relation when the reported rate is equal to or below target (non-negative OCP performance). Column (6) of Table 2 reports results from a regression used to plot this figure.

range of OCP performance, conditional on the regression model, is 1.2. Thus, if a mayor's OCP performance increases from the 25th- to the 75th-percentile of the distribution, her probability of promotion increases by $16 \%$. To compare with GDP, we also show the estimate of log GDP and find that increasing GDP by $1 \%$ increases the chance of promotion by 17.2 basis points. These estimates suggest an economically large effect of OCP performance compared to economic growth, since decreasing the rate of natural increase by 1 per 1000 is equivalent in its effect on promotion to a $10 \%$ increase in GDP. Finally, we also fit a spline in column (6) where OCP performance reported is interacted with indicators of being below the target and being above the target, respectively, controlling for the full set of controls. We find similar results that non-negative OCP performance is positively correlated with promotion.

Relative to our model, these results are consistent with Chinese governors having strong tastes for meritocracy (i.e., $\omega \leq \tilde{\omega}<1$ ) since, in this case, Proposition 3 predicts that OCP performance should be predictive of promotion $\left(\beta_{1}>0\right)$. However, one concern is that governors promote mayors on an unobserved measure of performance that is correlated with OCP performance. As discussed in Corollary 1 , even if mayors have no taste for meritocracy $(\omega=1)$, we might find that $\beta_{1}>0$. We distinguish between these two cases by testing additional predictions across provinces with different informational and competitive environments. 
Table 2: OLS Regression of Promotion on Reported and Actual OCP Performance

\begin{tabular}{|c|c|c|c|c|c|c|}
\hline & & & Prome & ion $=1$ & & \\
\hline & $(1)$ & $(2)$ & $(3)$ & $(4)$ & $(5)$ & $(6)$ \\
\hline OCP Performance Reported & $\begin{array}{c}0.002 \\
(0.004)\end{array}$ & & & & & \\
\hline OCP Performance from Census & $\begin{array}{c}0.000 \\
(0.002)\end{array}$ & & & & & \\
\hline OCP Performance Reported X Below Target & & $\begin{array}{l}0.011^{* *} \\
(0.006)\end{array}$ & $\begin{array}{l}0.016^{*} \\
(0.009)\end{array}$ & $\begin{array}{l}0.016^{*} \\
(0.010)\end{array}$ & $\begin{array}{l}0.017^{*} \\
(0.010)\end{array}$ & $\begin{array}{l}0.017^{*} \\
(0.009)\end{array}$ \\
\hline OCP Performance from Census X Below Target & & $\begin{array}{c}0.000 \\
(0.003)\end{array}$ & $\begin{array}{l}-0.002 \\
(0.005)\end{array}$ & $\begin{array}{l}-0.002 \\
(0.005)\end{array}$ & $\begin{array}{l}-0.002 \\
(0.005)\end{array}$ & $\begin{array}{l}-0.002 \\
(0.004)\end{array}$ \\
\hline OCP Performance Reported X Above Target & & & & & & $\begin{array}{c}0.005 \\
(0.013)\end{array}$ \\
\hline OCP Performance from Census X Above Target & & & & & & $\begin{array}{l}-0.007 \\
(0.009)\end{array}$ \\
\hline Log GDP & $\begin{array}{c}-0.011 \\
(0.009)\end{array}$ & $\begin{array}{l}-0.010 \\
(0.011)\end{array}$ & $\begin{array}{c}0.146^{* * *} \\
(0.056)\end{array}$ & $\begin{array}{c}0.146^{* * *} \\
(0.057)\end{array}$ & $\begin{array}{c}0.172^{\text {*** }}(0.054)\end{array}$ & $\begin{array}{l}-0.134 \\
(0.396)\end{array}$ \\
\hline Observations & 1,832 & 1,483 & 1,483 & 1,483 & 1,483 & 1,544 \\
\hline $\mathrm{R}^{2}$ & 0.06 & 0.07 & 0.58 & 0.58 & 0.58 & 0.49 \\
\hline Test $\beta^{\text {Reported }}>\beta^{\text {Census }}(\mathrm{p}$-val) & 0.37 & 0.08 & 0.07 & 0.08 & 0.07 & 0.06 \\
\hline Full Sample & $\mathrm{Y}$ & & & & & $\mathrm{Y}$ \\
\hline Sample of Mayors Below Target & & $\mathrm{Y}$ & $\mathrm{Y}$ & $\mathrm{Y}$ & $\mathrm{Y}$ & \\
\hline Year FE & $\mathrm{Y}$ & $\mathrm{Y}$ & $\mathrm{Y}$ & $\mathrm{Y}$ & $\mathrm{Y}$ & $\mathrm{Y}$ \\
\hline Person FE & & & Y & Y & Y & Y \\
\hline City FE & & & & Y & Y & Y \\
\hline Prefecture-year controls & & & & & Y & $\mathrm{Y}$ \\
\hline
\end{tabular}

Notes: OCP performance reported is the target for the rate of natural increase minus the reported rate of natural increase. OCP performance from census is birth rate target minus birth rate from census data. Tenure fixed effects and migration controls are included in all regressions. Prefecture-year controls include $\log$ (population), percentage of urban population and $\log$ (government investment). Standard errors are clustered at the province level and are bootstrapped. Table A.18 explores additional specifications of this regression. * significant at $10 \%$ level; ${ }^{* *}$ significant at $5 \%$ level; ${ }^{* * *}$ significant at $1 \%$ level. 


\subsection{Testing Model Implications for the Promotion Rule}

According to Proposition 3, if governors have strong tastes for meritocracy, captured by small $\omega$ (i.e., $0 \leq \omega<\tilde{\omega} \leq 1$ ), we should expect to find smaller effects of $O C P_{c p t}^{\text {reported }}$ on promotion when performance is noisier, and when more mayors are competing for promotion. In contrast, Corollary 1 shows that if $\omega=1$ and OCP performance is correlated with the unobserved metric used in promotion, we should expect to find larger effects of $O C P_{c p t}^{\text {reported }}$ on promotion when performance is noisier, but that competition should not change the effect of $O C P_{c p t}^{\text {reported }}$ on promotion. To test these predictions, we augment the linear probability model in Equation 2:

$$
\begin{aligned}
& \text { Promoted }_{i c p t}=\beta_{1} O C P_{c p t}^{\text {reported }}+\beta_{2} O C P_{c p t}^{\text {reported }} * N o i s e_{p}+X_{i c p t} \gamma+\mu_{i}+\eta_{c p}+\lambda_{t}+\varepsilon_{i c p t} \\
& \text { Promoted }_{i c p t}=\beta_{1} O C P_{c p t}^{\text {reported }}+\beta_{3} O C P_{c p t}^{\text {reported }} * C o m p_{p}+X_{i c p t} \gamma+\mu_{i}+\eta_{c p}+\lambda_{t}+\varepsilon_{i c p t} .
\end{aligned}
$$

From these equations, a meritocratic promotion rule would imply $\beta_{1}>0, \beta_{2}<0$, and $\beta_{3}<0$. In contrast, if $\omega=1$ and OCP performance is correlated with the unobserved metric used in promotion, we would expect to find $\beta_{1}>0, \beta_{2}>0$, and $\beta_{3}=0$.

In order to implement the test in Equation 3, we use two measures of the noisiness of OCP performance as a signal of effort and ability. The first measure is the standard deviation of gross migration (in-migration and out-migration), and the second one is the standard deviation of the rates of natural increase by province in the census data. Intuitively, a province with more gross migration or a province with a more variable rate will make it harder for a province-level official to disentangle the noise from the true performance. As these measures have no cardinal interpretation, we normalize them to have mean zero and standard deviation of one. We also use the average of these measures as a third measure.

Table 3 presents estimates of Equation 3. Column (1) reports our preferred estimate from Table 2 for comparison. Column (2) reports a negative coefficient for the interaction of reported OCP performance and the standard deviation of migration, indicating that the marginal effect of increased OCP performance on promotion is decreasing in this measure of noisiness. In columns (3) and (4), we replace the migration measure with the standard deviation of the census birth rate and with the average of the two measures, respectively, and find strikingly similar results. Table 3 also presents estimates of marginal effects at different points in the distribution of our noise measures as well as the p-value of a one-sided test of the hypothesis that $\beta_{2}>0$. We find consistent results in all specifications with marginal effects that are decreasing and statistically significant at the 25thand 50th-percentiles.

Figure 6a plots estimates of marginal effects normalized by the average probability of promotion using estimates from column (4) for different quantiles of the distribution of average noise, with larger quantiles indicating a noisier signal. The y-axis is the predicted percentage change in the probability of promotion of increasing OCP performance by 1 per 1000 . In the visual presentation, the effect of OCP performance on promotion continuously decreases as the signal becomes noisier. In provinces where the signal is the noisiest, the effect of OCP performance on promotion is null. By contrast, in provinces in the 25th-percentile of the distribution of noisiness, increasing OCP performance by 1 per 1000 leads to a $23 \%$ increase in the probability of promotion. 
Table 3: Heterogeneous Effects of Reported OCP Performance on Promotion by Signal Noise

\begin{tabular}{lcccc}
\hline \hline & $(1)$ & $(2)$ & $(3)$ & $(4)$ \\
\hline OCP Performance & $0.017^{*}$ & $0.019^{* *}$ & $0.018^{* *}$ & $0.019^{* *}$ \\
& $(0.010)$ & $(0.008)$ & $(0.009)$ & $(0.008)$
\end{tabular}

OCP Performance X Noise (SD Migration) - $-0.015^{*}$

OCP Performance X Noise (SD Birth Rate) $\quad-0.011$

$(0.010)$

OCP Performance X Noise (Both) $\quad-0.022^{*}$

$(0.011)$

\begin{tabular}{lcccc} 
Log GDP & $\begin{array}{c}0.172^{* * *} \\
(0.056)\end{array}$ & $\begin{array}{c}0.180^{* * *} \\
(0.054)\end{array}$ & $\begin{array}{c}0.164^{* * *} \\
(0.053)\end{array}$ & $\begin{array}{c}0.170^{* * *} \\
(0.054)\end{array}$ \\
\hline Observations & 1,483 & 1,483 & 1,483 & 1,483 \\
$\mathrm{R}^{2}$ & 0.584 & 0.588 & 0.586 & 0.588 \\
Mean of Dependent Variable & 0.132 & 0.132 & 0.132 & 0.132 \\
\hline Year FE & $\mathrm{Y}$ & $\mathrm{Y}$ & $\mathrm{Y}$ & $\mathrm{Y}$ \\
Person FE & $\mathrm{Y}$ & $\mathrm{Y}$ & $\mathrm{Y}$ & $\mathrm{Y}$ \\
City FE & $\mathrm{Y}$ & $\mathrm{Y}$ & $\mathrm{Y}$ & $\mathrm{Y}$ \\
Prefecture-year controls & $\mathrm{Y}$ & $\mathrm{Y}$ & $\mathrm{Y}$ & $\mathrm{Y}$ \\
\hline Marginal Effect at 25th pctil & & $.03^{* * *}$ & $.026^{* *}$ & $.031^{* * *}$ \\
Marginal Effect at 25th pctil (SE) & & $(.01)$ & $(.012)$ & $(.01)$ \\
Marginal Effect at 50th pctil & & $.021^{* *}$ & $.015^{*}$ & $.019^{* *}$ \\
Marginal Effect at 50th pctil (SE) & & $(.008)$ & $(.009)$ & $(.008)$ \\
Marginal Effect at 75th pctil & & .001 & .012 & .005 \\
Marginal Effect at 75th pctil (SE) & & $(.014)$ & $(.01)$ & $(.011)$ \\
One-Sided Test of Interaction (p-val) & & 0.031 & 0.124 & 0.025 \\
\hline \hline
\end{tabular}

Notes: OCP performance reported is the target for the rate of natural increase minus the reported rate of natural increase. Noise (SD Migration) is SD of gross migration (number of in-migrants + number of outmigrants) at the province-level. Noise (SD Birth Rate) is SD of retrospective birth rate in the census data at the province-level. Both noisiness measures are standardized. Noise (Both) is the average of SD Migration and SD Birth Rate. Tenure fixed effects and migration controls are included in all regressions. Prefecture-year controls include $\log$ (population), percentage of urban population and $\log$ (government investment). Standard errors are clustered at the province level and are bootstrapped. ${ }^{*}$ significant at $10 \%$ level; ${ }^{* *}$ significant at $5 \%$ level; ${ }^{* * *}$ significant at $1 \%$ level. 
We use two measures of competitiveness at the province level in order to implement the test in Equation 4. The first is the proportion of mayors that are never promoted in each province during our fifteen years of data, which is equivalent to one minus the promotion rate. The second measure is the average tenure of positions above the bureaucratic rank of mayors. In provinces with longer tenure at these upper-level positions (and thus less turnover), mayors have fewer opportunities of being promoted and must work harder at proving themselves worthy of promotion. ${ }^{39}$ As in the case of our measures of noisiness, we normalize the measures of competitiveness and also consider the average of the two measures.

Table 4 presents estimates of Equation 4 using a similar layout to Table 3. Columns (2)-(4) report negative coefficients for the interactions of OCP performance with our different measures of competitiveness. The one-sided tests reject the hypotheses that $\beta_{3}>0$. Similarly, we find decreasing marginal effects that are statistically significant at lower quantiles of the competitiveness measures. Figure $6 \mathrm{~b}$ uses the results in column (4) to plot estimates of the percentage increase in the probability of promotion from lowering the rate of natural increase by 1 per 1000 at different quantiles of average competitiveness and finds a quantitatively similar pattern to that of Figure 6a. Overall, we find that, in provinces where promotions are more competitive, the marginal effect of reported OCP performance on promotion is smaller, that is, $\beta_{3}<0$.

One potential concern is that our measures of noise and competitiveness are strongly correlated such that Tables 3 and 4 are not providing independent evidence. Table A.2 explores this possibility and shows that our noisiness measures are not statistically related to the competitiveness measures. Indeed, at most $4 \%$ of the variation in competitiveness can be explained by the noise measures, and vice versa. Table A.2 also shows that our measures of noise and competitiveness are not clustered in any one region and reports correlations with other demographic characteristics. Specifically, while the SD of Birth Rate is negatively correlated with urbanization and education, the SD of Migration and the competitiveness measures are not correlated with province-level demographic characteristics. In addition, Table A.3 estimates $\beta_{2}$ and $\beta_{3}$ jointly and finds similar results to Tables 3 and 4 . Figure $6 \mathrm{c}$ reports marginal effects as a function of both noise and competitiveness. To ease interpretation, we only report effects that are statistically significant at the $10 \%$ level.

To summarize, we test the predictions of our model for how OCP performance should affect promotion across provinces with different levels of competition and noise in the output variable. We find that $\beta_{1}>0, \beta_{2}<0$, and $\beta_{3}<0$, which is consistent with a meritocratic promotion rule, and which rules out the case where a positive effect of OCP performance on promotion is due to an omitted variable. These results show that provincial governors are instructed by the central government to value OCP performance both because population control is inherently valued and because doing so may select high-ability mayors for promotions. ${ }^{40}$

\footnotetext{
${ }^{39}$ In order to implement this strategy, we digitized hard-copy records on the term information of all province-level officials ranked higher than mayors. The average tenure of provincial officials ranges from 3 to 6 years across provinces. The distribution of average tenure across provinces is presented in Figure A.3.

${ }^{40}$ These results also discipline alternative models. For instance, while we assume that $\omega$ is fixed across provinces, one could alternatively consider province-varying tastes for meritocracy. However, in order for this story to match our empirical results, it would have to be the case that very competitive provinces and provinces where output is a noisier measure of effort and ability are precisely the provinces that have low tastes for meritocracy, which seems unlikely.
} 
Figure 6: Heterogeneous Effects of OCP on Promotion

(a) OCP Promotion and Outcome Noise

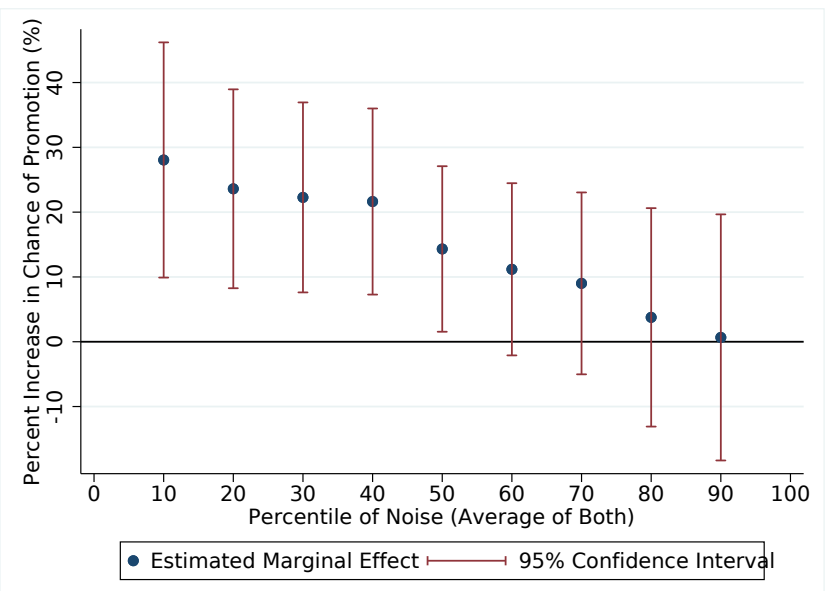

(b) OCP Promotion and Agent Competition

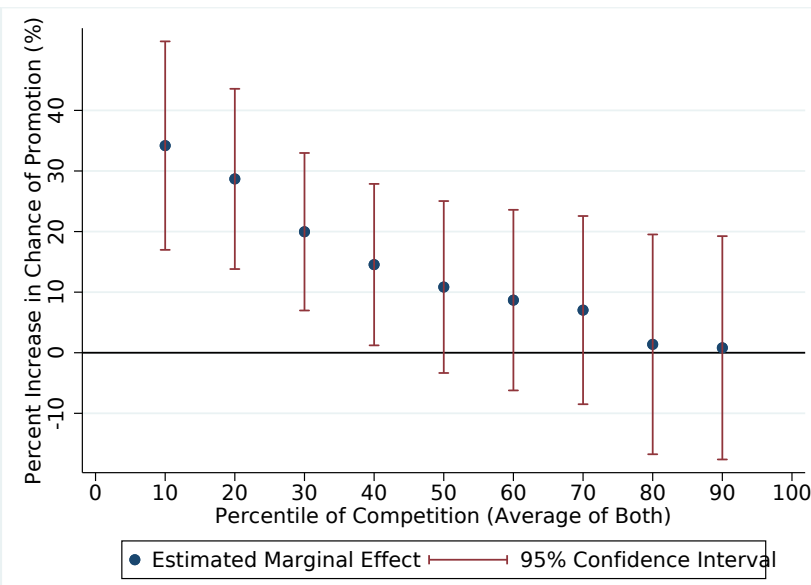

(c) Marginal Effects of OCP Promotion by Noise and Competition

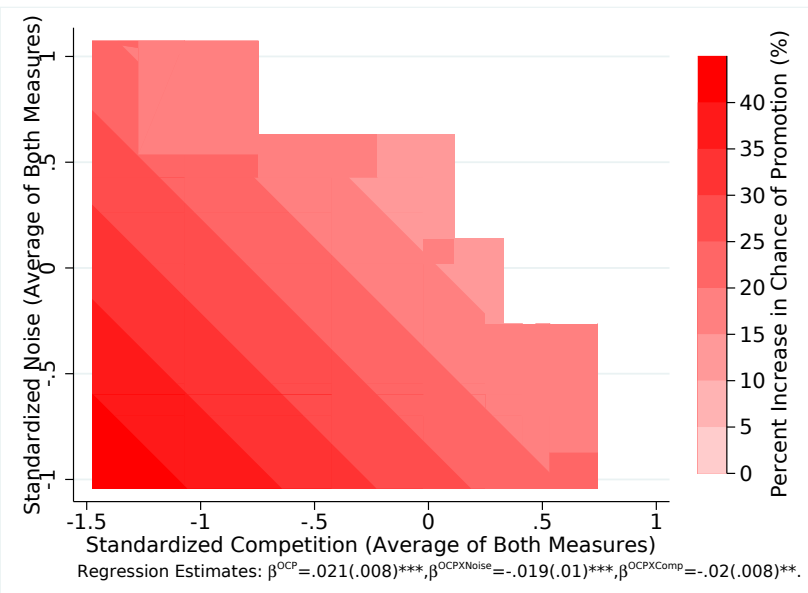

Notes: In Figure 6a, the x-axis represents different percentiles of the distribution of the average noisiness measure; the higher the percentile, the noisier the signal. The y-axis is the predicted percentage change in the probability of promotion of increasing OCP performance by 1 per 1000. The figure is plotted using estimates in column (4) of Table 3. In Figure 6b, the x-axis represents different percentiles of the distribution of the average competitiveness measure; the higher the percentile, the more competitive the tournament. The figure is plotted using estimates in column (4) of Table 4. Figure 6c plots marginal effects of increasing OCP performance by 1 per 1000 on the probability of promotion using estimates from Table A.3. For ease of interpretation, the figure only displays effects that are statistically significant at the $10 \%$ level.

\subsection{Robustness}

We explore the sensitivity of our results to a host of potential problems, including time-varying political connections as a source for endogeneity, targets that may vary at the prefecture-level, measurement error in OCP performance, as well as alternative specifications of our estimating equation. 
Table 4: Heterogeneous Effects of Reported OCP Performance on Promotion by Competitiveness

\begin{tabular}{|c|c|c|c|c|}
\hline & $\overline{(1)}$ & 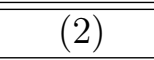 & (3) & (4) \\
\hline OCP Performance Reported & $\begin{array}{l}0.017^{*} \\
(0.010)\end{array}$ & $\begin{array}{l}0.018^{* *} \\
(0.008)\end{array}$ & $\begin{array}{l}0.018^{* *} \\
(0.009)\end{array}$ & $\begin{array}{l}0.019^{* *} \\
(0.008)\end{array}$ \\
\hline OCP Performance Reported X Competitiveness (Tenure) & & $\begin{array}{l}-0.012 \\
(0.007)\end{array}$ & & \\
\hline OCP Performance Reported X Competitiveness (1-Pr Rate) & & & $\begin{array}{c}-0.018^{* * *} \\
(0.006)\end{array}$ & \\
\hline OCP Performance Reported X Competitiveness (Average) & & & & $\begin{array}{c}-0.022^{* * *} \\
(0.008)\end{array}$ \\
\hline Log GDP & $\begin{array}{c}0.172^{* * *} \\
(0.056)\end{array}$ & $\begin{array}{c}0.175^{* * *} \\
(0.054)\end{array}$ & $\begin{array}{c}0.171^{* * *} \\
(0.054)\end{array}$ & $\begin{array}{c}0.174^{* * *} \\
(0.056)\end{array}$ \\
\hline Observations & 1,483 & 1,483 & 1,483 & 1,483 \\
\hline $\mathrm{R}^{2}$ & 0.584 & 0.586 & 0.589 & 0.589 \\
\hline Mean of Dependent Variable & 0.132 & 0.132 & 0.132 & 0.132 \\
\hline Year FE & $\mathrm{Y}$ & Y & $\mathrm{Y}$ & $\mathrm{Y}$ \\
\hline Person FE & Y & Y & Y & $\mathrm{Y}$ \\
\hline City FE & Y & Y & $\mathrm{Y}$ & Y \\
\hline Prefecture-year controls & Y & Y & Y & Y \\
\hline Marginal Effect at 25th pctil & & $.023^{* * *}$ & $.034^{* * *}$ & $.038^{* * *}$ \\
\hline Marginal Effect at 25th pctil (SE) & & $(.008)$ & $(.011)$ & $(.01)$ \\
\hline Marginal Effect at 50th pctil & & $.02^{* * *}$ & $.015^{*}$ & .014 \\
\hline Marginal Effect at 50th pctil (SE) & & $(.008)$ & $(.009)$ & $(.009)$ \\
\hline Marginal Effect at 75 th pctil & & .008 & .007 & .003 \\
\hline Marginal Effect at 75 th pctil (SE) & & $(.012)$ & $(.01)$ & $(.011)$ \\
\hline One-Sided Test of Interaction (p-val) & & 0.057 & 0.003 & 0.004 \\
\hline
\end{tabular}

Notes: OCP performance reported is the target for the rate of natural increase minus the reported rate of natural increase. Competitiveness (Tenure) is measured by the average tenure of upper-level officials at the province level. Competitiveness (1-Pr Rate) is (1-promotion rate by province). Both competitiveness measures are standardized. Competitiveness (Both) is the average of Competitiveness (Tenure) and Competitiveness (1-Pr Rate). Tenure fixed effects and migration controls are included in all regressions. Prefecture-year controls include $\log$ (population), percentage of urban population and $\log$ (government investment). Standard errors are clustered at the province level and are bootstrapped. * significant at $10 \%$ level; ** significant at $5 \%$ level; *** significant at $1 \%$ level. 


\subsubsection{Alternative measures of economic performance}

Our measure of economic performance follows the official evaluation metrics for mayors in Landry (2008). We also check the robustness of our comparative statics by controlling for alternative measures of economic performance. We first control for GDP growth rate, which is commonly used in the literature on the promotion of provincial leaders, and then control for less-manipulable measures such as electricity usage and railway cargo volume. In Table A.6, we find that the heterogeneous effects of reported OCP performance on promotion by signal noise are robust to including any of these alternative economic measures. Similarly, Table A.7 shows that the heterogeneous effects of reported OCP performance on promotion by competitiveness are also robust to including alternative economic measures.

\subsubsection{An Instrumental Variable for Reported OCP Performance}

We now turn to an instrumental variables approach, which alleviates concerns that time-varying unobservable factors, such as expanding political networks, are biasing our results. Our strategy leverages the fact that the targets are set at the province level by the central government in five-year plans. Changes in these targets generate "surprise changes" in reported OCP performance among mayors in office. For example, if there is a decrease in the target, it is harder for mayors to get closer to the target and thus achieve a better OCP performance. We use decreases in the target to instrument for reported OCP performance. ${ }^{41}$ Figure 4a shows the average target from 1985 to 2000. The targets were changed twice during these fifteen years; the 1990 plan saw an average increase from 1986-90 to 1991-95 and the 1995 plan saw an average decrease from 1991-95 to 1996-2000. For a given plan, however, there was substantial variation in whether a province experienced an increase or a decrease in target. Figure $4 \mathrm{~b}$ shows that 13 provinces saw a decrease in the target in the 1985 plan, while 21 provinces saw a decrease in the 1995 plan. The exclusion restriction is that target changes that occur as part of the five-year plans are not otherwise correlated with unobserved mayor characteristics that also affect promotion.

Table 5 presents results from this strategy. ${ }^{42}$ Column (1) presents the first-stage estimate, which displays a strong and positive correlation between decreases in the targets and reported OCP performance; the F-value of the first-stage coefficient is 21 . Table A.8 shows that the instrument is not correlated with $\log$ GDP and shows that the first stage is robust across different specifications, including ones that do not control for log GDP. We also find in Table A.9 that the instrument is uncorrelated with other measures of economic performance, including GDP growth rate, electricity usage and railway cargo volume. Column (3) presents the 2SLS estimate, which is slightly larger

\footnotetext{
${ }^{41}$ We use negative changes in targets to avoid analyzing cases where mayors are promoted by "getting lucky" through a relaxation of standards. In unreported results, we find a similar pattern when we use all changes in targets as the instrument. In order to increase the precision of the estimate, we also control for interactions between our instrument and our measures of noise and competitiveness. These controls leverage the model's insights that the strength of the incentive depends on the competitiveness and the noisiness of the environment.

${ }^{42}$ Note that the sample is smaller than that in column (4) of Table 2 because the target data are unavailable in a few years in a few provinces.
} 
Table 5: Instrumental Variable Regression of Promotion on Reported OCP Performance

\begin{tabular}{lccc}
\hline \hline & OCP Performance Reported & \multicolumn{2}{c}{ Promotion $=1$} \\
\cline { 2 - 4 } & $(1)$ & $(2)$ & $(3)$ \\
& First Stage & OLS & 2SLS \\
\hline Change in Birth Rate Target & $0.563^{* * *}$ & & \\
& $(0.124)$ & & \\
OCP Performance Reported & & $0.017^{*}$ & $0.028^{*}$ \\
& & $(0.010)$ & $(0.017)$ \\
Log GDP & & & \\
& 0.279 & $0.183^{* * *}$ & $0.179^{* * *}$ \\
\hline Observations & $(0.511)$ & $(0.056)$ & $(0.051)$ \\
$\mathrm{R}^{2}$ & 1,519 & 1,371 & 1,519 \\
First-Stage F-Stat & 0.80 & 0.47 & 0.58 \\
\hline Year FE & & & 20.65 \\
Person FE & $\mathrm{Y}$ & $\mathrm{Y}$ & $\mathrm{Y}$ \\
City FE & $\mathrm{Y}$ & $\mathrm{Y}$ & $\mathrm{Y}$ \\
Prefecture-year controls & $\mathrm{Y}$ & $\mathrm{Y}$ & $\mathrm{Y}$ \\
\hline
\end{tabular}

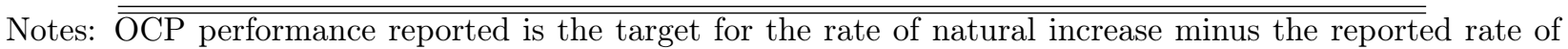
natural increase. Tenure fixed effects and migration controls are included in all regressions. Prefecture-year controls include $\log$ (population), percentage of urban population and $\log$ (government investment). Standard errors are clustered at the province level and are bootstrapped. Table A.10 tests potential violations of the exclusion restriction. Tables A.11 and A.12 explore heterogeneous effects by noisiness and competitiveness using this IV strategy. ${ }^{*}$ significant at $10 \%$ level; ${ }^{* *}$ significant at $5 \%$ level; ${ }^{* * *}$ significant at $1 \%$ level.

than the OLS estimate in column (2). Decreasing the rate of natural increase by 1 per 1000 increases the chance of promotion by 2.8 percentage points, which represents a $21 \%$ increase in the probability of promotion. This estimate has a similar economic magnitude, falls within the range of estimates in the previous section, and is not statistically different from the OLS estimate. However, one interpretation of a larger effect is that well-connected candidates for promotion might be assigned to "problem places" with larger challenges. An alternative interpretation is that the 2SLS estimate might reduce measurement error in OCP performance, leading to a larger estimate. As is often the case with IV estimates, these interpretations are at best speculative given the loss in statistical precision.

While the exclusion restriction is fundamentally untestable, we provide corroborating evidence of its plausibility. First, one concern is that province targets are set to favor a particular mayor within a province. While this does not seem feasible given that most provinces have five or more prefectures, we nevertheless analyze the potential for this concern. For example, if politically-connected mayors performed worse in birth control than unconnected ones, the target might be raised to help connected mayors improve their performance. Although an increase in target could favor every mayor within a province, only those staying in office after the change experience the benefit. We test this possibility in Table A.10, Panel A. We split the sample into two parts: column (1) uses the sub-sample in provinces and years with an increase in the target, and column (2) uses the sub-sample in provinces and years with a decrease in the target. In both sub-samples, we fail to find evidence that the 
OCP performance prior to a target change is correlated with whether they stay in office after the change. A second concern is that if connected mayors anticipate a change in the target, there could be selection on whether they are promoted prior to the change. We test this hypothesis in Panel B and we do not find a statistically significant correlation between future changes in the targets and promotion, suggesting that the target is not changed to favor some (connected) mayors. Finally, one might be concerned that mayors respond to a decrease in target by reporting lower rates of natural increase. Panel $\mathrm{C}$ indicates that changes in the target do not significantly change the difference between the rate from census data and the reported rate, which rules out this last concern.

We also test whether 2SLS estimates of the effect of OCP performance on promotion differ by noisiness and competitiveness. In Table A.11, we include the interaction of OCP performance with our noisiness measures, which we instrument with interacted versions of decreases in targets. Consistent with the results in Table 3, the OCP performance has a smaller effect on promotion in noisier environments. In Table A.12, we estimate the average effect of OCP performance on promotion allowing for heterogeneous effects across regions with low versus high competitiveness. ${ }^{43}$ We instrument for low competition interacted with OCP performance using low competition interacted with the decrease in target, and for high competition interacted with OCP performance using high competition interacted with the decrease in target. The 2SLS results are consistent with the baseline results that the promotion incentive is smaller in more competitive environments.

\subsubsection{Using Estimated Prefecture-Level Targets}

To the best of our knowledge, mayors are evaluated using province-level targets. However, a potential concern is that the relevant target for mayors' evaluations is subcontracted to prefecture-level governments. If this were the case, measurement error in OCP performance using province-level targets might affect our estimates. We address this concern by estimating an allocation rule of targets across provinces and using this rule to predict targets at the prefecture level. Table A.13 reports the estimated allocation rule at the province level. We find that higher targets are allocated to provinces with a higher number of women of reproductive age (15-45) and a higher fraction of rural women. Using these estimates and the same demographic measures at the prefecture level, we predict a prefecture-level target.

Table A.14 shows that our main results are robust to using our estimated province-level targets. Column (1) shows that controlling for the prefecture-level demographic variables used in Table A.13 results in similar average estimates to those in Table 2. Columns (2)-(4) consider different linear combinations of the province- and prefecture-level measures, which result in statistically and economically similar estimates. Further, columns (5)-(7) use the average of these measures in the comparative static analysis, which result in similar interactions with our measures of noise and competitiveness, confirming the role of meritocracy in the promotion rule.

Another potential concern is that some provinces are dominated by a few mayors and that the targets are set in order to favor them. To address this concern, we create two measures of mayor dominance: (1) the share of a province's population represented by a given mayor and (2) the Herfindahl-Hirschman Index (HHI) for each province. On average, mayors represent $16 \%$ of a

\footnotetext{
${ }^{43}$ We define low competitiveness as the lower tercile of the distribution.
} 
province's population. Similarly, the average HHI is $21 \%$, which implies that, on average, provinces are divided into 5 equally-populated areas. In Table A.15, we show that excluding mayors that account for more than $25 \%$ of a province's population or relatively more concentrated provinces (those with $\mathrm{HHI}>33 \%$ ) does not affect the results of Table 2. These results show that most provinces are not dominated by a few or even a single mayor. Therefore, it is unlikely that the concerns of potentially dominant mayors could sway the setting of targets.

\subsubsection{Measurement Error}

We now perform a set of analyses where we leverage our two measures of targets (province- and prefecture-level) to assuage concerns of potential measurement error. Following the repeated measures literature (see, e.g., Bound et al. 2001), we use one measure as an instrument for the other. Tables A.16 and A.17 present results from both iterations of this procedure. In both cases, we find very similar estimates of the main effect of OCP performance on the probability of promotion as well as similar comparative static results that support our conclusion that $\beta_{1}>0, \beta_{2}<0$, and $\beta_{3}<0$.

\subsubsection{Alternative Specifications}

We also explore whether lagged OCP performances in the past four years affect our contemporaneous estimate in Table A.18 and find that our main result is robust to including lagged OCP performance in the regression. Additionally, Table A.3 shows that our results are robust to using different levels of clustering, Table A.5 shows that our results are robust to including interactions between OCP performance and $\log$ GDP, and Table A.4 shows that we obtain very similar results when we include province-by-5-year-plan fixed effects and province-by-year fixed effects.

\section{$5 \quad$ Empirical Evidence of Manipulation and Screening Efficacy}

The previous section shows that reported OCP performance has a positive and substantively large effect on the probability that a given mayor is promoted. Moreover, tests of comparative statics further support the view that the promotion rule is consistent with a meritocratic objective. However, it is still an open question whether such a tournament mechanism with non-contractible output is able to screen successfully for high-ability mayors, and whether the population audits have an effect on misreporting behavior.

\subsection{Effects of Audits on Output and Data Manipulation}

In this section we analyze the misreporting behavior of mayors. As we discuss in Section 3, we find significant disparities between the reported OCP performance and the Census OCP. While this is consistent with strategic misreporting, it could also be the case that this difference is influenced by measurement error. In order to show that mayors engage in strategic misreporting, we focus on how misreporting changes in years when mayors have a lower incentive to misreport. As discussed in Section 1.3, the central government uses population census and national fertility surveys to investigate the actual rates and the credibility of reported rates, which are organized at the province level. The 
audit year is the year before the census or fertility survey when the actual rates are fully observed. Equation 5 tests whether the difference between reported rates and the rates using the census data is smaller one year prior to the census or national fertility survey (i.e. the audit year):

$$
\text { Birth Rate }_{c p t}^{\text {census }}-\text { Birth Rate }_{c p t}^{\text {reported }}=\delta A_{u d i t_{t}}+f(t)+X_{i c p t} \gamma+\mu_{i}+\eta_{c p}+\varepsilon_{i c p t},
$$

where the binary variable Audit $_{t}$ is equal to 1 in years 1987, 1989, 1991, 1994, and 1996. We include a flexible year trend $f(t)$. If the difference indeed suggests data manipulation, we should observe that $\delta<0$. If this is the case, we further examine whether the decrease in the difference from these two data sources comes from higher reported rates, suggesting less manipulation, or from lower actual rates in census, indicating actual improvement in OCP enforcement.

Table 6 presents estimates of Equation 5. In column (1), we find that the difference between reported rates and actual rates from the census is smaller in audit years. This is consistent with the view that birth rates are manipulated in non-audit years. We further examine whether the decrease in the difference from these two data sources comes from higher reported rates, suggesting less manipulation, or lower actual rates, indicating actual improvement in OCP enforcement. Columns (2) and (3) suggest that most of the decrease is attributable to mayors exerting more effort to lower the actual rate. Finally, if lower birth rates and higher GDP growth rate are substitutes, we would expect that, in audit years when mayors reported higher rates of natural increase (thus doing worse on the OCP dimension), mayors might work harder to improve GDP or report higher GDP numbers. We find that this is indeed the case in column (4). ${ }^{44}$

Table 6: Effects of Population Audits

\begin{tabular}{lcccc}
\hline \hline & $(1)$ & $(2)$ & $(3)$ & $(4)$ \\
\hline & $\begin{array}{c}\text { Census - Reported } \\
\text { Birth Rates }\end{array}$ & $\begin{array}{c}\text { Reported } \\
\text { Birth Rate }\end{array}$ & $\begin{array}{c}\text { Census } \\
\text { Birth Rate }\end{array}$ & Log GDP \\
\hline Audit Year & $-0.325^{* *}$ & 0.039 & $-0.286^{*}$ & $0.174^{* * *}$ \\
& $(0.164)$ & $(0.132)$ & $(0.164)$ & $(0.014)$ \\
\hline Observations & 1,524 & 1,524 & 1,524 & 1,524 \\
$\mathrm{R}^{2}$ & 0.84 & 0.81 & 0.92 & 0.98 \\
\hline Cubic Year Trend & $\mathrm{Y}$ & $\mathrm{Y}$ & $\mathrm{Y}$ & $\mathrm{Y}$ \\
Person FE & $\mathrm{Y}$ & $\mathrm{Y}$ & $\mathrm{Y}$ & $\mathrm{Y}$ \\
City FE & $\mathrm{Y}$ & $\mathrm{Y}$ & $\mathrm{Y}$ & $\mathrm{Y}$ \\
Prefecture-year controls & $\mathrm{Y}$ & $\mathrm{Y}$ & $\mathrm{Y}$ & $\mathrm{Y}$ \\
\hline \hline
\end{tabular}

Notes: Misreporting is measured as the difference: Census - Reported Birth Rates. Audit years include the year before the census year in 1990 and 1995, and the year before the national fertility survey in 1988, 1992, and 1997. Tenure fixed effects and migration controls are included in all regressions. Prefecture-year controls include $\log$ (population), percentage of urban population and $\log$ (government investment). Standard errors are clustered at the province level and are bootstrapped. ${ }^{*}$ significant at $10 \%$ level; ${ }^{* *}$ significant at $5 \%$ level; $* * *$ significant at $1 \%$ level.

We can use the estimates in Tables 2 and 6 to provide an assessment of the relative costs of

\footnotetext{
${ }^{44}$ Note that the misreporting of mayors above the target does not respond to audits, as we show in Table A.23.
} 
increasing monitoring. First, we compute the government's perceived benefit from reducing the birth rate. Given our estimates from Table 2, the government is willing to trade-off 10\% in GDP growth for a 1 in 1000 birth rate reduction. Second, we compute the benefits of an additional audit. Following Table 6, we find that an audit resulted in -0.29 fewer births per 1000 people. This implies that the government's willingness to pay for an audit is approximately $2.9 \%$ of local GDP. We view this back-of-the-envelope calculation as suggestive of two insights. First, given the high willingness to pay for an audit, this implies that the government faces significant costs from not being able to perfectly verify OCP performance. Second, given that the government only conducted audits in five of the fifteen years in our dataset, we infer that conducting additional audits (to increase the degree of verifiability) was simply too expensive for the government.

\subsection{Screening Ability in the Presence of Misreporting}

Our model predicts that when mayors manipulate reported birth rates, the expected ability of the promoted mayor will be lower than when output is contractible. In the extreme case where output is completely non-verifiable, the ability of the promoted mayor will approach the population average. We test this hypothesis in Equation 6:

$$
\text { Promoted }_{i c p t}=\beta_{4} O C P_{c p t}^{c e n s u s}+X_{i c p t} \gamma+\mu_{i}+\eta_{c p}+\lambda_{t}+\varepsilon_{i c p t},
$$

where the key regressor of interest is the OCP performance measure from census data, measured as $O C P_{c p t}^{\text {census }}=$ Target $_{p t}-$ Birth Rate $_{c p t}^{\text {census }}$. In the case where output is non-verifiable, our theory predicts that $\beta_{4} \approx 0$.

Table 2 presents estimates of $\beta_{4}$, where we control for the same controls as Equation 2 as well as for $O C P_{c p t}^{r e p o r t e d}$. From column (1) through column (6), results from all specifications suggest that actual OCP performance is not significantly predictive of promotion. These findings imply that promoted mayors are not significantly more able to lower the actual rate than mayors who are not promoted. This shows that meritocracies may not screen high ability agents when output is imperfectly verifiable. In addition to showing that $\beta_{4} \approx 0$, we also test whether the effect of $O C P_{c p t}^{\text {reported }}$ is statistically larger than the effect of $O C P_{c p t}^{c e n s u s}$, that is, that $\beta_{1}>\beta_{4}$. We report p-values from this test in the bottom of Table 2 . The hypothesis that $\beta_{1}<\beta_{4}$ is rejected with p-values between 0.06-0.08.

Table 2 uses the best information available in the census to account for migration. In Table A.19, we explore the potential for migration to explain our null results by studying the effect of removing migration controls. ${ }^{45}$ Similarly, in Table A.20 we follow the robustness checks described in Section 4.2. In both cases, we find that migration controls, controlling for alternative measures of economic performance, 2SLS estimates, prefecture-level targets, and corrections for measurement error deliver economically small and statistically insignificant correlations between promotion and actual performance. This suggests that the lack of correlation between actual OCP performance

\footnotetext{
${ }^{45}$ This analysis investigates the potential measurement error from not directly observing migration before 1995 (when the migration rate was below 4\%). We repeat the specification in column (4) of Table 2, with various incomplete controls for migration and using the same sub-sample, and report the results in column (1) through column (3) in Table A.19; the main estimate is not sensitive to including these controls.
} 
and promotion is not a statistical anomaly, but rather a result of the impaired capacity of the tournament mechanism to screen for ability when output is non-contractible and reported performance is manipulated.

\section{Conclusion}

This paper analyzes the role of meritocracy in determining the promotion of mayors in China. We document that, despite potential for corruption through political connections, promotion rules are partly driven by perceived performance in implementing the OCP. Moreover, we show that the relationship between performance and promotion is determined by a desire to screen high-ability mayors for higher office. While we confirm that observed promotion decisions are consistent with a meritocratic objective, the efficacy of this screening mechanism is weakened by mayors' ability to manipulate reported outcomes. Empirically, we find that mayors manipulate less in audit years (that is, when monitoring is increased), which is consistent with the importance of OCP as a performance metric. Nonetheless, we find that audits are not able to resolve the fundamental problem of noncontractible output.

The combination of theory and empirical analysis makes our findings particularly compelling and demonstrates the importance of interpreting empirical results through the lens of a rigorous model of incentives. Without guidance from our model, the applied econometrician could arrive at the mistaken conclusion that meritocracy was not a driving force in the Chinese government, as promoted mayors do not appear to be of higher ability than mayors who are not promoted. However, by testing more subtle predictions of our model, we are able to separate the desire to implement the OCP from the meritocratic objective, a distinction which previous studies of promotion based on other measures of performance were not able to address.

While our study focuses foremost on the implementation of the OCP, it also yields interesting lessons for the literature studying the relation between economic growth and cadre promotion. Our model suggests that promotions are less likely to stem from a meritocratic motive in cases where the government places a relatively higher value on output production. For instance, it may be the case that economic growth is valued much more as a production objective than as a screening mechanism. From the perspective of the OCP, a similar logic implies that the government may place a lower importance on this policy than was previously thought. Instead, the enduring permanence of the OCP may be due to the fact that the government believed this task helped improve the screening of mayors. This discussion highlights two facts that are evinced by our study. First, identifying the role of meritocracy in selection requires an understanding of the trade-offs faced by the principal across different incentive forms. Second, the reason why performance in policy implementation is linked to promotion is important for understanding the provenance of those policies as well as the potential for their reform.

We conclude by noting that, while critics of the implementation of the OCP point toward local government promotion incentives as a cause for human rights abuses, including forced abortions and sterilizations (see, e.g., Wong 2012), the alternative piece rate compensation mechanism would likely lead to more such cases as effort from lower-ability mayors would likely increase. Moreover, 
one consequence of the non-contractibility and manipulation of the rates of natural increase is that marginal incentives may have little or no effect on actual birth rates, even though the policy on the whole may lead to human rights abuses. 


\section{References}

Acemoglu, D. (2005). Politics and economics in weak and strong states. Journal of Monetary Economics 52, $1199-226$.

Baker, G., M. Gibbs, and B. Holmstrom (1994). The Internal Economics of the Firm: Evidence from Personnel Data. The Quarterly Journal of Economics 109(4), 881-919.

Banerjee, A., P. Gertler, and M. Ghatak (2002). Empowerment and Efficiency: Tenancy Reform in West Bengal. Journal of Political Economy.

Banister, J. (1992). China: Recent Mortality Levels and Trends. Paper presented at the Annual Meeting of the Population Association of America, 30 April-2 May, Denver, Colorado.

Bell, D. (2015). The China Model: Political Meritocracy and the limits of democracy. Princeton University Press.

Bell, D. and E. Li (2012, November 11). In defence of how China picks its leaders. The Financial Times.

Bertrand, M. and S. Mullainathan (2001). Are CEOs Rewarded for Luck? The Ones Without Principals Are. Quarterly Journal of Economics 116(3), 901-932.

Besley, T. (2005, September). Political selection. Journal of Economic Perspectives 19(3), 43-60.

Besley, T. J., K. B. Burchardi, and M. Ghatak (2012). Incentives and the De Soto Effect. The Quarterly Journal of Economics 127(1), 237-282.

Besley, T. J. and T. Persson (2010). State capacity, conflict and development. Econometrica 78(1-34).

Birney, M. (2014). Decentralization and veiled corruption under China's rule of mandates. World Development 53, 55-67.

Bobonis, G., L. R. C. Fuertes, and R. Schwabe (2013). Monitoring Corruptible Politicians. American Economic Review, forthcoming.

Bound, J., C. Brown, and N. Mathiowetz (2001). Measurement error in survey data. In The Handbook of Econometrics.

Chay, K. Y., P. J. McEwan, and M. Urquiola (2005). The Central Role of Noise in Evaluating Interventions That Use Test Scores to Rank Schools. American Economic Review 95(4), 1237-1258.

Chen, Y.-Y., G. Z. Jin, N. Kumar, and G. Shi (2012). Gaming in Air Pollution Data? Lessons from China. The B.E. Journal of Economic Analysis 83 Policy 13(3).

Chevalier, J. and G. Ellison (1999). Career Concerns of Mutual Fund Managers. Quarterly Journal of Economics 14(2), 389-432.

Chiappori, P. and B. Salanie (2000). Testing for Asymmetric Information in Insurance Markets. Journal of Political Economy 108, 56-78.

Choukhmane, T., N. Coeurdacier, and K. Jin (2014). The One Child Policy and Household Saving. mimeo.

Cullen, J. B. and R. Reback (2006). Tinkering toward accolades: School gaming under a performance accountability system. In T. Gronberg and D. Jansen (Eds.), Improving School Accountability: Check-Ups or Choice, Advances in Applied Microeconomics 14, pp. 1-34. Amsterdam: Elsevier Science. 
Ebenstein, A. (2010). The "Missing Girls" of China and the Unintended Consequences of the One Child Policy. The Journal of Human Resources 45(1), 87-115.

Ferraz, C. and F. Finan (2008). Exposing Corrupt Politicians: The Effects of Brazil's Publicly Released Audits on Electoral Outcomes. The Quarterly Journal of Economics 123(2), 703-745.

Ferraz, C. and F. Finan (2011). Electoral Accountability and Corruption: Evidence from the Audits of Local Governments. American Economic Review 101(4), 1274-1311.

Fisman, R. and Y. Wang (2015). The Economics of Death Ceilings. Working Paper.

Fisman, R. and S.-J. Wei (2004). Tax Rates and Tax Evasion: Evidence From 'Missing Imports' in China. Journal of Political Economy 112(2), 471-96.

Ghanem, D. and J. Zhang (2014). Effortless Perfection: Do Chinese Cities Manipulate Air Pollution Data? Journal of Environmental Economics and Management 68, 203-225.

Hardee-Cleaveland, K. and J. Banister (1988). Fertility Policy and Implementation in China, 1986-88. Population and Development Review 14(2), 245-286.

Holmstrom, B. (1999). Managerial Incentive Problems: A Dynamic Perspective. Review of Economic Studies $66(1), 169-182$.

Holmstrom, B. and P. Milgrom (1991). Multitask principal-agent analyses: Incentive contracts, asset ownership, and job design. Journal of Law, Economics, 83 Organization 7, 24-52.

Jacob, B. and S. Levitt (2003). Rotten Apples: An Investigation of the Prevalence and Predictors of Teacher Cheating. The Quarterly Journal of Economics 118, 843-877.

Jia, R.-X. (2014). Pollution for Promotion. mimeo.

Jia, R.-X., M. Kudamatsu, and D. Seim (2015). Political Selection in China: Complementary Role of Connections and Performance. Journal of the European Economic Association 13(4), 631-668.

Johansson, S. and O. Nygren (1991). The Missing Girls of China: A New Demographic Account. Population and Development Review 17(1), 35-51.

Kane, T., D. G. D. Staiger, and H. Ladd (2002). Volatility in school test scores: Implications for test-based accountability systems. Brookings Papers on Education Policy, 235-283.

Laffont, J.-J. (2001). Incentives and Political Economy. Clarendon Lectures in Economics. Oxford University Press.

Landry, P. (2008). Decentralized Authoritarianism in China: The Communist Party's Control of Local Elites in the Post-Mao Era. Cambridge and New York: Cambridge University Press.

Lazear, E. and S. Rosen (1981). Rank-Order Tournaments as Optimum Labor Contracts. Journal of Political Economy 89(5), 841-864.

Li, H.-B. and L.-A. Zhou (2005). Political Turnover and Economic Performance: The Incentive Role of Personnel Control in China. Journal of Public Economics 89(9-10), 1743-62.

Maskin, E., Y.-Y. Qian, and C.-G. Xu (2000). Incentives, Information, and Organizational Form. Review of Economic Studies 67(2), 359-78. 
Olken, B. (2006). Monitoring Corruptible Politicians: Evidence from a Field Experiment in Indonesia. Journal of Political Economy 115(2), 200-249.

Oyer, P. and S. Schaefer (2011). Personnel Economics: Hiring and Incentives. In O. Ashenfelter and D. Card (Eds.), The Handbook of Labor Economics, Volume 4b, pp. 1769-1823.

Persson, P. and E. Zhuravskaya (2015). The Limits of Career Concerns in Federalism: Evidence from China. Journal of the European Economics Association, forthcoming.

Prendergast, C. (1999). The Provision of Incentives in Firms. Journal of Economic Literature 37, 7-63.

Qian, N. (2009, May). Quantity-Quality and the One Child Policy: The Only-Child Disadvantage in School Enrollment in Rural China. Working Paper 14973, National Bureau of Economic Research.

Rasul, I. and D. Rogger (2016, January). Management of bureaucrats and public service delivery: Evidence from the nigerian civil service. Technical Report No. DP11078., CEPR Discussion Paper.

Rochet, J.-C. and L. Stole (2003). The Economics of Multidimensional Screening. In M. Dewatripont and L. Hansen (Eds.), Advances in Economic Theory, rth World Congress. Cambridge University Press.

Rockoff, J., D. Staiger, T. Kane, and E. Taylor (2012). Information and Employee Evaluation: Evidence from a Randomized Intervention in Public Schools. American Economic Review 102(7), 3184-3213.

Scharping, T. (2003). Birth Control in China 1949-2000: Population Policy and Demographic Development. London and New York: Routledge-Curzon.

Shih, V., C. Adolph, and M.-X. Liu (2012). Getting Ahead in the Communist Party: Explaining the Advancement of Central Committee Members in China. American Political Science Review 106, 16687.

Wei, S.-J. and X. Zhang (2011). The Competitive Saving Motive: Evidence from Rising Sex Ratios and Saving Rates in China. The Journal of Political Economy 119(3), 511-564.

Wong, E. (2012, July, 22). Reports of Forced Abortions Fuel Push to End Chinese Law. The New York Times.

Xu, C.-G. (2011). The Fundamental Institutions of China's Reforms and Development. Journal of Economic Literature 49(4), 1076-1151.

Zeng, Y., P. Tu, B. Gu, Y. Xu, B. Li, and Y. Li (1993). Causes and implications of the recent increase in the reported sex ratio at birth in china. Population and Development Review 19(2), 283-302.

Zheng, S., M. E. Kahn, W. Sun, and D. Luo (2014). Incentives for china's urban mayors to mitigate pollution externalities: The role of the central government and public environmentalism. Regional Science and Urban Economics 47, 61 - 71. SI: Tribute to John Quigley.

Zitzewitz, E. (2012). Forensic Economics. Journal of Economic Literature 50(3), 731-769. 


\section{Online Appendices Not For Publication}

\section{A Appendix - Theory}

\section{A.1 The probability that $a_{i}$ produces the maximum output}

Recall that the expected value of the maximal order statistic for $N$ iid draws from an exponential distribution with parameter $\lambda$ is:

$$
E\left[\varepsilon_{(N)}\right]=\left(1+\frac{1}{2}+\ldots+\frac{1}{N}\right) \frac{1}{\lambda}
$$

Since agent $a_{i}$ only knows the average ability of the agent population, her belief about the probability that her output $y_{i}$ is the maximal output is:

$$
\begin{aligned}
\operatorname{Pr}\left(y_{i} i s \max \mid e_{1}, \ldots, e_{N}\right) & =\operatorname{Pr}\left(y_{i} \geq \frac{1}{N-1} \sum_{j \neq i} y_{j}+\left(1+\frac{1}{2}+\ldots+\frac{1}{N-1}\right) \frac{1}{\lambda}\right) \\
& =\operatorname{Pr}\left(\varepsilon_{i} \geq \frac{1}{N-1} \sum_{j \neq i} e_{j}-e_{i}+\left(1+\frac{1}{2}+\ldots+\frac{1}{N-1}\right) \frac{1}{\lambda}\right)
\end{aligned}
$$

where $\frac{1}{N-1} \sum_{j \neq i} e_{j}+E\left[\varepsilon_{(N-1)}\right]$ is the expected value of the sample maximum of the realized outputs of the other $(\mathrm{N}-1)$ agents: $\hat{y}_{i}=e_{i}+\hat{\varepsilon}_{i}$.

Recall that if $\varepsilon \sim \exp (\lambda)$, then the cdf is $F_{\varepsilon}(x)=1-e^{-\lambda x}, x>0$. Thus, this probability is:

$$
\begin{aligned}
\operatorname{Pr}\left(y_{i} i s \max \mid e_{1}, \ldots, e_{N}\right) & =1-F_{\exp (\lambda)}\left(\frac{1}{N-1} \sum_{j \neq i} e_{j}-e_{i}+\left(1+\frac{1}{2}+\ldots+\frac{1}{N-1}\right) \frac{1}{\lambda}\right) \\
& =\exp \left(-\lambda\left[\frac{1}{N-1} \sum_{j \neq i} e_{j}-e_{i}+\left(1+\frac{1}{2}+\ldots+\frac{1}{N-1}\right) \frac{1}{\lambda}\right]\right) .
\end{aligned}
$$

\section{A.2 Meritocracy and the Compensation Scheme (Proof of Proposition 1)}

We establish the relationship between the principal's value of meritocracy and the compensation scheme by comparing the maximal social welfare achieved under a tournament to the maximal social welfare achieved under a piece rate for each possible value of $\omega \in[0,1]$, where a smaller $\omega$ represents a more meritocratic objective. The compensation scheme which maximizes social welfare for a given value of $\omega$ is the scheme chosen by the principal, because utility is perfectly-transferable in our model and any equilibrium is Pareto-efficient. In other words, because the principal and the agents "maximize the pie and then split it," the compensation scheme which yields higher social welfare is preferred because it generates a larger pie to split.

We characterize the maximal social welfare that can be achieved under the piece rate and the tournament for a given value of $\omega$ by taking the following steps. First, given any $\omega$, we characterize the effort exerted by an agent with ability $a_{i}$ who faces either a piece rate or a tournament which 
rewards the promoted agent with a bonus. Next, we solve for the social welfare-maximizing piece rate and bonus when the principal cares about output only for its production value $(\omega=1)$, and show that higher social welfare is achieved under the piece rate. Then, we solve for the social welfare-maximizing piece rate and bonus when the principal cares about output only for its screening value $(\omega=0)$, and show that higher social welfare is achieved under the tournament. Finally, we show that the maximal level of social welfare achieved under the piece rate increases continuously and monotonically in $\omega$, while the maximal level of social welfare achieved under the tournament decreases continuously and monotonically in $\omega$. By the Intermediate Value Theorem, it follows that there exists $\tilde{\omega} \in(0,1)$ such that, when $\omega>\tilde{\omega}$ and meritocracy is relatively unimportant to the principal, the compensation scheme is a piece rate, and when $\omega<\tilde{\omega}$ and meritocracy is relatively important to the principal, the compensation scheme is a tournament.

\section{Characterizing agent effort under the piece rate and the tournament, given $\omega \in$} $[0,1]$.

Suppose that the principal maximizes the following expression by setting a piece rate, $s\left(\hat{y}_{i}\right)=\alpha \hat{y}_{i}$, to compensate agents for their reported output, as well as choosing which agent $i$ to promote:

$$
\omega E\left[\sum_{i=1}^{N} y_{i}\right]+(1-\omega) E\left[a_{i} \mid i \text { is promoted }\right] .
$$

An agent's effort choice in the "all lie" equilibrium, where an agent who is caught lying gets fired, solves:

$$
\max _{e_{i}} p F+(1-p)\left[\alpha_{\omega} \delta e_{i}+\frac{\alpha_{\omega} \delta}{\lambda}\right]-\frac{1}{a_{i}} \exp \left(e_{i}\right)
$$

Thus, $a_{i}$ 's equilibrium effort choice when facing the piece rate $\alpha_{\omega}$ is (where the subscript indicates that the piece rate may depend on $\omega$ ):

$$
e_{i, l i e}^{P R}=\log \left((1-p) \delta \alpha_{\omega}\right)+\log \left(a_{i}\right)
$$

Suppose, alternatively, that the principal compensates reported output via a tournament which promotes one agent and rewards her with a bonus, $B .{ }^{46}$ The promoted agent who is rewarded with a bonus, $B$, will optimally be the agent with highest reported output who is not caught lying. ${ }^{47}$

An agent's effort choice in the "all lie" equilibrium, where an agent who is caught lying gets fired, solves:

$$
\max _{e_{i}} B_{\omega} \operatorname{Pr}\left(\hat{y_{i}}>\hat{y_{-i}}\right)-\frac{1}{a_{i}} \exp \left(e_{i}\right) .
$$

\footnotetext{
${ }^{46}$ Note that we could have allowed for a more powerful tournament which includes our structure as a case (e.g. bonuses of varying magnitudes, or a lottery over bonuses, or the possibility that no agent is promoted). However, the main point of our model is to show that sufficient value of meritocracy causes a principal to prefer a tournament. Thus, we consider the weakest possible tournament-otherwise, it could be that valuing meritocracy only causes a principal to prefer the tournament if it is sufficiently (and unrealistically) powerful.

${ }^{47}$ The principal has no reason to incentivize lower output, and the probability of detection increases in the magnitude of the lie.
} 
We obtain:

$$
\begin{aligned}
E U_{i \text { lies }}^{-i \text { lies }}= & p F+(1-p) \exp \left(-\lambda\left[\frac{1}{N-1} \sum_{j \neq i} e_{j}-e_{i}\right]\right) E(p, N) B_{\omega} \\
& +(1-p) p^{N-1} B_{\omega}-\frac{1}{a_{i}} \exp \left(e_{i}\right),
\end{aligned}
$$

where $E(p, N)$ denotes the expected probability $a_{i}$ 's error is weakly greater than the maximal order statistic for the error in the population of non-fired mayors:

$$
\begin{aligned}
E(p, N) & \equiv\left[(1-p)^{N-1} \exp \left(-\lambda \bar{\varepsilon}_{N-1}\right)+\ldots+(1-p) p^{N-2} \exp \left(-\lambda \bar{\varepsilon}_{1}\right)\right] \\
& =\left[(1-p)^{N-1} \exp \left(-\sum_{j=1}^{N-1} \frac{1}{j}\right)+\ldots+(1-p) p^{N-2} \exp (-1)\right] .
\end{aligned}
$$

Agent $a_{i}$ 's expected utility breaks down in an intuitive way:

1. The first term addresses the case where $a_{i}$ gets caught lying, which happens with probability $p$. If she gets caught, she is fired and receives $F<0$.

2. The second term is the most complex: it addresses the case where $a_{i}$ does not get caught, but various subsets of the other $(N-1)$ lying mayors are caught. All possibilities ranging from "none of the other mayors is caught" to "all but one of the other mayors are caught" are addressed in this term.

The key observation is that the average effort of the non-detected other mayors is always $\frac{1}{N-1} \sum_{j \neq i} e_{j}$, regardless of how many of the other mayors are not detected. This is because the probability of detection is always $p$ for each lying mayor. A simple example will illustrate. Suppose there are four mayors, $a_{1}, a_{2}, a_{3}, a_{4}$. The mayor $a_{1}$ calculates the average effort of the pool of non-fired mayors she will face, in the case that one of the other mayors is caught. This means that she might face $\left\{a_{2}, a_{3}\right\}$, or $\left\{a_{2}, a_{4}\right\}$, or $\left\{a_{3}, a_{4}\right\}$. But she faces each of these pools with equal probability. Thus, the average of the average effort in each of these pools is just $\frac{1}{3} a_{2}+\frac{1}{3} a_{3}+\frac{1}{3} a_{4}$-but that's just the average ability of the three other mayors.

Thus, we can "factor out" $e^{-\lambda\left[\frac{1}{N-1} \sum_{j \neq i} e_{j}-e_{i}\right]} .48$

3. The third term addresses the case where our mayor $a_{i}$ is not caught, but all the other mayors are caught. Then our mayor is promoted for sure.

4. The fourth term is the cost of effort of $a_{i}$ from exerting effort $e_{i}$.

\footnotetext{
${ }^{48}$ Recall that $\bar{\varepsilon}_{k}$ is the maximal order statistic for a sample of $k$ iid draws from the error distribution, $\exp (\lambda)$. Recall that $\bar{\varepsilon}_{k}=\left(1+\ldots+\frac{1}{k}\right) \frac{1}{\lambda}$.
} 
Then the first-order condition characterizing optimal effort in the "pure lie" scenario is:

$$
\begin{gathered}
F O C_{e_{i}}:(1-p) B_{\omega} \lambda \exp \left(-\lambda\left[\frac{1}{N-1} \sum_{j \neq i} e_{j}-e_{i}\right]\right) \\
\times\left[(1-p)^{N-1} \exp \left(-\lambda \bar{\varepsilon}_{N-1}\right)+\ldots+(1-p) p^{N-2} \exp \left(-\lambda \bar{\varepsilon}_{1}\right)\right]=\frac{1}{a_{i}} \exp \left(e_{i}\right) .
\end{gathered}
$$

Solving yields equilibrium effort:

$$
\begin{aligned}
e_{i, l i e}^{T}= & \frac{(N-1)}{N(1-\lambda)-1} \log \left(a_{i}\right)-\frac{\lambda}{N(1-\lambda)-1} \sum_{j=1}^{N} \log \left(a_{j}\right) \\
& +\log \left[(1-p) B_{\omega} \lambda\right]+\log E(p, N)
\end{aligned}
$$

\section{Piece rates are Optimal when $\omega=1$.}

When $\omega=1$, social welfare is:

$$
\sum_{i=1}^{N} E\left[e_{i}+\epsilon_{i}\right]-\sum_{i=1}^{N} c\left(e_{i}\right)
$$

Let $\alpha_{x} \equiv \alpha_{\omega=x}$. Using our expression for effort under the piece rate and our functional form for cost of effort, we see that the piece rate $\alpha_{1}$ that maximizes social welfare solves:

$$
\max _{\alpha_{1}} E\left[\sum_{i=1}^{N} \log \left((1-p) \delta \alpha_{1}\right)+\log \left(a_{i}\right)\right]+\frac{N}{\lambda}-\sum_{i=1}^{N} \frac{1}{a_{i}} \exp \left(\log \left((1-p) \delta \alpha_{1}\right)+\log \left(a_{i}\right)\right) .
$$

This yields:

$$
\alpha_{1}=\frac{1}{(1-p) \delta}
$$

which implements first-best effort, $e_{i, \omega=1}^{F B}=\log \left(a_{i}\right)$. Thus, the maximal level of social welfare under the piece rate is:

$$
S W_{1}^{P R}=\sum_{i=1}^{N} \log \left(a_{i}\right)+\frac{N}{\lambda}-N .
$$

The tournament bonus, $B_{1}$, which maximizes social welfare solves:

$$
\max _{B_{1}} E\left[\sum_{i=1}^{N} e_{i, l i e}^{T}\right]+\frac{N}{\lambda}-\sum_{i=1}^{N} \frac{1}{a_{i}} \exp \left(e_{i, l i e}^{T}\right)
$$

which yields:

$$
B_{1}=\frac{1}{(1-p) \lambda E(p, N)} \frac{N}{\sum_{i=1}^{N}\left[\frac{a_{i} * \ldots * a_{i}}{a_{1} * \ldots * a_{N}}\right]^{\frac{\lambda}{N(1-\lambda)-1}}},
$$

so that the maximal level of social welfare under the tournament is: 


$$
S W_{1}^{T}=\sum_{i=1}^{N} \log \left(a_{i}\right)+\frac{N}{\lambda}+N \log \left(\frac{N}{\sum_{i=1}^{N}\left[\frac{a_{i} * \ldots * a_{i}}{a_{1} * \ldots * a_{N}}\right]^{\frac{\lambda}{N(1-\lambda)-1}}}\right)-N^{2} .
$$

Observe that:

$$
\frac{N}{\sum_{i=1}^{N}\left[\frac{a_{i} * \ldots * a_{i}}{a_{1} * \ldots * a_{N}}\right]^{\frac{\lambda}{N(1-\lambda)-1}}}<1
$$

where

$$
\frac{\lambda}{N(1-\lambda)-1}= \begin{cases}-1, & \lambda=1 \\ \infty, & \lambda=\frac{N-1}{N} \\ 0, & \lambda=0\end{cases}
$$

To see this, define a sequence $\left\{s_{i}\right\}_{i=1}^{N}$, where $s_{i}=a_{i}^{\frac{\lambda N}{N(1-\lambda)-1}}>0 \forall i$. Then the inequality we want to show can be re-expressed as:

$$
\begin{gathered}
\frac{1}{N} \sum_{i=1}^{N} \frac{s_{i}}{\left(\prod_{i=1}^{N} s_{i}\right)^{\frac{1}{N}}}>1 \Longleftrightarrow \\
\frac{1}{N} \sum_{i=1}^{N} s_{i}>\left(\prod_{i=1}^{N} s_{i}\right)^{\frac{1}{N}}
\end{gathered}
$$

This holds by the AM-GM inequality, which states that, for any sequence of non-negative real numbers, the arithmetic mean is greater than the geometric mean as long as all the terms are not equal (and holds at equality iff all the terms are equal). Hence:

$$
\log \left(\frac{N}{\sum_{i=1}^{N}\left[\frac{a_{i} * \ldots * a_{i}}{a_{1} * \ldots * a_{N}}\right]^{\frac{\lambda}{N(1-\lambda)-1}}}\right)<0
$$

Since $N^{2}>N$, as $N>1$, it follows that:

$S W_{1}^{P R}=\sum_{i=1}^{N} \log \left(a_{i}\right)+\frac{N}{\lambda}-N>\sum_{i=1}^{N} \log \left(a_{i}\right)+\frac{N}{\lambda}+N \log \left(\frac{N}{\sum_{i=1}^{N}\left[\frac{a_{i} * \ldots * a_{i}}{a_{1} * \ldots * a_{N}}\right]^{\frac{\lambda}{N(1-\lambda)-1}}}\right)-N^{2}=S W_{1}^{T}$.

In other words, the maximal level of social welfare achieved under the piece rate surpasses the maximal level of social welfare achieved under the tournament when $\omega=1$.

\section{Tournaments are Optimal when $\omega=0$.}

When $\omega=0$, social welfare is: 


$$
E\left[a_{i} \mid i \text { is promoted }\right]-\sum_{i=1}^{N} c\left(e_{i}\right) .
$$

Social welfare will be higher under the mechanism which generates a higher probability of promoting the highest-ability agent $a_{1}$ for a given amount of total cost of effort.

Recall that, for any piece rate $\alpha_{0}$, effort is:

$$
e_{i, P R}^{l i e}=\log \left((1-p) \delta \alpha_{0}\right)+\log \left(a_{i}\right)
$$

so that the probability that agent $a_{i}$ is promoted is:

$$
\operatorname{Pr}\left(a_{i} \text { highest output }\right)=\exp \left(-\lambda\left[\frac{1}{N-1} \sum_{j \neq i} \log \left(a_{j}\right)-\log \left(a_{i}\right)+\left(1+\ldots+\frac{1}{N-1}\right) \lambda\right]\right) .
$$

(Note that this probability does not depend on the piece rate $\alpha_{0}$, only on the abilities of the agents in the economy and other parameters.)

On the other hand, under the tournament mechanism, for any bonus $B_{0}$, effort is:

$$
e_{i, T}^{l i e}=\frac{(N-1)}{N(1-\lambda)-1} \log \left(a_{i}\right)-\frac{\lambda}{N(1-\lambda)-1} \sum_{j=1}^{N} \log \left(a_{j}\right)+\log \left[(1-p) B_{0} \lambda\right]+\log E(p, N),
$$

so that the probability that agent $a_{i}$ is promoted is:

$\operatorname{Pr}\left(a_{i}\right.$ highest output $)=\exp \left(-\lambda\left[\frac{(N-1)}{N(1-\lambda)-1}\left(\frac{1}{N-1} \sum_{j \neq i} \log \left(a_{j}\right)-\log \left(a_{i}\right)\right)+\left(1+\ldots+\frac{1}{N-1}\right) \lambda\right]\right)$.

(Again, note that this probability does not depend on $B_{0}$.)

Observe that, because $\frac{1}{N-1} \sum_{j \neq i} \log \left(a_{j}\right)-\log \left(a_{i}\right)<0$ precisely for the above-average ability agents, and $\frac{1}{N-1} \sum_{j \neq i} \log \left(a_{j}\right)-\log \left(a_{i}\right)>0$ precisely for the below-average ability agents, it is the case that:

$$
\begin{aligned}
& \operatorname{Pr}\left(a_{i} \text { promoted }\right)^{T}>\operatorname{Pr}\left(a_{i} \text { promoted }\right)^{P R} \text { for } a_{i}>\operatorname{avg}\left(a_{i}\right) \\
& \operatorname{Pr}\left(a_{i} \text { promoted }\right)^{T}<\operatorname{Pr}\left(a_{i} \text { promoted }\right)^{P R} \text { for } a_{i}<\operatorname{avg}\left(a_{i}\right)
\end{aligned}
$$

Again, note that this is independent of the bonus $B_{0}$ or the piece rate $\alpha_{0}$-these probabilities only depend on agent abilities (and other exogenously-given parameters). Thus, for every possible piece rate $\alpha_{0}$, there exists a bonus $B_{0}$ such that total cost of effort exertion is equalized, but the higher-ability agents have a higher probability of getting promoted, and the lower-ability agents have a lower probability of getting promoted. Hence, the expected ability of the promoted agent is higher under the tournament mechanism than under the piece rate mechanism given any level of total cost of effort exertion.

Therefore, the maximal level of social welfare achieved under the tournament surpasses the 
maximal level of social welfare achieved under the piece rate when $\omega=0$.

\section{Optimality when $\omega \in(0,1)$.}

Finally, we compare the maximal social welfare achieved under the piece rate and under the tournament for interior $\omega \in(0,1)$.

Social welfare given a piece rate $\alpha_{\omega}$ is:

$$
\omega \sum_{i=1}^{N} E\left[e_{i, l i e}^{P R}+\epsilon_{i}\right]+(1-\omega) E\left[a_{i} \mid i \text { is promoted, } \alpha_{\omega}\right]-\sum_{i=1}^{N} c\left(e_{i, l i e}^{P R}\right),
$$

and, given a tournament bonus $B_{\omega}$, social welfare is:

$$
\omega \sum_{i=1}^{N} E\left[e_{i, l i e}^{T}+\epsilon_{i}\right]+(1-\omega) E\left[a_{i} \mid i \text { is promoted, } B_{\omega}\right]-\sum_{i=1}^{N} c\left(e_{i, l i e}^{T}\right) .
$$

Crucially, recall that $E\left[a_{i} \mid i\right.$ is promoted, $\left.\alpha_{\omega}\right]$ does not depend on $\alpha_{\omega}$, and $E\left[a_{i} \mid i\right.$ is promoted, $\left.B_{\omega}\right]$ does not depend on $B_{\omega}$ : that is, neither the amount of the piece rate nor the amount of the bonus enters into the expression for the expected ability of the promoted mayor. This is because both the piece rate and the bonus enter as constants in each agent's equilibrium effort:

$$
e_{i, P R}^{l i e}=\log \left((1-p) \delta \alpha_{0}\right)+\log \left(a_{i}\right)
$$

and:

$$
e_{i, T}^{l i e}=\frac{(N-1)}{N(1-\lambda)-1} \log \left(a_{i}\right)-\frac{\lambda}{N(1-\lambda)-1} \sum_{j=1}^{N} \log \left(a_{j}\right)+\log \left[(1-p) B_{0} \lambda\right]+\log E(p, N)
$$

Thus, the piece rate and the bonus shift effort levels in a constant way across agents of different ability. Hence, the probability that an agent $a_{i}$ produces the maximal output does not depend on the piece rate or the bonus-the constant terms cancel each other-and consequently the expected ability of the promoted agent (the agent with highest reported output who is not caught lying) does not depend on the piece rate or the bonus, either.

This means that the piece rate $\alpha_{\omega}$ which maximizes social welfare simply maximizes:

$$
\omega \sum_{i=1}^{N} E\left[e_{i, l i e}^{P R}+\epsilon_{i}\right]-\sum_{i=1}^{N} c\left(e_{i, l i e}^{P R}\right),
$$

while the bonus $B_{\omega}$ which maximizes social welfare simply maximizes:

$$
\omega \sum_{i=1}^{N} E\left[e_{i, l i e}^{T}+\epsilon_{i}\right]-\sum_{i=1}^{N} c\left(e_{i, l i e}^{T}\right) .
$$

The piece rate $\alpha_{\omega}$ generating maximal social welfare is: 


$$
\alpha_{\omega}=\omega \alpha_{1}=\frac{\omega}{(1-p) \delta}
$$

and the bonus $B_{\omega}$ generating maximal social welfare is:

$$
B_{\omega}=\omega B_{1}=\frac{\omega}{(1-p) \lambda E(p, N)} \frac{N}{\sum_{i=1}^{N}\left[\frac{a_{i} * \ldots * a_{i}}{a_{1} * \ldots * a_{N}}\right]^{\frac{\lambda}{N(1-\lambda)-1}}} .
$$

Hence, the maximal social welfare under the piece rate is:

$$
\omega \sum_{i=1}^{N} \log \left(a_{i}\right)+\omega \frac{N}{\lambda}+\omega N \log \omega+(1-\omega) E\left[a_{i} \mid i \text { is promoted, } P R\right]-\omega N,
$$

and the maximal social welfare under the tournament is:

$\omega \sum_{i=1}^{N} \log \left(a_{i}\right)+\omega \frac{N}{\lambda}+\omega N \log \omega+\omega N \log \left(\frac{N}{\sum_{i=1}^{N}\left[\frac{a_{i} * \ldots * a_{i}}{a_{1} * \ldots * a_{N}}\right]^{\frac{\lambda}{N(1-\lambda)-1}}}\right)+(1-\omega) E\left[a_{i} \mid\right.$ i is promoted, $\left.T\right]-\omega N^{2}$.

Then maximal social welfare under the piece rate surpasses maximal social welfare under the tournament if:

$$
\begin{gathered}
\omega\left[\sum_{i=1}^{N} \log \left(a_{i}\right)+\frac{N}{\lambda}-N\right]+(1-\omega) E\left[a_{i} \mid i \text { is promoted, } P R\right]> \\
\omega\left[\sum_{i=1}^{N} \log \left(a_{i}\right)+\frac{N}{\lambda}+N \log \left(\frac{N}{\sum_{i=1}^{N}\left[\frac{a_{i} * \ldots * a_{i}}{a_{1} * \ldots * a_{N}}\right]^{\frac{\lambda}{N(1-\lambda)-1}}}\right)-N^{2}\right]+(1-\omega) E\left[a_{i} \mid i \text { is promoted, } T\right] .
\end{gathered}
$$

But we know from the case $\omega=1$ that this condition is simply:

$$
\omega S W_{1}^{P R}+(1-\omega) E\left[a_{i} \mid i \text { is promoted, } P R\right]>\omega S W_{1}^{T}+(1-\omega) E\left[a_{i} \mid i \text { is promoted, } T\right] .
$$

Since we know from the case $\omega=1$ that $S W_{1}^{P R}>S W_{1}^{T}$, and we know from the case $\omega=0$ that $E\left[a_{i} \mid i\right.$ is promoted, $\left.P R\right]<E\left[a_{i} \mid i\right.$ is promoted, $\left.T\right]$, and since the left-hand side and the right-hand side are continuous in $\omega$, it follows by the Intermediate Value Theorem that there exists $\tilde{\omega} \in(0,1)$ such that, when the principal sufficiently values meritocracy $(\omega<\tilde{\omega})$, the tournament is preferred. Otherwise, when $\omega>\tilde{\omega}$, the piece rate is preferred.

\section{A.3 Proof of Proposition 2 and Corollary 1}

Let $\omega=1$. We know from Proposition 1 that the equilibrium compensation scheme is a piece rate.

Proposition 2 is straightforward. If the principal values output only for production (not for screening), and the equilibrium compensation scheme to reward the birth rate is the piece rate, then we should not expect OCP to impact the probability of promotion (since promotion must be based on something that isn't OCP). 
There are two possibilities: either the dimension on which the principal promotes is not related to ability at all, or there is a correlation. Proposition 2 addresses the former case, Corollary 1 the latter.

If the dimension on which the principal promotes is not related to ability, then OCP (which is correlated with ability) should not have an impact on the probability of promotion, and this non-effect should not vary by noisiness or competitiveness of environment.

If the dimension on which the principal promotes is related to ability (but isn't OCP), then if we observe that better OCP performance corresponds with increased probability of promotion, it must be that the non-OCP dimension on which promotion is based is positively correlated with ability.

But then we should observe that better OCP performance has a larger positive effect on the probability of promotion in environments that are more noisy, and the effect should not differ by competitiveness of environment. Why is this?

Recall that in the "all lie" equilibrium, the effort exerted by $a_{i}$ is (see Appendix A.2):

$$
e_{i, P R}^{l i e}=\log ((1-p) \delta \alpha)+\log \left(a_{i}\right)
$$

Note that if $(1-p) \delta<1$, all agents tell the truth. A necessary condition for agents to lie is therefore $(1-p) \delta>1$ (probability of detection low enough, scope for lying high enough). This isn't sufficient (we also need $F$, the disutility from being fired, to not be too negative, and so on), but this is the primary condition.

Then, the principal solves:

$$
\max _{\alpha}(1-\alpha)\left(\log [(1-p) \delta \alpha]+\log \left(a_{i}\right)+\frac{1}{\lambda}\right)(1-p)
$$

This yields:

$$
\alpha^{*}: 1-\alpha\left(1+\frac{1}{\lambda}\right)-\alpha \log [(1-p) \delta \alpha]-\alpha \log \left(a_{i}\right)=0
$$

We then calculate the following important comparative statics:

$$
\begin{aligned}
& \frac{\partial \alpha^{*}}{\partial a_{i}}=-\frac{\alpha}{a_{i}} \frac{1}{2+\frac{1}{\lambda}+\log \left[(1-p) \delta \alpha a_{i}\right]}<0 \\
& \frac{\partial \alpha^{*}}{\partial \lambda}=\frac{\alpha \frac{1}{\lambda^{2}}}{\left[1+\frac{1}{\lambda}+\log \left[(1-p) \delta \alpha a_{i}\right]+\frac{\alpha_{i}}{\alpha_{i}}+\log \left(a_{i}\right)\right]}>0
\end{aligned}
$$

Thus, the incentive strength of the piece rate is lower for higher-ability mayors, and is lower in noisier environments.

To be specific:

1. OCP performance and promotion: There is no reason to think that better reported or actual performance on OCP should affect probability of promotion.

The principal, by assumption in the set up, does not care what the ability of the promoted mayor is. So, if agents are observed to be promoted, it must be on a dimension other than 
ability. Of course, this dimension may be positively correlated with ability. Thus, since we observe better OCP performance increasing the probability of promotion, if we are in this world, it must be that the principal is promoting based on a dimension that is positively correlated with ability (where higher ability also improves OCP performance).

2. Noisiness predictions: If we think that ability is positively correlated with the dimension on which the principal is promoting, then, in this world, this implies that better OCP performance has a larger effect (increase) on probability of promotion in environments that are more noisy.

This is because, both in the "all lie" and the "all true" equilibrium:

$$
\begin{aligned}
\frac{\partial e_{i}^{l i e}}{\partial a_{i}} & =\frac{1}{a_{i}}\left[1-\frac{1}{2+\frac{1}{\lambda}+\log \left[(1-p) \delta \alpha a_{i}\right]}\right] \\
\frac{\partial e_{i}^{\text {true }}}{\partial a_{i}} & =\frac{1}{a_{i}}\left[1-\frac{1}{2+\frac{1}{\lambda}+\log \left[\alpha a_{i}\right]}\right]
\end{aligned}
$$

But note that both of these expressions are larger when $\frac{1}{\lambda}$, the variance of the error, is larger. That is, higher ability has a larger positive impact on effort and thus OCP performance when the environment is noisier.

This contradicts our observation that better OCP performance has a larger effect (increase) on probability of promotion in environments that are less noisy.

3. Competition predictions: In this world, there should be no difference in the effect of decreasing the birth rate on the probability of promotion in more versus less competitive environments, since $e_{i}$ and the piece rate $\alpha$ depend only on own ability, and not the abilities of any other mayor in your region, or on the number of mayors in your region.

This contradicts our empirical observation that the impact of better OCP performance on the probability of promotion does depend on competitiveness.

\section{A.4 Proof of Proposition 3}

Now, suppose $\omega$ is small enough-the principal cares sufficiently about the ability of the agent she promotes, and she no longer directly observes ability-so that the principal prefers to use the tournament mechanism (the lower $\omega$ is, that is, the more that the principal values output as a screening device to identify the highest-ability mayor, the more likely the principal is to prefer the tournament mechanism).

Then, by introspection, there are potentially three types of pure strategy equilibria:

1. "Pure lie": all the mayors misreport

2. "Pure truth": all the mayors report truthfully

3. "Partial truth": some mayors misreport, and some mayors report truthfully 
Again, we focus on the first equilibrium ("pure lie"), since we observe that everyone misreports in the data. (See Appendix A.6 for a discussion of the other equilibrium possibilities, and the sustainability of the "pure lie" equilibrium we focus on.)

Recall that we have already characterized how a given mayor $a_{i}$ responds optimally depending on the effort exerted by the other $(N-1)$ mayors (in Appendix A.2), which we need to characterize the conditions under which each of these types is supported as an equilibrium (if ever).

$$
\begin{aligned}
e_{i}(\text { i lies, others lie })= & \frac{(N-1)}{N(1-\lambda)-1} \log \left(a_{i}\right)-\frac{\lambda}{N(1-\lambda)-1} \sum_{j=1}^{N} \log \left(a_{j}\right) \\
& +\log [(1-p) B \lambda]+\log E(p, N)
\end{aligned}
$$

The principal solves:

$$
\begin{aligned}
& \max _{B} \omega\left[\sum_{j=1}^{N}\left(\begin{array}{c}
\frac{(N-1)}{N(1-\lambda)-1} \log \left(a_{i}\right)-\frac{\lambda}{N(1-\lambda)-1} \sum_{j=1}^{N} \log \left(a_{j}\right)+\log [(1-p) B \lambda] \\
+\log E(p, N)
\end{array}\right)\right] \\
& +(1-\omega) E\left[a_{i} \mid \text { i is promoted }\right]-B .
\end{aligned}
$$

The FOC is:

$$
F O C_{B}: \omega \frac{N}{(1-p) B \lambda}(1-p) \lambda-1=0
$$

since $E\left[a_{i} \mid i\right.$ is promoted $]$ does not depend on $B$. This implies $B^{*}=\omega N$.

Then, given the bonus $B^{*}$, what is the probability that $a_{i}$ is promoted in this "pure lie" equilibrium, given $e_{i}(i$ lies, others lie $)$ ?

$$
\operatorname{Pr}\left(a_{i} \text { is promoted, cheating }\right)=\frac{a_{i}^{\frac{N-1}{N(1-\lambda)-1}-1} E(p, N)}{\left(\sum_{j=1}^{N} \log a_{j}\right)^{\frac{\lambda}{N(1-\lambda)-1}}}+p^{N-1}(1-p)
$$

Compare this to the probability that $a_{i}$ is promoted in the model where output is contractible and there is thus no possibility of cheating.

$$
\operatorname{Pr}\left(a_{i} \text { is promoted, no cheating }\right)=\frac{a_{i}^{\frac{\lambda}{(1-\lambda)}} \exp \left(-\sum_{j=1}^{N-1} \frac{1}{j}\right)}{\left(\sum_{j=1}^{N} \log a_{j}\right)^{\frac{\lambda}{N(1-\lambda)}}}
$$

(See Appendix A.5 for the analysis of this case when output is contractible and there is thus no cheating.)

Note that the important differences are:

(1) there is an extra element in the "pure lie" probability $a_{i}$ gets promoted which does not depend on ability at all: $p^{N-1}(1-p)$

(2) there is subsequently less weight in the "pure lie" scenario on the ability term. This is captured by the expected maximal order statistic (because our lying mayor $a_{i}$ is not always competing against all the other mayors, because some of them will get caught): $E(p, \lambda, N)<\exp \left(-\lambda \bar{\varepsilon}_{N-1}\right)$. 
The main takeaway is that, when output is not contractible and we are in the "pure lie" cheating equilibrium, the probability that any mayor $a_{i}$ is promoted depends less on her ability $a_{i}$ than in the no cheating scenario.

This is driven home when we look at:

$$
E\left[a_{i} \mid i \text { is promoted }\right]=\sum_{j=1}^{N} \operatorname{Pr}\left(a_{i} \mid i \text { is promoted }\right) a_{i} .
$$

Then:

$$
\begin{aligned}
E^{\text {cheat }}\left[a_{i} \mid i \text { is promoted }\right] & =\frac{\sum_{j=1}^{N} a_{j}^{\frac{N-1}{N(1-\lambda)-1}-1} E(p, N)}{N\left(\sum_{j=1}^{N} \log a_{j}\right)^{\frac{\lambda}{N(1-\lambda)-1}}+p^{N-1}(1-p) \sum_{j=1}^{N} a_{j}} \\
E^{\text {no cheat }}\left[a_{i} \mid i \text { is promoted }\right] & =\frac{\sum_{j=1}^{N} a_{j}^{\frac{\lambda}{(1-\lambda)}} \exp \left(-\sum_{j=1}^{N-1} \frac{1}{j}\right)}{N\left(\sum_{j=1}^{N} \log a_{j}\right)^{\frac{\lambda}{N(1-\lambda)}}}
\end{aligned}
$$

This just emphasizes the key difference in effectiveness of the promotion mechanism at identifying the highest-ability mayor: in the cheating equilibrium, the expected ability of the promoted mayor includes an extra term which is not present in the benchmark model: $p^{N-1}(1-p) \sum_{j=1}^{N} a_{j}$. This is the average ability in expectation, which is proportional to the population average:

$$
p^{N-1}(1-p) \sum_{j=1}^{N} a_{j} \propto \frac{1}{N} \sum_{j=1}^{N} a_{j} .
$$

Note that

$$
p^{N-1}(1-p)<\frac{1}{N}, p \in[0,1] .
$$

The LHS is maximized at $p=\frac{N-1}{N}$ (first order condition is necessary and sufficient since LHS is concave in $p$ as long as $\frac{N-2}{N}<p$, which holds since $\left.p^{*}=\frac{N-1}{N}\right)$. Then

$$
\left(\frac{N-1}{N}\right)^{N-1} \frac{1}{N}<\frac{1}{N}
$$

which holds since $\frac{N-1}{N}<1$.

That is, the promotion mechanism in the cheating scenario is closer to simply choosing a mayor at random. Moreover, note that the promotion mechanism performs the worst (most closely resembles random promotion) for intermediate audit probabilities $p$ : if $p=0$, so people's lies are completely undetectable as long as they stay within $\delta$ of their true output, then even though everyone is lying, the highest-ability guys are still exerting the most effort and so their reported lie will still be reasonably likely to be the highest. If $p=1$, then people are detected for sure if they lie and we are in the truthful equilibrium. It is when $p$ is low and intermediate that individuals distort the most.

We find that the following important comparative statics are reflected in our data: 
1. Increasing effort increases $a_{i}$ 's probability of promotion:

$$
\begin{aligned}
\frac{\partial \operatorname{Pr}\left(a_{i} \text { is promoted, cheating }\right)}{\partial e_{i}} & =\frac{\frac{\partial \operatorname{Pr}\left(a_{i} \text { is promoted,cheating }\right)}{\partial a_{i}}}{\frac{\partial e_{i}}{\partial a_{i}}} \\
& >0
\end{aligned}
$$

2. Increasing effort has a larger positive impact on $a_{i}$ 's probability of promotion in less noisy environments (larger $\lambda$ ):

$$
\frac{\partial \frac{\partial \operatorname{Pr}\left(a_{i} \text { is promoted,cheating }\right)}{\partial e_{i}}}{\partial \lambda}>0
$$

3. Increasing effort has a smaller positive impact on $a_{i}$ 's probability of promotion in more competitive environments (larger $N$ ):

$$
\frac{\partial \frac{\partial \operatorname{Pr}\left(a_{i} \text { is promoted,cheating }\right)}{\partial e_{i}}}{\partial N}<0
$$

\section{Comparative statics - the details}

1. Increasing effort increases $a_{i}$ 's probability of promotion.

Denote:

$$
\begin{aligned}
& A(N) \equiv\left[\left(\frac{N-1}{N(1-\lambda)-1}-1\right) \sum_{j=1}^{N} \log \left(a_{j}\right)-\frac{\lambda}{N(1-\lambda)-1}\right] \\
& \frac{\partial \operatorname{Pr}\left(a_{i} \text { is promoted, cheating }\right)}{\partial e_{i}}=\frac{\frac{\partial \operatorname{Pr}\left(a_{i} \text { is promoted,cheating }\right)}{\partial a_{i}}}{\frac{\partial e_{i}}{\partial a_{i}}} \\
& =\frac{\left(\sum_{j=1}^{N} \log a_{j}\right)^{\frac{\lambda}{N(1-\lambda)-1}-1} a_{j}^{\frac{N-1}{N(1-\lambda)-1}-2} E(p, N) A(N)}{\left(\sum_{j=1}^{N} \log a_{j}\right)^{\frac{2 \lambda}{N(1-\lambda)-1}}} \\
& =\frac{a_{j}^{\frac{N-1}{N(1-\lambda)-1}-2} E(p, N) A(N)}{\left(\sum_{j=1}^{N} \log a_{j}\right)^{1+\frac{\lambda}{N(1-\lambda)-1}}} \\
& >\frac{a_{j}^{\frac{N-1}{N(1-\lambda)-1}-2} E(p, N)\left[\frac{(N-1) \lambda}{N(1-\lambda)-1}\right]}{\left(\sum_{j=1}^{N} \log a_{j}\right)^{1+\frac{\lambda}{N(1-\lambda)-1}}} \\
& >0
\end{aligned}
$$

where the last inequality holds since $A(N)>\frac{(N-1) \lambda}{N(1-\lambda)-1}>0$. (Recall that $a_{i}>1$ for all $i$, so that $\log \left(a_{i}\right)>0$ for all $i$.)

2. Increasing effort has a larger positive impact on $a_{i}$ 's probability of promotion in less noisy 
environments (larger $\lambda)$ :

$$
\begin{aligned}
& \frac{\partial \frac{\partial \operatorname{Pr}\left(a_{i} \text { is promoted,cheating }\right)}{\partial e_{i}}}{\partial \lambda}=\frac{a_{j}^{\frac{N-1}{N(1-\lambda)-1}-2} \log \left(a_{j}\right) \frac{N(N-1)}{[N(1-\lambda)-1]^{2}} E(p, N) A(N)}{\left(\sum_{j=1}^{N} \log a_{j}\right)^{\frac{2 \lambda}{N(1-\lambda)-1}}}+ \\
& +\frac{a_{j}^{\frac{N-1}{N(1-\lambda)-1}-2} E(p, N)\left[\frac{N(N-1)}{[N(1-\lambda)-1]^{2}} \sum_{j=1}^{N} \log a_{j}-\frac{(N-1)}{[N(1-\lambda)-1]^{2}}\right]}{\left(\sum_{j=1}^{N} \log a_{j}\right)^{\frac{2 \lambda}{N(1-\lambda)-1}}}
\end{aligned}
$$

Then this expression is positive since each term is positive:

(a) We know that $A(N)>0$ from the lower bound established in (1). And, $a_{i}>1$ for all $i$, so that $\log \left(a_{i}\right)>0$ for all $i$. Thus, the first term is positive.

(b) $\frac{N(N-1)}{[N(1-\lambda)-1]^{2}} \sum_{j=1}^{N} \log a_{j}-\frac{(N-1)}{[N(1-\lambda)-1]^{2}}=\frac{(N-1)}{[N(1-\lambda)-1]^{2}}\left(N \sum_{j=1}^{N} \log a_{j}-1\right)>0$, so the second term is positive.

3. Increasing effort has a smaller positive impact on $a_{i}$ 's probability of promotion in more competitive environments (larger $N$ ).

There is a question of what ability to assume that the additional $(N+1) s t$ mayor has. We characterize an upper bound (below) of the effect of increasing effort on $a_{i}$ 's probability of promotion when competition increases by supposing that $\sum_{j=1}^{N} \log a_{j}=\sum_{j=1}^{N+1} \log a_{j}$ (this is an upper bound because this is the weakest possible way in which competition can increase-the additional mayor is of the lowest ability), and we show that this upper bound is negative.

Denote $\log \bar{a}=\sum \log a_{j}, \bar{a}=\sum a_{j}$.

$$
\begin{aligned}
& \frac{\partial \frac{\partial \operatorname{Pr}\left(a_{i} \text { is promoted,cheating }\right)}{\partial e_{i}}}{\partial N}=\frac{-\log \bar{a}^{1+\frac{\lambda}{N(1-\lambda)-1}} a_{j}^{\frac{N-1}{N(1-\lambda)-1}-2} E(p, N) A(N)}{\log \bar{a}^{2\left(1+\frac{\lambda}{N(1-\lambda)-1}\right)}} \\
& \times\left[\left[\log \left(a_{j}\right)-\log \left(\log \left(a_{j}\right)\right)\right] \frac{\lambda}{[N(1-\lambda)-1]^{2}}\right] \\
& +\frac{\frac{\partial E(p, N)}{\partial N} a_{j}^{\frac{N-1}{N(1-\lambda)-1}-2} E(p, N) A(N)}{\log \bar{a}^{2\left(1+\frac{\lambda}{N(1-\lambda)-1}\right)}} \\
& -\frac{\left(\frac{\lambda}{[N(1-\lambda)-1]^{2}}\right)(\bar{a}-1) a_{j}^{\frac{N-1}{N(1-\lambda)-1}-2} E(p, N)}{\log \bar{a}^{2\left(1+\frac{\lambda}{N(1-\lambda)-1}\right)}} \\
& <0
\end{aligned}
$$

where the negative relationship holds because each term is negative:

(a) The first term is negative because $\log \left(a_{j}\right)>\log \left(\log \left(a_{j}\right)\right)\left(a_{i}>1\right.$ for all $\left.i\right)$.

(b) The second term is negative because $\frac{\partial E(p, N)}{\partial N}<0$ : the maximal order statistic for the error is larger in larger samples, so the probability that a given $a_{i}$ 's error draw is weakly 
larger than the maximal order statistic is smaller in larger samples.

(c) $\bar{a}>1 \Leftrightarrow \sum a_{j}>1$ since $a_{i}>1$ for all $i$.

\section{A.5 Model with Contractible Output (no cheating)}

The optimization program is:

$$
\begin{array}{r}
\max _{B} \omega E\left[\sum_{i=1}^{N} y_{i}\right]+(1-\omega) E\left[a_{i} \mid i \text { is promoted }\right]-B \quad \text { s.t. } \\
e_{i} \in \arg \max _{\tilde{e}_{i}} B \operatorname{Pr}\left(y_{i} \text { is } \max \mid \tilde{e}_{i}, e_{-i}\right)-\frac{1}{a_{i}} \exp \left(\tilde{e}_{i}\right) \quad \forall i \in\{1, \ldots, N\} .
\end{array}
$$

Thus, this probability is:

$$
\begin{aligned}
\operatorname{Pr}\left(y_{i} i s \max \mid e_{1}, \ldots, e_{N}\right) & =1-F_{\exp (\lambda)}\left(\frac{1}{N} \sum_{j=1}^{N} e_{j}-e_{i}+\left(1+\frac{1}{2}+\ldots+\frac{1}{N}\right) \frac{1}{\lambda}\right) \\
& =\exp \left(-\lambda\left[\frac{1}{N} \sum_{j=1}^{N} e_{j}-e_{i}+\left(1+\frac{1}{2}+\ldots+\frac{1}{N}\right) \frac{1}{\lambda}\right]\right)
\end{aligned}
$$

We use this to characterize the optimal effort of each agent $a_{i}$. Recall $(I C)_{i}$, the incentive compatibility constraint of agent $a_{i}$ :

$$
\begin{aligned}
e_{i} & \in B \operatorname{Pr}\left(y_{i} \text { is } \max \mid e_{1}, \ldots, e_{N}\right)-\frac{1}{a_{i}} \exp \left(e_{i}\right) \\
F O C_{e_{i}} & : B \frac{\partial \operatorname{Pr}\left(y_{i} i s \max \mid e_{1}, \ldots, e_{N}\right)}{\partial e_{i}}-\frac{1}{a_{i}} \exp \left(e_{i}\right)=0 .
\end{aligned}
$$

The FOC is necessary and sufficient because $c\left(e_{i} ; a_{i}\right)$ is convex in $e_{i}$ and $\frac{\partial \operatorname{Pr}\left(y_{i} \text { is } \max \mid e_{1}, \ldots, e_{N}\right)}{\partial e_{i}}$ is concave in $e_{i}$ (as will shortly be seen), so strict concavity of the agent's objective function is assured.

Hence, we can characterize the first-order conditions which characterize optimal effort choice by each agent:

$$
F O C_{e_{i}}: \frac{1}{a_{i}} \exp \left(e_{i}\right)=B \lambda\left(1-\frac{1}{N}\right) \exp \left(-\lambda\left[\frac{1}{N} \sum_{j=1}^{N} e_{j}-e_{i}+\left(1+\frac{1}{2}+\ldots+\frac{1}{N}\right) \frac{1}{\lambda}\right]\right) .
$$

Taking logs and rearranging yields:

$$
F O C_{e_{i}}:(1-\lambda) e_{i}+\lambda \frac{1}{N} \sum_{j=1}^{N} e_{j}=\log \left(a_{i}\right)+\log (B \lambda)+\log \left(1-\frac{1}{N}\right)-\left(1+\frac{1}{2}+\ldots+\frac{1}{N}\right)
$$

Sum over all the FOCs:

$$
\sum_{j=1}^{N} e_{j}^{*}=\sum_{j=1}^{N} \log \left(a_{j}\right)+N \log (B \lambda)+N \log \left(1-\frac{1}{N}\right)-(1+\ldots+N) .
$$


Then use this characterization of total effort to solve for individual effort, using the individual $\mathrm{FOC}_{e_{i}}$ :

$$
e_{i}^{*}=\frac{1}{(1-\lambda)} \log \left(a_{i}\right)-\frac{\lambda}{(1-\lambda)} \frac{1}{N} \sum_{i=1}^{N} \log \left(a_{i}\right)+\log (B \lambda)+\log \left(1-\frac{1}{N}\right)-\left(1+\frac{1}{2}+\ldots+\frac{1}{N}\right) .
$$

Then we can use this to solve for the optimal bonus $B^{*}$ set by the principal:

$$
\max _{B} \omega E\left[\sum_{j=1}^{N} y_{j}\right]+(1-\omega) E\left[a_{i} \mid i \text { is promoted }\right]-B
$$

But note that $E\left[a_{i} \mid i\right.$ is promoted $]$ does not depend on $B$ : that is, the bonus that the principal sets does not influence the screening quality of the "promote the mayor with the highest output" rule. In other words, a higher bonus $B$ is not differentially better or worse than a lower $B$ at screening for ability. The quality of screening (how close $E\left[a_{i} \mid y_{i}\right.$ is $\left.\max \right]$ is to $a_{1}$, which is the ideal case) depends only on the exogenously-given distribution of the abilities in the economy, $\left\{a_{1}, \ldots, a_{N}\right\}$, and how noisy output is given effort. That is, if variance is high (lots of noise), the quality of screening will be lower (because less weight will be placed on $a_{1}$ given that $y_{1}$ is the maximum output vs. when the principal can be very sure that high effort corresponds to high output (low noise)). This quality depends only on parameters:

$$
\begin{aligned}
E\left[a_{i} \mid i \text { is promoted }\right] & =\sum_{i=1}^{N} a_{i} \operatorname{Pr}\left(i \text { has } \max y_{i}\right) \\
& =\sum_{j=1}^{N} a_{j} \exp \left(-\lambda\left[\frac{1}{(1-\lambda)} \frac{1}{N} \sum_{j=1}^{N} \log \left(a_{j}\right)-\frac{1}{1-\lambda} \log \left(a_{i}\right)+\frac{1}{\lambda}\left(1+\ldots+\frac{1}{N}\right)\right]\right) .
\end{aligned}
$$

Thus, the principal's problem can be re-expressed as:

$$
\max _{B} \omega E\left[\sum_{i=1}^{N} \log \left(a_{i}\right)+N \log (B \lambda)+N \log \left(1-\frac{1}{N}\right)-(1+\ldots+N)\right]+\omega \frac{N}{\lambda}-B .
$$

The first-order condition for the principal is:

$$
F_{B}: \omega \frac{N}{B}=1
$$

so that

$$
B^{*}(N, \omega)=\omega N .
$$

The equilibrium effort exerted by an agent with ability $a_{i}$ is:

$e_{i}^{*}=\frac{1}{(1-\lambda)} \log \left(a_{i}\right)-\frac{\lambda}{(1-\lambda)} \frac{1}{N} \sum_{i=1}^{N} \log \left(a_{i}\right)+\log (\omega N)+\log (\lambda)+\log \left(1-\frac{1}{N}\right)-\left(1+\frac{1}{2}+\ldots+\frac{1}{N}\right)$.

Important comparative statics are: 
1. The partial derivative of equilibrium effort in ability:

$$
\frac{\partial e_{i}^{*}}{\partial a_{i}}=\frac{1}{1-\lambda} \frac{1}{a_{i}}\left(1-\frac{\lambda}{N}\right)>0
$$

Essentially, equilibrium effort monotonically increases in ability as long as $\lambda \in(0,1)$ (looking at the expression for $e_{i}^{*}$, one can see that for $\lambda>1$, the expression for equilibrium effort becomes negative). But recall that we have imposed the parametric assumption $\lambda \in(0,1)$.

2. The partial derivative of equilibrium effort in $N$ (assume that $\frac{1}{N} \sum_{i=1}^{N} \log \left(a_{i}\right)=\frac{1}{N+1} \sum_{i=1}^{N+1} \log \left(a_{i}\right) \equiv$ $\bar{a}$, so that in expectation the $(N+1)$ st agent has average ability-this is the most logical way to analyze the effect of increased competition):

$$
\frac{\partial e_{i}^{*}}{\partial N}=\frac{1}{2 N}+\frac{1}{N(N-1)}+\frac{1}{N^{2}}>0
$$

Individual effort increases as competition increases.

Note that if we are considering the addition of an $(N+1)$ st agent with a specific ability-say, an agent with very high ability-than the lowest-ability agents may decrease their effort in equilibrium, because the average ability rises: $\frac{1}{N+1} \sum_{i=1}^{N+1} \log \left(a_{i}\right)>\frac{1}{N} \sum_{i=1}^{N} \log \left(a_{i}\right)$, and this increase depresses the effort of the lowest-ability agents by the most. It is possible that the added agent has such high ability that all of the original $N$ agents decrease their effort levels. Similarly, if the $(N+1)$ st added agent is known to have very low ability, so low that he lowers the average ability of the new population, and all of the original $N$ agents increase their effort.

3. Individual effort is:

$e_{i}^{*}=\frac{1}{(1-\lambda)} \log \left(a_{i}\right)-\frac{\lambda}{(1-\lambda)} \frac{1}{N} \sum_{i=1}^{N} \log \left(a_{i}\right)+\log (\omega N)+\log (\lambda)+\log \left(1-\frac{1}{N}\right)-\left(1+\frac{1}{2}+\ldots+\frac{1}{N}\right)$

Then:

$$
\begin{aligned}
\frac{\partial e_{i}^{*}}{\partial \lambda} & =\frac{1}{(1-\lambda)^{2}} \log \left(a_{i}\right)-\frac{1}{(1-\lambda)^{2}} \frac{1}{N} \sum_{i=1}^{N} \log \left(a_{i}\right)+\frac{1}{\lambda} \\
& =\frac{1}{(1-\lambda)^{2}}\left[\log \left(a_{i}\right)-\frac{1}{N} \sum_{i=1}^{N} \log \left(a_{i}\right)\right]+\frac{1}{\lambda}
\end{aligned}
$$

Higher $\lambda$ implies lower variance $\left(V(\varepsilon)=\frac{1}{\lambda^{2}}\right)$. Thus, for the high-ability agents, that is, those agents who have above average ability, the less variance there is, the more effort they exert. On the other hand, for the low-ability agents, that is, those agents who have substantially below-average ability, the less variance there is, the less effort they exert. 
4. Average effort is:

$$
\begin{aligned}
\bar{e} & =\frac{1}{N} \sum_{i=1}^{N} e_{i}^{*} \\
& =\frac{1}{N} \sum_{i=1}^{N} \log \left(a_{i}\right)+\log (\omega N)+\log (\lambda)+\log \left(1-\frac{1}{N}\right)-\left(1+\frac{1}{2}+\ldots+\frac{1}{N}\right)
\end{aligned}
$$

Then:

$$
\begin{aligned}
\frac{\partial \bar{e}}{\partial \lambda} & =\frac{1}{\lambda} \\
& >0
\end{aligned}
$$

Thus, the lower the variance of the noise factor, the higher the average effort exerted in equilibrium.

5. The equilibrium bonus is:

$$
B=\omega N
$$

It's straightforward to observe that $B$ is increasing in $\omega$ and in $N$.

6. The probability that agent $a_{i}$ is promoted is:

$$
\operatorname{Pr}(i \text { is promoted })=e^{-\lambda\left[\frac{1}{N(1-\lambda)} \sum_{i=1}^{N} \log \left(a_{i}\right)-\frac{1}{(1-\lambda)} \log \left(a_{i}\right)+\left(1+\frac{1}{2}+\ldots+\frac{1}{N}\right) \frac{1}{\lambda}\right]}
$$

Then:

$$
\begin{aligned}
\frac{\partial \operatorname{Pr}(i \text { is promoted })}{\partial a_{i}} & =\frac{\lambda}{1-\lambda} \frac{1}{a_{i}}\left(1-\frac{1}{N}\right) e^{-\lambda\left[\frac{1}{N(1-\lambda)} \sum_{i=1}^{N} \log \left(a_{i}\right)-\frac{1}{(1-\lambda)} \log \left(a_{i}\right)+\left(1+\frac{1}{2}+\ldots+\frac{1}{N}\right) \frac{1}{\lambda}\right]} \\
& >0
\end{aligned}
$$

since $N>1$.

7. The marginal impact of increased effort from agent $a_{i}$ on the probability that $a_{i}$ gets promoted is smaller when output is a noisier signal of effort and ability, that is, the variance of the noise factor is high. (The same is true of the average of the marginal impacts.)

Then:

$$
\begin{aligned}
\frac{\partial \frac{\partial \operatorname{Pr}\left(y_{i} \max \mid e_{i}, e_{-i}\right)}{\partial e_{i}}}{\partial \lambda} & =\frac{\partial \lambda\left(1-\frac{1}{N}\right) e^{-\lambda\left[\frac{1}{1-\lambda} \frac{1}{N} \sum_{i=1}^{N} \log a_{i}-\frac{1}{1-\lambda} \log a_{i}+\left(1+\frac{1}{2}+\ldots+\frac{1}{N}\right) \frac{1}{\lambda}\right]}}{\partial \lambda} \\
& =\left[\left(1-\frac{1}{N}\right)+\lambda\left(1-\frac{1}{N}\right)\left(\frac{1}{(1-\lambda)^{2}} \frac{1}{N} \sum_{i=1}^{N} \log a_{i}+\frac{1}{(1-\lambda)^{2}} \log a_{i}\right)\right] \\
& \times \exp (-\lambda[\ldots])>0 .
\end{aligned}
$$

Recall that higher $\lambda$ means less noise, since $\operatorname{Var}(\varepsilon)=\frac{1}{\lambda}$. Hence, as output becomes a more 
and more precise signal of effort/ability, the marginal impact of increasing effort on prob. of promotion increases.

In other words, we should observe a gap between actual and target OCP being more predictive of promotion in low-variance vs. high-variance places.

Clearly, this property also holds for the average marginal impact of increasing effort on probability of promotion:

$$
\begin{aligned}
\frac{\partial \frac{1}{N} \sum \frac{\partial \operatorname{Pr}\left(y_{i} \max \mid e_{i}, e_{-i}\right)}{\partial e_{i}}}{\partial \lambda} & >0 \\
\text { since } \frac{\partial \operatorname{Pr}\left(y_{i} \max \mid e_{i}, e_{-i}\right)}{\partial e_{i}} & >0 \text { for each } i
\end{aligned}
$$

8. The marginal impact of increased effort from agent $a_{i}$ on the probability that $a_{i}$ gets promoted is smaller when there is more competition. (The same is true of the average of the marginal impacts.)

Assume that there are $N$ mayors who are candidates for promotion, and we add an $(N+1)^{t h}$ mayor. We ask: is the marginal impact of increasing effort on the probability of promotion less for each of the $i$ mayors when there is more competition?

Assume that the $(N+1)^{t h}$ mayor exerts average effort, which is the rational assumption to make ex ante when the ability of the $(N+1)^{t h}$ mayor is not known. Thus, $\frac{1}{N} \sum e_{i}=\frac{1}{N+1} \sum e_{i+1} \equiv \bar{e}$.

$$
\begin{gathered}
\frac{\partial \operatorname{Pr}\left(y_{i} \max \mid e_{i}, e_{-i}\right)}{\partial e_{i}}(N+1)-\frac{\partial \operatorname{Pr}\left(y_{i} \max \mid e_{i}, e_{-i}\right)}{\partial e_{i}}(N)=\lambda \exp \left(-\lambda\left[\bar{e}-e_{i}+\left(1+\frac{1}{2}+\ldots+\frac{1}{N}\right) \frac{1}{\lambda}\right]\right) \\
\times\left(\exp \left(-\frac{1}{N+1}\right)-1\right)-\frac{\lambda}{N+1} \exp \left(-\lambda\left[\bar{e}-e_{i}+\left(1+\frac{1}{2}+\ldots+\frac{1}{N}+\frac{1}{N+1}\right) \frac{1}{\lambda}\right]\right) \\
\quad+\frac{\lambda}{N} \exp \left(-\lambda\left[\bar{e}-e_{i}+\left(1+\frac{1}{2}+\ldots+\frac{1}{N}\right) \frac{1}{\lambda}\right]\right) \\
<\exp \left(-\lambda\left[\bar{e}-e_{i}+\left(1+\frac{1}{2}+\ldots+\frac{1}{N}+\frac{1}{N+1}\right) \frac{1}{\lambda}\right]\right) \lambda\left(\left(\exp \left(-\frac{1}{N+1}\right)-1\right)-\frac{1}{N+1}+\frac{1}{N}\right)
\end{gathered}
$$

where the upper bound follows from

$$
\exp \left(-\lambda\left[\bar{e}-e_{i}+\left(1+\frac{1}{2}+\ldots+\frac{1}{N}+\frac{1}{N+1}\right) \frac{1}{\lambda}\right]\right)<\exp \left(-\lambda\left[\bar{e}-e_{i}+\left(1+\frac{1}{2}+\ldots+\frac{1}{N}\right) \frac{1}{\lambda}\right]\right)
$$

But:

$$
\begin{aligned}
& \exp \left(-\lambda\left[\bar{e}-e_{i}+\left(1+\frac{1}{2}+\ldots+\frac{1}{N}+\frac{1}{N+1}\right) \frac{1}{\lambda}\right]\right) \lambda\left(\left(\exp \left(-\frac{1}{N+1}\right)-1\right)-\frac{1}{N+1}+\frac{1}{N}\right)= \\
& \exp \left(-\lambda\left[\bar{e}-e_{i}+\left(1+\frac{1}{2}+\ldots+\frac{1}{N}+\frac{1}{N+1}\right) \frac{1}{\lambda}\right]\right) \lambda\left(\frac{1}{N(N+1)}+\exp \left(-\frac{1}{N+1}\right)-1\right)<0
\end{aligned}
$$


since

$$
\begin{aligned}
\frac{1}{6}+\exp \left(-\frac{1}{3}\right)-1 & <0:(N=2) \\
\frac{\partial\left[\frac{1}{N(N+1)}+\exp \left(-\frac{1}{N+1}\right)-1\right]}{\partial N} & >0 \\
\lim _{N \rightarrow \infty} \frac{1}{N(N+1)}+\exp \left(-\frac{1}{N+1}\right)-1 & =0
\end{aligned}
$$

Hence, the more competitive the region, the less predictive better performance in output production should be of promotion.

The same property holds for the average, since it holds for each individual marginal impact.

\section{A.6 Equilibrium Possibilities Other Than "All Lie"}

Suppose that $a_{i}$ anticipates that all the other mayors will lie. What is her expected utility from exerting some effort $e_{i}$ and reporting truthfully?

In this case, $a_{i}$ solves:

$$
\max _{e_{i}} \exp \left(-\lambda\left[\frac{1}{N-1} \sum_{j \neq i} \delta e_{j}-e_{i}\right]\right) E(p, \lambda, N) B+p^{N-1} B-\frac{1}{a_{i}} \exp \left(e_{i}\right)
$$

Then the first-order condition is:

$$
F O C_{e_{i}}:(1-\lambda) e_{i}=\log \left(a_{i}\right)+\log (B \lambda)+\log E(p, \lambda, N)-\frac{\lambda}{(N-1)} \sum_{j \neq i} \delta e_{j}
$$

Thus, the equilibrium effort exerted by $a_{i}$ when she anticipates that the other agents will all exert $\left\{e_{j}\right\}_{j \neq i}$ and misreport, but she tells the truth, is:

$$
e_{i \text { truth }}^{\text {others lie }}=\frac{1}{1-\lambda}\left[\log \left(a_{i} \lambda\right)+\log (B)+\log (E(p, N))-\frac{\lambda}{N-1} \sum_{j \neq i} \delta e_{j}\right]
$$

Recall that the effort she exerts when she also chooses to misreport is:

$$
e_{i \text { lie }}^{\text {others lie }}=\frac{1}{1-\lambda}\left[\log \left(a_{i} \lambda(1-p)\right)+\log (B)+\log (E(p, N))-\frac{\lambda}{N-1} \sum_{j \neq i} \delta e_{j}\right]
$$

Note that $e_{i}^{\text {others }}$ lie $<e_{i \text { truth }}^{\text {other }}$, sie , since the only difference is the $(1-p)<1$ in the first term of the expression characterizing $a_{i}^{\prime} s$ effort when she also misreports.

Then, her expected utility when she chooses to be truthful and her expected utility when she also chooses to misreport are described by:

$$
E U_{i \text { truth }}^{\text {others lie }}=e^{-\frac{\lambda}{1-\lambda} \frac{1}{N-1} \sum_{j \neq i} \delta e_{j}} a_{i}^{\frac{\lambda}{1-\lambda}} \lambda^{\frac{\lambda}{1-\lambda}} E(p, N)^{\frac{1}{1-\lambda}} B^{\frac{1}{1-\lambda}}(1-\lambda)+p^{N-1} B
$$




$$
E U_{i}^{\text {others }} \text { lie }=e^{-\frac{\lambda}{1-\lambda} \frac{1}{N-1} \sum_{j \neq i} e_{j}} a_{i}^{\frac{\lambda}{1-\lambda}} \lambda^{\frac{\lambda}{1-\lambda}} E(p, N)^{\frac{1}{1-\lambda}} B^{\frac{1}{1-\lambda}}(1-\lambda)+(1-p) p^{N-1} B+p F
$$

An "all lie" equilibrium is therefore maintained when $E U_{i \text { lie }}^{\text {others lie }}>E U_{i \text { truth }}^{\text {others }}$ lie for every $i$ :

$$
p^{N} B-p F<\left[(1-p)^{\frac{1}{1-\lambda}} e^{-\frac{\lambda}{1-\lambda} \frac{1}{N-1} \sum_{j \neq i} e_{j}}-e^{-\frac{\lambda}{1-\lambda} \frac{1}{N-1} \sum_{j \neq i} \delta e_{j}}\right] a_{i}^{\frac{\lambda}{1-\lambda}} \lambda^{\frac{\lambda}{1-\lambda}} E(p, N)^{\frac{1}{1-\lambda}} B^{\frac{1}{1-\lambda}}(1-\lambda)
$$

Observe that the bracketed term is positive when small lies are hard to detect (probability of detecting a small lie is low and/or misreports have to be pretty large to be detected for sure). When the bracketed term is positive, the right-hand side is increasing in $a_{i}$, and the lowest-ability agents are the first to prefer to tell the truth. The intuition is that the lowest-ability agents would have to lie a lot in order to have a shot at winning the tournament, whereas higher-ability agents only need small lies. However, large lies are detected for sure, while small lies are hard to detect. Thus, the lowest-ability agents tell the truth while the higher-ability agents misreport. An "all lie" equilibrium is maintained if and only if even the lowest-ability agent prefers to tell the truth.

By examining the condition in Equation 7, we infer conditions that make an "all lie" equilibrium more likely. We can easily see that as the probability of detection decreases ( $p$ decreases), the bonus $B$ increases, the noise level increases ( $\lambda$ decreases), and $F$ becomes less harsh (recall that $F$, the disutility from being fired, is negative), the "all lie" equilibrium becomes more likely.

Thus, when all or most agents lie in equilibrium, any truth-telling agents are the lowest-ability (and lowest-performing) ones. 


\section{B Data Appendix}

\section{B.1 Promotion data}

To construct a comprehensive database on the promotion of mayors, we have gone through extensive searches for records of Chinese officials at and above the prefecture level. We first match the name list of mayors with the name lists of the potential positions they could be promoted to. We collected the following complete lists of officials in office during 1985-2000:

1. List of prefecture party secretaries: from the History of Party Organizations published by each provincial party office;

2. List of provincial governor or vice-governor, Party secretary or vice-secretary, Party committee member, chairman or vice-chairman of the People's Political Consultative, chairman or vicechairman of the People's Congress: from the History of Party Organizations by province and Who is Who in China.

3. List of ministers or vice-ministers of central ministries: from Who is Who in China.

The matching algorithm is straightforward. There is no instance where two mayors have the same Chinese name. We use the unique Chinese name and the term year to match. If a mayor's name is matched with the name of an official in any of these higher ranked positions listed above, after his/her term as mayor, he/she is promoted.

We have also searched for resumes of mayors. We double checked the completeness of our matching from their working experiences. If one is not promoted, we learn from the resume where they move to next. Data on the demographic characteristics of mayors are also compiled from their resumes, such as age, gender, education, province and prefecture of birth, etc.

\section{B.2 Measuring the rate of natural increase from census data}

We compute crude birth rate from census data and calculate the rate of natural increase by the crude birth rate minus the crude death rate from City Statistical Yearbooks. First, in the 2000 Census, migrants who moved in 1995-2000 reported the prefecture they moved from. We use the information on out-migration and in-migration by prefecture and year in constructing birth rate measures in 1995-2000. We find that ignoring migration leads to underestimation of birth rate in 1995-2000. The average rate of natural increase from 1995-2000 accounting for migration is 4.8 (per 1000 population), while it is 4.3 without considering migration. Second, in 1985-1994 when we do not observe migration by prefecture and year, the migration rate was below $4 \%$. The potential underestimation without accounting for precise migration information would be much lower. Nevertheless, we include a set of controls on migration in these earlier years in our estimation. Specifically, we control for interactions of average migration measures in 1990-1994 and 1985-1990 and time fixed effects. See the details of the measurement below. 
Crude birth rates in 1995-2000 from the 2000 Census

Migration rate in 1995-2000 is relatively high in the period 1985-2000, rising from 4\% in 1995 to $11 \%$ in 2000 . For these five years, we observe the prefecture-by-year migration information in the 2000 Census that we use to construct birth rate. We use the following formula to compute birth rate:

Brate $_{c p t}=\frac{\text { Birth }_{c p t}^{1}+\text { Birth }_{c p t}^{2}}{\text { Population }_{c p t+1}-\left(\text { Birth }_{c p t+1}^{1}+\text { Births }_{c p t+1}^{2}\right)+\text { Outmigrants }_{c p t+1}-\text { Inmigrants }_{c p t+1}}$,

where $c$ denotes the prefecture, $p$ the province, and $t$ the year. Brate $e_{c p t}$ is the ratio of the number of births in prefecture $c$ of province $p$ in year $t$ to the end-of-year population in the same prefecture. In the numerator, Births $s_{p c t}^{1}$ is the number of births in prefecture $c$ in year $t$ who are in prefecture $c$ in 2000, and Births $s_{p c t}^{2}$ is number of people born in prefecture $c$ in year $t$ who moved out of prefecture c. The sum of Births $s_{p c t}^{1}$ and Births $s_{p c t}^{2}$ is the total number of births in prefecture $c$ in year $t$. In the denominator, the end-of-year population in prefecture $c$ in year $t$ is computed by the population in year $t+1$ minus the number of births in $t+1$, plus migrants who moved out of prefecture $c$ in year $t+1$, and minus migrants who moved into prefecture $c$ in year $t+1$. Population cpt $+1_{1}$ is computed retrospectively. Starting with the number of population in 2000, we compute population in 1999 based on the denominator, and then population in 1998, and so on.

Crude birth rates in 1990-1994 from the 2000 Census and in 1985-1989 from the 1990 Census

Migration rate before 1995 is below 4\%. For 1985-1994, migration information in the census is limited. The 2000 Census did not have the prefecture-by-year migration information for migrants who moved to the current prefecture before 1995, and it is the same for migrants in the 1990 Census. In 1985-1994, we are not able to use the exact migration information in computing birth rate. See the formula for 1985-1994 below:

$$
\text { Brate }_{c p t}=\frac{\text { Births }_{c p t}^{1}}{\text { Population }_{c p t+1}-\text { Birth }_{c p t+1}^{1}} .
$$

Nevertheless, we use available information from census to control for migration in our estimation. In the 2000 Census, migrants who moved to the current prefecture before 1995 reported the province they moved from. In the 1990 Census, migrants reported the province they moved from since 1985. We construct two sets of aggregate migration measures at the prefecture level:

1) The number of out-migrants by the province they moved out in 1990-1994 and in 1985-1989, respectively

2) The number of in-migrants by the current province in 1990-1994 and 1985-1989, respectively

To control for migration in these years, we include interactions of each aggregate measure of migration at the province level interacted with time dummy, for example, the number of out-migrants in province $p$ in 1990-1994 interacted with a dummy indicating the time period 1990-1994. 


\section{Additional Figures}

Figure A.1: Percentage of Migrants in 1982-2000

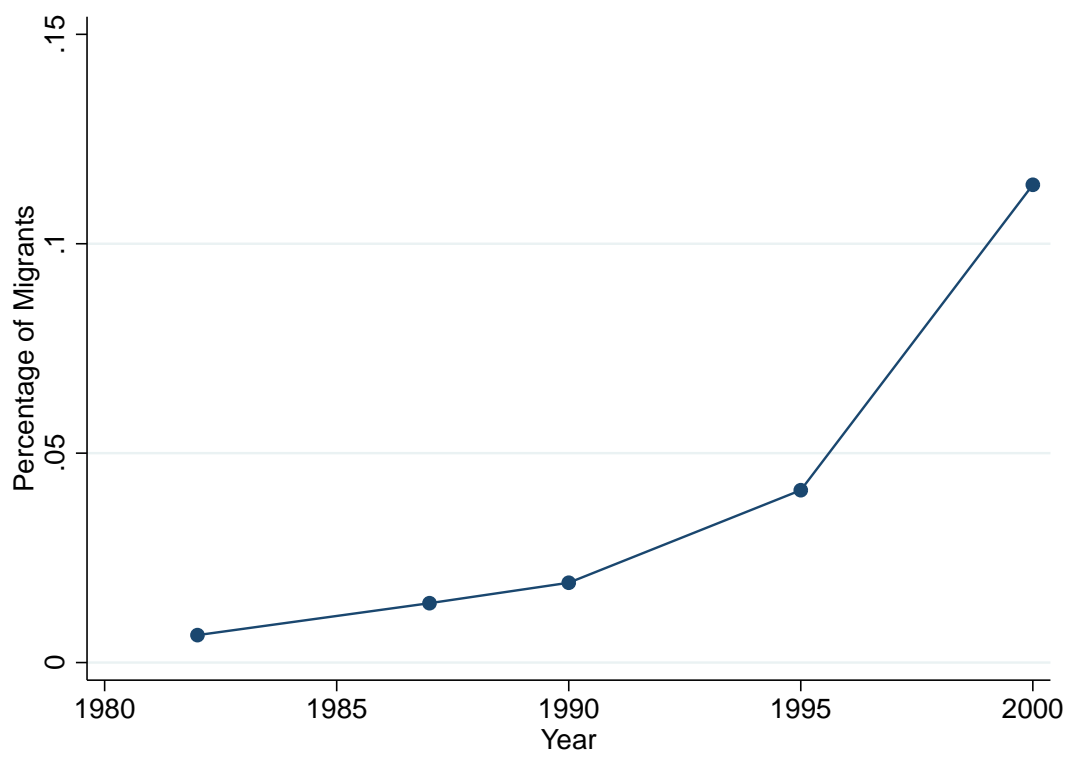

Notes: Data are from population censuses 1990 and 2000. The figure is plotted using the entire population. Migration is defined as not residing in one's prefecture of birth at the time of the census. 
Figure A.2: Number of Prefectures Per Province

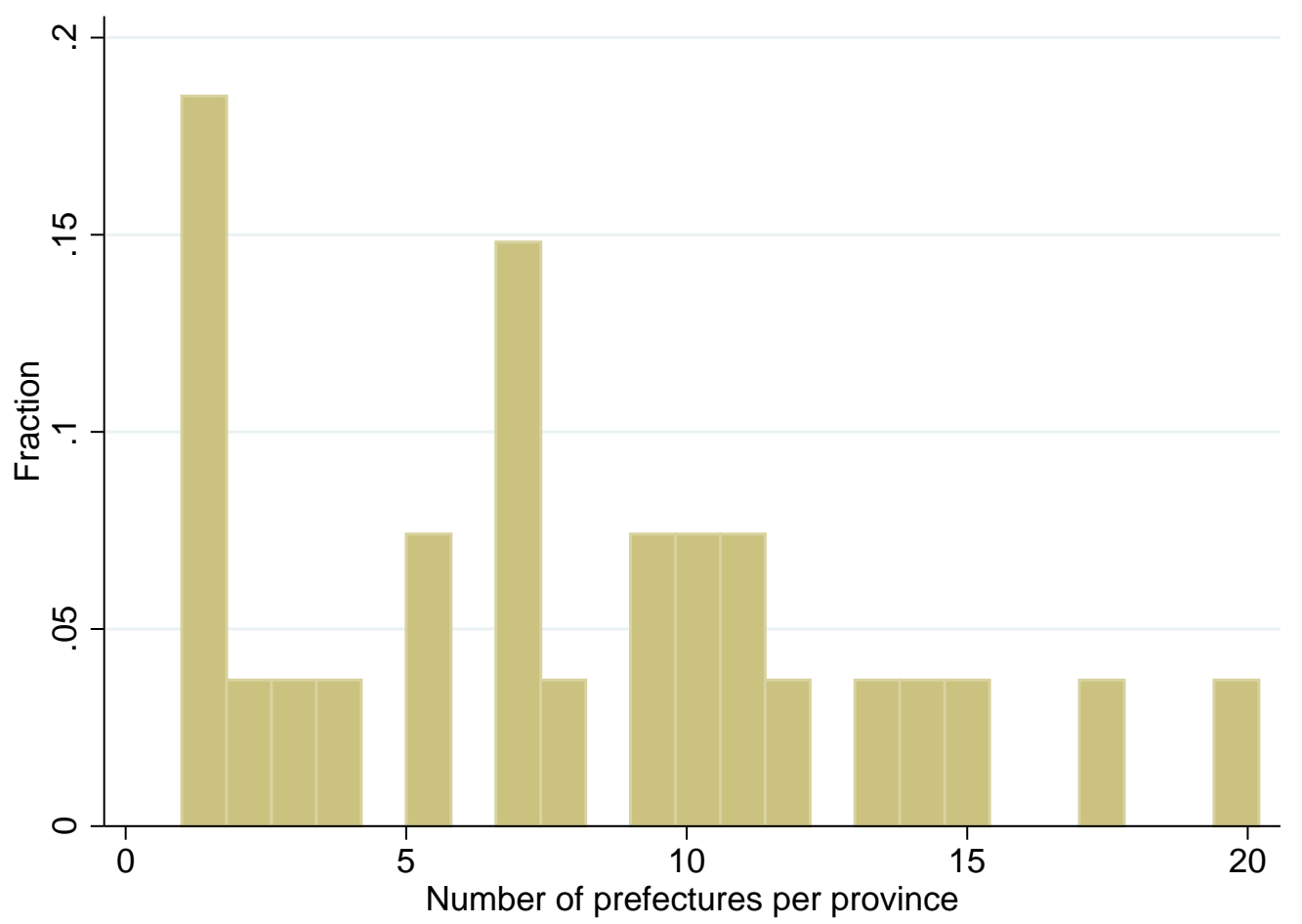

Notes: Provinces in our mayor data that have 1 prefectures include province-level prefectures (Beijing, Shanghai, Tianjin and Chongqing), and Hainan and Xinjiang province. 
Figure A.3: Competitiveness Measure: Average Tenure of Upper-Level Officials

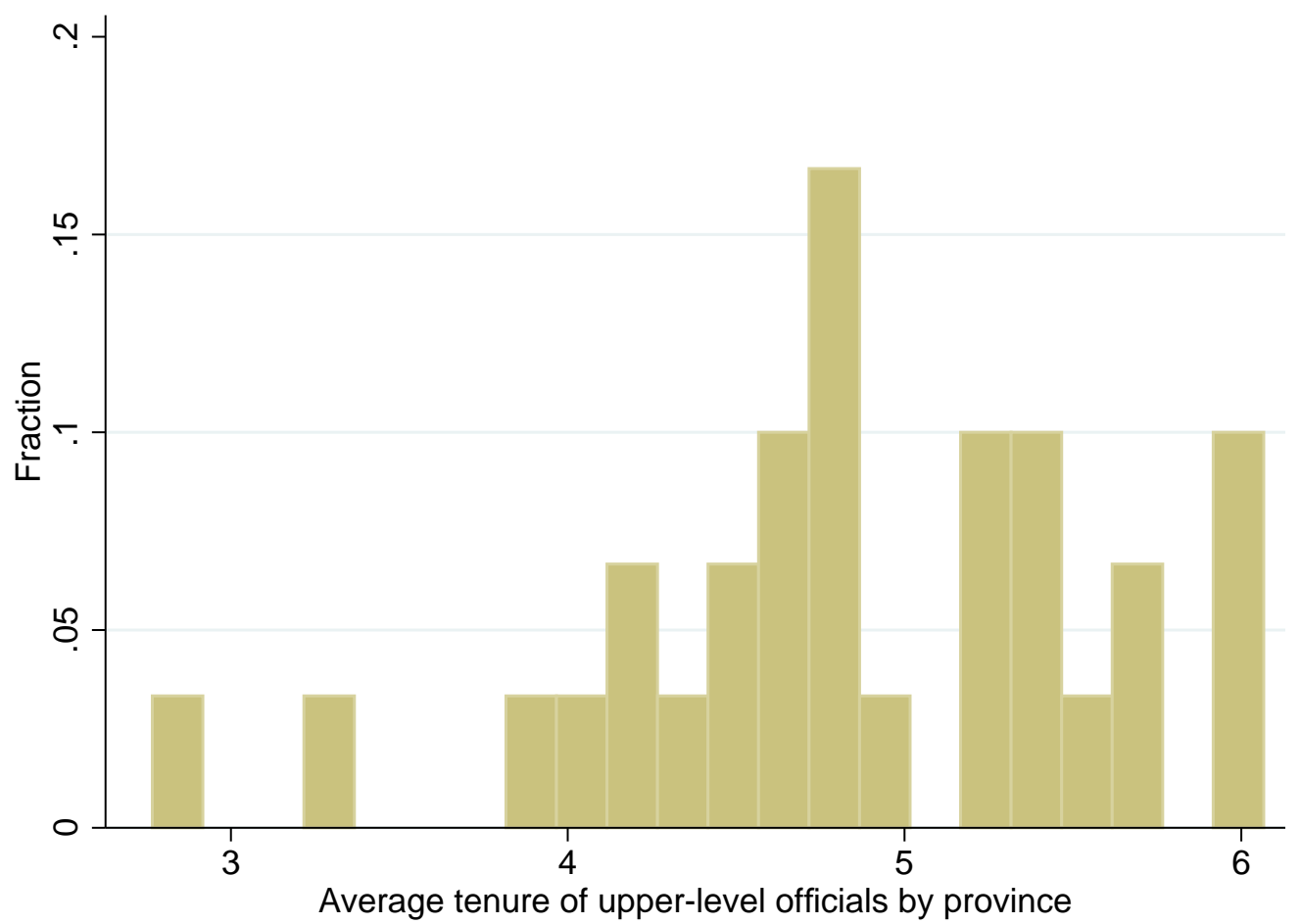

Notes: Data are from digitized term information of all province-level officials ranked higher than mayors. The competitiveness measure is across provinces.

\section{Additional Tables}




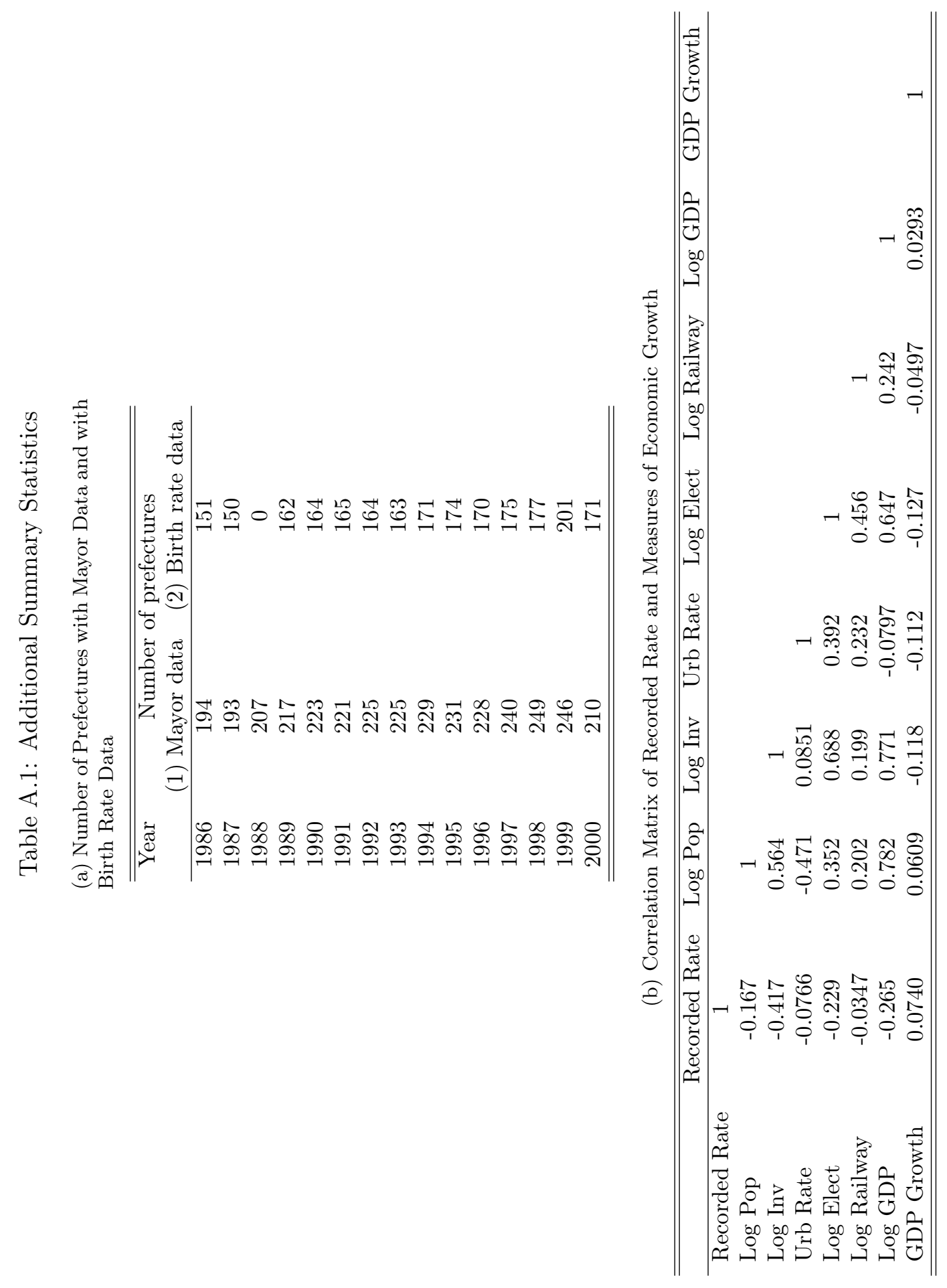


Table A.2: Relation Between Measures of Noise and Competitiveness

\begin{tabular}{|c|c|c|c|c|c|c|}
\hline & $\begin{array}{c}(1) \\
\text { SD Birth } \\
\text { Rate }\end{array}$ & $\begin{array}{c}(2) \\
\text { SD Migration }\end{array}$ & $\begin{array}{c}(3) \\
\text { Mean of } \\
\text { SDs }\end{array}$ & $\begin{array}{c}(4) \\
\text { Average } \\
\text { Tenure }\end{array}$ & $\begin{array}{c}(5) \\
1-P r \\
\text { Rate }\end{array}$ & $\begin{array}{c}(6) \\
\text { Mean of } \\
\text { Compete }\end{array}$ \\
\hline Average Tenure & $\begin{array}{c}0.037 \\
(0.166)\end{array}$ & $\begin{array}{c}0.118 \\
(0.152)\end{array}$ & $\begin{array}{c}0.078 \\
(0.109)\end{array}$ & & & \\
\hline 1-Promotion Rate & $\begin{array}{c}0.192 \\
(0.223)\end{array}$ & $\begin{array}{c}0.139 \\
(0.204)\end{array}$ & $\begin{array}{c}0.166 \\
(0.146)\end{array}$ & & & \\
\hline SD Birth Rate & & & & $\begin{array}{c}0.059 \\
(0.342)\end{array}$ & $\begin{array}{c}0.218 \\
(0.251)\end{array}$ & $\begin{array}{c}0.138 \\
(0.200)\end{array}$ \\
\hline SD Migration & & & & $\begin{array}{c}0.267 \\
(0.371)\end{array}$ & $\begin{array}{c}0.175 \\
(0.272)\end{array}$ & $\begin{array}{c}0.221 \\
(0.217)\end{array}$ \\
\hline Fraction of rural population & $\begin{array}{l}7.707^{* *} \\
(3.259)\end{array}$ & $\begin{array}{l}-1.638 \\
(2.986)\end{array}$ & $\begin{array}{l}3.034 \\
(2.140)\end{array}$ & $\begin{array}{c}6.832 \\
(4.873)\end{array}$ & $\begin{array}{l}-5.764 \\
(3.574)\end{array}$ & $\begin{array}{c}0.534 \\
(2.850)\end{array}$ \\
\hline Fraction of ethnic minorities & $\begin{array}{l}-1.945 \\
(1.233)\end{array}$ & $\begin{array}{l}-0.902 \\
(1.130)\end{array}$ & $\begin{array}{c}-1.424^{*} \\
(0.810)\end{array}$ & $\begin{array}{c}0.418 \\
(1.824)\end{array}$ & $\begin{array}{c}1.927 \\
(1.338)\end{array}$ & $\begin{array}{c}1.173 \\
(1.067)\end{array}$ \\
\hline $\operatorname{Ln}($ number of women aged $15-45)$ & $\begin{array}{c}0.005 \\
(0.004)\end{array}$ & $\begin{array}{c}0.011^{* * *} \\
(0.003)\end{array}$ & $\begin{array}{c}0.008^{* * *} \\
(0.002)\end{array}$ & $\begin{array}{l}-0.005 \\
(0.006)\end{array}$ & $\begin{array}{l}-0.009^{*} \\
(0.005)\end{array}$ & $\begin{array}{l}-0.007^{*} \\
(0.004)\end{array}$ \\
\hline Fraction completed high school & $\begin{array}{c}28.369^{* *} \\
(10.586)\end{array}$ & $\begin{array}{c}8.482 \\
(9.699)\end{array}$ & $\begin{array}{c}18.426^{* *} \\
(6.952)\end{array}$ & $\begin{array}{c}2.185 \\
(16.861)\end{array}$ & $\begin{array}{l}-23.595^{*} \\
(12.366)\end{array}$ & $\begin{array}{c}-10.705 \\
(9.861)\end{array}$ \\
\hline Fraction completed college & $\begin{array}{c}-47.542^{* *} \\
(22.075)\end{array}$ & $\begin{array}{l}-30.252 \\
(20.226)\end{array}$ & $\begin{array}{c}-38.897^{* *} \\
(14.498)\end{array}$ & $\begin{array}{c}16.953 \\
(37.508)\end{array}$ & $\begin{array}{c}12.135 \\
(27.510)\end{array}$ & $\begin{array}{c}14.544 \\
(21.936)\end{array}$ \\
\hline East regions & $\begin{array}{l}-0.039 \\
(0.530)\end{array}$ & $\begin{array}{l}-0.061 \\
(0.485)\end{array}$ & $\begin{array}{l}-0.050 \\
(0.348)\end{array}$ & $\begin{array}{c}0.181 \\
(0.738)\end{array}$ & $\begin{array}{c}0.547 \\
(0.542)\end{array}$ & $\begin{array}{c}0.364 \\
(0.432)\end{array}$ \\
\hline Central regions & $\begin{array}{l}-0.074 \\
(0.478)\end{array}$ & $\begin{array}{l}-0.717 \\
(0.438)\end{array}$ & $\begin{array}{l}-0.395 \\
(0.314)\end{array}$ & $\begin{array}{l}-0.321 \\
(0.737)\end{array}$ & $\begin{array}{c}0.082 \\
(0.541)\end{array}$ & $\begin{array}{l}-0.119 \\
(0.431)\end{array}$ \\
\hline Observations & 27 & 27 & 27 & 27 & 27 & 27 \\
\hline $\mathrm{R}^{2}$ & 0.67 & 0.73 & 0.81 & 0.33 & 0.64 & 0.59 \\
\hline
\end{tabular}

Notes: Mean of Noise is the average of standardized versions of SD Migration and SD Birth Rate. Mean of Compete is the average of standardized versions of Competitiveness (Tenure) and Competitiveness (1-Pr Rate). Please refer to Section 4 for details regarding these measures. This table shows that our measures of Noise and Competitiveness are not statistically related to each other. Each observation is at the provincelevel. * significant at $10 \%$ level; ${ }^{* *}$ significant at $5 \%$ level; $* * *$ significant at $1 \%$ level. 
Table A.3: Robustness of Heterogeneous Effects of OCP Performance by Noise and Competitiveness to Different Levels of Clustering

\begin{tabular}{|c|c|c|c|c|}
\hline & $(1)$ & $(2)$ & $(3)$ & $(4)$ \\
\hline OCP Performance & $\begin{array}{c}0.021^{* * *} \\
(0.007)\end{array}$ & $\begin{array}{l}0.021^{* *} \\
(0.009)\end{array}$ & $\begin{array}{l}0.021^{* *} \\
(0.008)\end{array}$ & $\begin{array}{l}0.021^{* *} \\
(0.009)\end{array}$ \\
\hline OCP Performance Reported X Noise (Average) & $\begin{array}{c}-0.019^{* *} \\
(0.008)\end{array}$ & $\begin{array}{c}-0.019^{* *} \\
(0.009)\end{array}$ & $\begin{array}{l}-0.019^{*} \\
(0.010)\end{array}$ & $\begin{array}{c}-0.019^{*} \\
(0.011)\end{array}$ \\
\hline OCP Performance Reported X Competitiveness (Average) & $\begin{array}{c}-0.020^{* * *} \\
(0.007)\end{array}$ & $\begin{array}{c}-0.020^{* * *} \\
(0.008)\end{array}$ & $\begin{array}{c}-0.020^{* *} \\
(0.008)\end{array}$ & $\begin{array}{c}-0.020^{* *} \\
(0.009)\end{array}$ \\
\hline Log GDP & $\begin{array}{l}0.172^{* *} \\
(0.073)\end{array}$ & $\begin{array}{l}0.172^{* *} \\
(0.067)\end{array}$ & $\begin{array}{c}0.172^{* * *} \\
(0.052)\end{array}$ & $\begin{array}{l}0.172^{*} \\
(0.089)\end{array}$ \\
\hline Observations & 1,483 & 1,483 & 1,483 & 1,483 \\
\hline $\mathrm{R}^{2}$ & 0.592 & 0.592 & 0.592 & 0.592 \\
\hline Mean of Dependent Variable & 0.132 & & & \\
\hline Marginal Effect at 25th pctil & $.048^{* * *}$ & $.048^{* * *}$ & $.048^{* * *}$ & $.048^{* * *}$ \\
\hline Marginal Effect at 25th pctil (SE) & $(.012)$ & $(.013)$ & $(.012)$ & $(.015)$ \\
\hline Marginal Effect at 50th pctil & $.016^{* *}$ & $.016^{*}$ & $.016^{*}$ & $.016^{*}$ \\
\hline Marginal Effect at 50th pctil (SE) & $(.007)$ & $(.009)$ & $(.009)$ & $(.009)$ \\
\hline Marginal Effect at 75 th pctil & -.006 & -.006 & -.006 & -.006 \\
\hline Marginal Effect at 75 th pctil (SE) & $(.008)$ & $(.011)$ & $(.013)$ & $(.012)$ \\
\hline Year FE & $\mathrm{Y}$ & $\mathrm{Y}$ & $\mathrm{Y}$ & $\mathrm{Y}$ \\
\hline Person FE & $\mathrm{Y}$ & $\mathrm{Y}$ & $\mathrm{Y}$ & $\mathrm{Y}$ \\
\hline City FE & Y & $\mathrm{Y}$ & $\mathrm{Y}$ & $\mathrm{Y}$ \\
\hline Prefecture-year controls & $\mathrm{Y}$ & $\mathrm{Y}$ & $\mathrm{Y}$ & Y \\
\hline Clustering Level & $\begin{array}{l}\text { Province } \\
\text { X Year }\end{array}$ & $\begin{array}{c}\text { Province } \\
\text { X } 5 \text { Year Plan }\end{array}$ & Province & Prefecture \\
\hline $\begin{array}{l}\text { Number of Clusters } \\
\text { Bootstrap }\end{array}$ & 297 & 78 & $\begin{array}{l}27 \\
Y\end{array}$ & 194 \\
\hline
\end{tabular}

Notes: OCP performance reported is the birth rate target minus the reported birth rate. Noise (Average) is the average of SD Migration and SD Birth Rate. Competitiveness (Average) is the average of Competitiveness (Tenure) and Competitiveness (1-Pr Rate). Tenure fixed effects and migration controls are included in all regressions. Prefecture-year controls include $\log$ (population), percentage of urban population and $\log$ (government investment). Marginal effects are computed at percentiles of both variables. Figure $6 \mathrm{c}$ plots marginal effects of increasing OCP performance on the chance on promotion using estimates from this table. Standard errors are clustered at different levels in each column. ${ }^{*}$ significant at $10 \%$ level; ${ }^{* *}$ significant at $5 \%$ level; ${ }^{* * *}$ significant at $1 \%$ level. 
Table A.4: Robustness of Heterogeneous Effects of OCP Performance by Noise and Competitiveness to Province-by-Time Period Fixed Effects

\begin{tabular}{lccc}
\hline \hline & $(1)$ & $(2)$ & $(3)$ \\
\hline OCP Performance & $0.021^{* *}$ & $0.024^{* * *}$ & $0.028^{* *}$ \\
& $(0.008)$ & $(0.009)$ & $(0.011)$ \\
OCP Performance Reported X Noise (Average) & $-0.019^{*}$ & $-0.022^{* *}$ & -0.022 \\
& $(0.010)$ & $(0.009)$ & $(0.016)$ \\
OCP Performance Reported X Competitiveness (Average) & $-0.020^{* *}$ & $-0.020^{* *}$ & -0.020 \\
& $(0.008)$ & $(0.009)$ & $(0.014)$ \\
& & & \\
Log GDP & $0.172^{* * *}$ & $0.138^{* * *}$ & $0.195^{*}$ \\
& $(0.052)$ & $(0.047)$ & $(0.110)$ \\
\hline Observations & 1,483 & 1,483 & 1,483 \\
$\mathrm{R}^{2}$ & 0.592 & 0.599 & 0.713 \\
Mean of Dependent Variable & 0.132 & 0.132 & 0.132 \\
Marginal Effect at 25th pctil & $.048^{* * *}$ & $.052^{* * *}$ & $.057^{* * *}$ \\
Marginal Effect at 25th pctil (SE) & $(.012)$ & $(.014)$ & $(.017)$ \\
Marginal Effect at 50th pctil & $.016^{*}$ & $.02^{* *}$ & $.024^{* *}$ \\
Marginal Effect at 50th pctil (SE) & $(.009)$ & $(.009)$ & $(.011)$ \\
Marginal Effect at 75th pctil & -.006 & -.005 & -.001 \\
Marginal Effect at 75th pctil (SE) & $(.013)$ & $(.01)$ & $(.015)$ \\
\hline Year FE & $\mathrm{Y}$ & & \\
Person FE & $\mathrm{Y}$ & $\mathrm{Y}$ & $\mathrm{Y}$ \\
City FE & $\mathrm{Y}$ & $\mathrm{Y}$ & $\mathrm{Y}$ \\
Prefecture-year controls & $\mathrm{Y}$ & $\mathrm{Y}$ & $\mathrm{Y}$ \\
Province-5-year FE & & $\mathrm{Y}$ & \\
Province-year FE & & & $\mathrm{Y}$ \\
\hline \hline
\end{tabular}

Notes: OCP performance reported is the birth rate target minus the reported birth rate. Noise (Average) is the average of SD Migration and SD Birth Rate. Competitiveness (Average) is the average of Competitiveness (Tenure) and Competitiveness (1-Pr Rate). Tenure fixed effects and migration controls are included in all regressions. Prefecture-year controls include $\log$ (population), percentage of urban population and $\log$ (government investment). Marginal effects are computed at percentiles of both variables. Standard errors are clustered at the province level and are bootstrapped. ${ }^{*}$ significant at $10 \%$ level; ${ }^{* *}$ significant at $5 \%$ level; *** significant at $1 \%$ level. 
Table A.5: Robustness of Heterogeneous Effects of OCP Performance by Noise and Competitiveness to Interactions with Log GDP

\begin{tabular}{|c|c|c|c|c|c|}
\hline & $(1)$ & 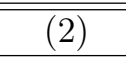 & $(3)$ & $(4)$ & $(5)$ \\
\hline OCP Performance & $\begin{array}{c}0.017^{*} \\
(0.010)\end{array}$ & $\begin{array}{c}0.041 \\
(0.031)\end{array}$ & $\begin{array}{c}0.017 \\
(0.030)\end{array}$ & $\begin{array}{c}0.039 \\
(0.028)\end{array}$ & $\begin{array}{c}0.018 \\
(0.026)\end{array}$ \\
\hline Log GDP & $\begin{array}{c}0.172^{* * *} \\
(0.056)\end{array}$ & $\begin{array}{l}0.204^{* *} \\
(0.081)\end{array}$ & $\begin{array}{l}0.167^{* *} \\
(0.074)\end{array}$ & $\begin{array}{c}0.200^{* * *} \\
(0.077)\end{array}$ & $\begin{array}{c}0.169^{* *} \\
(0.071)\end{array}$ \\
\hline OCP Performance Reported X Log GDP & & $\begin{array}{l}-0.006 \\
(0.007)\end{array}$ & $\begin{array}{c}0.000 \\
(0.007)\end{array}$ & $\begin{array}{l}-0.005 \\
(0.007)\end{array}$ & $\begin{array}{c}0.001 \\
(0.006)\end{array}$ \\
\hline OCP Performance Reported X Noise (Average) & & & $\begin{array}{c}-0.023^{*} \\
(0.012)\end{array}$ & & $\begin{array}{c}-0.020^{*} \\
(0.011)\end{array}$ \\
\hline OCP Performance Reported X Competitiveness (Average) & & & & $\begin{array}{c}-0.022^{* * *} \\
(0.009)\end{array}$ & $\begin{array}{c}-0.020^{* *} \\
(0.008)\end{array}$ \\
\hline Observations & 1,483 & 1,483 & 1,483 & 1,483 & 1,483 \\
\hline $\mathrm{R}^{2}$ & 0.584 & 0.585 & 0.588 & 0.590 & 0.592 \\
\hline Mean of Dependent Variable & 0.132 & 0.132 & 0.132 & 0.132 & 0.132 \\
\hline Marginal Effect at 25th pctil & & & .029 & $.05^{*}$ & $.046^{*}$ \\
\hline Marginal Effect at 25th pctil (SE) & & & $(.029)$ & $(.028)$ & $(.025)$ \\
\hline Marginal Effect at 50th pctil & & & .017 & .038 & .014 \\
\hline Marginal Effect at 50th pctil (SE) & & & $(.031)$ & $(.028)$ & $(.026)$ \\
\hline Marginal Effect at 75 th pctil & & & .003 & .025 & -.009 \\
\hline Marginal Effect at 75 th pctil (SE) & & & $(.034)$ & $(.029)$ & $(.03)$ \\
\hline Year FE & $\mathrm{Y}$ & $\mathrm{Y}$ & $\mathrm{Y}$ & $\mathrm{Y}$ & $\mathrm{Y}$ \\
\hline Person FE & Y & Y & Y & Y & $\mathrm{Y}$ \\
\hline City FE & Y & Y & Y & Y & Y \\
\hline Prefecture-year controls & Y & Y & Y & Y & Y \\
\hline
\end{tabular}

Notes: OCP performance reported is the target for the rate of natural increase minus the reported rate of natural increase. Noise (Average) is the average of SD Migration and SD Birth Rate. Competitiveness (Average) is the average of Competitiveness (Tenure) and Competitiveness (1-Pr Rate). Tenure fixed effects and migration controls are included in all regressions. Prefecture-year controls include log(population), percentage of urban population and $\log$ (government investment). Marginal effects are computed at percentiles of both variables. Standard errors are clustered at the province level and are bootstrapped. ${ }^{*}$ significant at $10 \%$ level; ${ }^{* *}$ significant at $5 \%$ level; ${ }^{* * *}$ significant at $1 \%$ level. 
Table A.6: Heterogeneous by Signal Noise Controlling for Alternative Measures of Economic Performance

\begin{tabular}{lccc}
\hline \hline & $(1)$ & $(2)$ & $(3)$ \\
\hline OCP Performance & $0.018^{* *}$ & $0.015^{*}$ & 0.016 \\
& $(0.007)$ & $(0.009)$ & $(0.010)$ \\
OCP Performance Reported X Noise (Average) & $-0.021^{* *}$ & $-0.022^{*}$ & $-0.023^{*}$ \\
& $(0.009)$ & $(0.012)$ & $(0.013)$ \\
\hline Observations & 1,357 & 1,361 & 1,136 \\
$\mathrm{R}^{2}$ & 0.590 & 0.619 & 0.661 \\
Mean of Dependent Variable & 0.132 & 0.130 & 0.140 \\
Marginal Effect at 25th pctil & $.029^{* * *}$ & $.027^{* *}$ & $.029^{* *}$ \\
Marginal Effect at 25th pctil (SE) & $(.009)$ & $(.011)$ & $(.012)$ \\
Marginal Effect at 50th pctil & $.017^{* *}$ & $.015^{*}$ & .016 \\
Marginal Effect at 50th pctil (SE) & $(.007)$ & $(.009)$ & $(.01)$ \\
Marginal Effect at 75th pctil & .005 & .001 & .001 \\
Marginal Effect at 75th pctil (SE) & $(.009)$ & $(.011)$ & $(.013)$ \\
GDP growth rate & $\mathrm{Y}$ & & \\
Log electricity usage & & $\mathrm{Y}$ & \\
Log railway cargo volume & & & $\mathrm{Y}$ \\
Year FE & $\mathrm{Y}$ & $\mathrm{Y}$ & $\mathrm{Y}$ \\
Person FE & $\mathrm{Y}$ & $\mathrm{Y}$ & $\mathrm{Y}$ \\
City FE & $\mathrm{Y}$ & $\mathrm{Y}$ & $\mathrm{Y}$ \\
Prefecture-year controls & $\mathrm{Y}$ & $\mathrm{Y}$ & $\mathrm{Y}$ \\
\hline \hline
\end{tabular}

Notes: OCP performance reported is the target for the rate of natural increase minus the reported rate of natural increase. Noise (Average of Both) is the average of SD Migration and SD Birth Rate. Tenure fixed effects and migration controls are included in all regressions. Prefecture-year controls include log(population), percentage of urban population and $\log$ (government investment). Standard errors are clustered at the province level and are bootstrapped. ${ }^{*}$ significant at $10 \%$ level; ${ }^{* *}$ significant at $5 \%$ level; ${ }^{* * *}$ significant at $1 \%$ level. 
Table A.7: Heterogeneous by Competitiveness Controlling for Alternative Measures of Economic Performance

\begin{tabular}{lccc}
\hline \hline & $(1)$ & $(2)$ & $(3)$ \\
\hline OCP Performance & $0.017^{* *}$ & $0.015^{*}$ & 0.016 \\
& $(0.007)$ & $(0.008)$ & $(0.010)$ \\
OCP Performance Reported X Competitiveness (Average) & $-0.020^{* *}$ & $-0.026^{* * *}$ & $-0.026^{* * *}$ \\
& $(0.008)$ & $(0.008)$ & $(0.010)$ \\
\hline Observations & 1,357 & 1,361 & 1,136 \\
$\mathrm{R}^{2}$ & 0.590 & 0.621 & 0.663 \\
Mean of Dependent Variable & 0.132 & 0.130 & 0.140 \\
Marginal Effect at 25th pctil & $.028^{* * *}$ & $.029^{* * *}$ & $.03^{* * *}$ \\
Marginal Effect at 25th pctil (SE) & $(.008)$ & $(.009)$ & $(.011)$ \\
Marginal Effect at 50th pctil & $.017^{* *}$ & $.015^{*}$ & .016 \\
Marginal Effect at 50th pctil (SE) & $(.007)$ & $(.008)$ & $(.01)$ \\
Marginal Effect at 75th pctil & .005 & -.001 & -.001 \\
Marginal Effect at 75th pctil (SE) & $(.009)$ & $(.011)$ & $(.011)$ \\
\hline GDP growth rate & $\mathrm{Y}$ & & \\
Log electricity usage & & $\mathrm{Y}$ & \\
Log railway cargo volume & & & $\mathrm{Y}$ \\
Year FE & $\mathrm{Y}$ & $\mathrm{Y}$ & $\mathrm{Y}$ \\
Person FE & $\mathrm{Y}$ & $\mathrm{Y}$ & $\mathrm{Y}$ \\
City FE & $\mathrm{Y}$ & $\mathrm{Y}$ & $\mathrm{Y}$ \\
Prefecture-year controls & $\mathrm{Y}$ & $\mathrm{Y}$ & $\mathrm{Y}$ \\
\hline \hline
\end{tabular}

Notes: OCP performance reported is the target for the rate of natural increase minus the reported rate of natural increase. Competitiveness (Average of Both) is the average of Competitiveness (Tenure) and Competitiveness (1-Pr Rate). Tenure fixed effects and migration controls are included in all regressions. Prefecture-year controls include $\log$ (population), percentage of urban population and $\log$ (government investment). Standard errors are clustered at the province level and are bootstrapped. * significant at $10 \%$ level; ** significant at $5 \%$ level; $* * *$ significant at $1 \%$ level. 
Table A.8: First Stage and Reduced-Form Effects of Changes in Birth Rate Target

(a) Changes in Birth Rate Target are Not Correlated with Log GDP

\begin{tabular}{lcccc}
\hline \hline & \multicolumn{4}{c}{ Log GDP } \\
\cline { 2 - 5 } & $(1)$ & $(2)$ & $(3)$ & $(4)$ \\
\hline Change in birth rate target & -0.024 & -0.003 & -0.003 & -0.004 \\
& $(0.043)$ & $(0.011)$ & $(0.010)$ & $(0.006)$ \\
\hline Observations & 1,519 & 1,519 & 1,519 & 1,519 \\
$\mathrm{R}^{2}$ & 0.48 & 0.99 & 0.99 & 0.99 \\
\hline Year FE & $\mathrm{Y}$ & $\mathrm{Y}$ & $\mathrm{Y}$ & $\mathrm{Y}$ \\
Person FE & & $\mathrm{Y}$ & $\mathrm{Y}$ & $\mathrm{Y}$ \\
City FE & & & $\mathrm{Y}$ & $\mathrm{Y}$ \\
Prefecture-year controls & & & & $\mathrm{Y}$ \\
\hline \hline
\end{tabular}

(b) First Stage is Robust to Controlling for Log GDP

\begin{tabular}{lccccc}
\hline \hline & \multicolumn{5}{c}{ OCP Performance } \\
\cline { 2 - 6 } & $(1)$ & $(2)$ & $(3)$ & $(4)$ & $(5)$ \\
\hline Change in birth rate target & $0.323^{* * *}$ & $0.455^{* * *}$ & $0.455^{* * *}$ & $0.449^{* * *}$ & $0.448^{* * *}$ \\
& $(0.085)$ & $(0.085)$ & $(0.086)$ & $(0.082)$ & $(0.086)$ \\
Log GDP & & & & & \\
& -0.041 & 0.291 & 0.291 & 0.228 & \\
\hline Observations & $(0.234)$ & $(0.295)$ & $(0.271)$ & $(0.385)$ & \\
$\mathrm{R}^{2}$ & 1,519 & 1,519 & 1,519 & 1,519 & 1,519 \\
\hline Year FE & 0.31 & 0.79 & 0.79 & 0.79 & 0.79 \\
Person FE & $\mathrm{Y}$ & $\mathrm{Y}$ & $\mathrm{Y}$ & $\mathrm{Y}$ & $\mathrm{Y}$ \\
City FE & & $\mathrm{Y}$ & $\mathrm{Y}$ & $\mathrm{Y}$ & $\mathrm{Y}$ \\
Prefecture-year controls & & & $\mathrm{Y}$ & $\mathrm{Y}$ & $\mathrm{Y}$ \\
\hline \hline
\end{tabular}

Notes: OCP performance reported is the target for the rate of natural increase minus the reported rate of natural increase. Tenure fixed effects and migration controls are included in all regressions. Prefecture-year controls include $\log$ (population), percentage of urban population and $\log$ (government investment). Standard errors are clustered at the province level and are bootstrapped. ${ }^{*}$ significant at $10 \%$ level; ${ }^{* *}$ significant at $5 \%$ level; *** significant at $1 \%$ level. 
Table A.9: Instrument Variable and Alternative Measures of Economic Performance

\begin{tabular}{lccc}
\hline \hline & $(1)$ & $(2)$ & $(3)$ \\
& GDP growth rate & Log electricity usage & Log railway cargo volume \\
\hline Change in birth rate target & 0.035 & -0.002 & $-0.028^{*}$ \\
& $(0.027)$ & $(0.005)$ & $(0.017)$ \\
\hline Observations & 1,398 & 1,402 & 1,184 \\
$\mathrm{R}^{2}$ & 0.59 & 0.98 & 0.92 \\
\hline Year FE & $\mathrm{Y}$ & $\mathrm{Y}$ & $\mathrm{Y}$ \\
Person FE & $\mathrm{Y}$ & $\mathrm{Y}$ & $\mathrm{Y}$ \\
City FE & $\mathrm{Y}$ & $\mathrm{Y}$ & $\mathrm{Y}$ \\
Prefecture-year controls & $\mathrm{Y}$ & $\mathrm{Y}$ & $\mathrm{Y}$ \\
\hline \hline
\end{tabular}

Notes: Tenure fixed effects and migration controls are included in all regressions. Prefecture-year controls include $\log$ (population), percentage of urban population and $\log$ (government investment). Standard errors are clustered at the province level and are bootstrapped. ${ }^{*}$ significant at $10 \%$ level; ${ }^{* *}$ significant at $5 \%$ level; $* * *$ significant at $1 \%$ level. 
Table A.10: Test of IV Identifying Assumptions

\begin{tabular}{|c|c|c|}
\hline \multirow[t]{3}{*}{ Panel A } & \multicolumn{2}{|c|}{ Stay in position after the change in target $=1$} \\
\hline & $(1)$ & $\overline{(2)}$ \\
\hline & Increase in birth rate target & Decrease in birth rate target \\
\hline \multirow[t]{2}{*}{ OCP Performance Reported } & 0.013 & 0.004 \\
\hline & $(0.011)$ & $(0.010)$ \\
\hline \multirow[t]{2}{*}{ Log GDP } & 0.039 & $0.082^{* * *}$ \\
\hline & $(0.034)$ & $(0.030)$ \\
\hline Observations & 338 & 397 \\
\hline $\mathrm{R}^{2}$ & 0.05 & 0.07 \\
\hline Panel B & \multicolumn{2}{|c|}{ Promotion $=1$} \\
\hline Future Change in birth rate target & \multirow{2}{*}{\multicolumn{2}{|c|}{$\begin{array}{c}-0.014 \\
(0.016)\end{array}$}} \\
\hline & & \\
\hline Log GDP & \multirow{2}{*}{\multicolumn{2}{|c|}{$\begin{array}{c}0.173^{*} \\
(0.091)\end{array}$}} \\
\hline & & \\
\hline Observations & \multicolumn{2}{|c|}{931} \\
\hline $\mathrm{R}^{2}$ & \multicolumn{2}{|c|}{0.60} \\
\hline Panel C & \multicolumn{2}{|c|}{ Birth rate from Census - Reported birth rate } \\
\hline Change in birth rate target & \multirow{2}{*}{\multicolumn{2}{|c|}{$\begin{array}{c}0.010 \\
(0.042)\end{array}$}} \\
\hline & & \\
\hline Log GDP & \multirow{2}{*}{\multicolumn{2}{|c|}{$\begin{array}{c}-0.192 \\
(0.442)\end{array}$}} \\
\hline & & \\
\hline Observations & \multicolumn{2}{|c|}{1,406} \\
\hline $\mathrm{R}^{2}$ & \multicolumn{2}{|c|}{0.85} \\
\hline
\end{tabular}

Notes: OCP performance reported is the target for the rate of natural increase minus the reported rate of natural increase. OCP performance from census is birth rate target minus birth rate from census data. In Panel A, column (1) uses the sub-sample in provinces and years with an increase in birth rate target, and column (2) uses the sub-sample in provinces and years with an decrease in birth rate target. In Panel B, we use the sample of 1986-1995, during which the next change in birth rate target is observed in the data. Tenure fixed effects and migration controls are included in all regressions. Prefecture-year controls include $\log$ (population), percentage of urban population and $\log$ (government investment). Standard errors are clustered at the province level and are bootstrapped. ${ }^{*}$ significant at $10 \%$ level; ${ }^{* *}$ significant at $5 \%$ level; $* * *$ significant at $1 \%$ level. 
Table A.11: 2SLS Estimates: Heterogeneity by Noisiness

\begin{tabular}{|c|c|c|c|c|}
\hline & $\begin{array}{l}\text { (1) } \\
\text { IV }\end{array}$ & $\begin{array}{l}\text { (2) } \\
\text { IV }\end{array}$ & $\begin{array}{l}\text { (3) } \\
\text { IV }\end{array}$ & $\begin{array}{l}\text { (4) } \\
\text { IV }\end{array}$ \\
\hline OCP Performance & $\begin{array}{l}0.028^{*} \\
(0.017)\end{array}$ & $\begin{array}{c}0.009 \\
(0.028)\end{array}$ & $\begin{array}{l}0.039^{* *} \\
(0.015)\end{array}$ & $\begin{array}{c}0.044 \\
(0.027)\end{array}$ \\
\hline OCP Performance X Noise (SD Migration) & & $\begin{array}{c}0.032 \\
(0.025)\end{array}$ & & \\
\hline OCP Performance X Noise (SD Birth Rate) & & & $\begin{array}{c}-0.059 \\
(0.047)\end{array}$ & \\
\hline OCP Performance X Noise (Average of Both) & & & & $\begin{array}{c}-0.039 \\
(0.029)\end{array}$ \\
\hline Log GDP & $\begin{array}{c}0.179^{* * *} \\
(0.051)\end{array}$ & $\begin{array}{c}0.162^{* *} \\
(0.066)\end{array}$ & $\begin{array}{l}0.143^{* *} \\
(0.062)\end{array}$ & $\begin{array}{c}0.177^{* * *} \\
(0.044)\end{array}$ \\
\hline Observations & 1,519 & 1,519 & 1,519 & 1,519 \\
\hline $\mathrm{R}^{2}$ & 0.575 & 0.547 & 0.564 & 0.577 \\
\hline Mean of Dependent Variable & 0.145 & 0.145 & 0.145 & 0.145 \\
\hline Marginal Effect at 25th pctil & & -.016 & $.075^{* *}$ & .063 \\
\hline Marginal Effect at 25th pctil (SE) & & $(.045)$ & $(.035)$ & $(.039)$ \\
\hline Marginal Effect at 50th pctil & & .004 & .025 & .043 \\
\hline Marginal Effect at 50th pctil (SE) & & $(.031)$ & $(.017)$ & $(.027)$ \\
\hline Marginal Effect at 75 th pctil & & $.046^{* *}$ & .007 & .019 \\
\hline Marginal Effect at 75 th pctil (SE) & & $(.018)$ & $(.028)$ & $(.015)$ \\
\hline Year FE & $\mathrm{Y}$ & $\mathrm{Y}$ & $\bar{Y}$ & $\mathrm{Y}$ \\
\hline Person FE & $\mathrm{Y}$ & Y & $\mathrm{Y}$ & $\mathrm{Y}$ \\
\hline City FE & Y & Y & Y & Y \\
\hline Prefecture-year controls & Y & Y & Y & Y \\
\hline
\end{tabular}

Notes: OCP Performance and OCP Performance*Noise (SD Migration) are instrumented with decreases in birth rate target and decreases in target*SD Migration. OCP Performance and OCP Performance*Noise (SD Birth Rate) are instrumented with decreases in birth rate target and decreases in target*SD Birth Rate. OCP Performance and OCP Performance*Noise (Both) are instrumented with decreases in birth rate target and decreases in target*average of two noisiness measures. Tenure fixed effects and migration controls are included in all regressions. Prefecture-year controls include $\log$ (population), percentage of urban population and $\log$ (government investment). Standard errors are clustered at the province level and are bootstrapped. * significant at $10 \%$ level; ${ }^{* *}$ significant at $5 \%$ level; *** significant at $1 \%$ level. 
Table A.12: Heterogeneity by Competitiveness

(a) OLS Estimates

\begin{tabular}{|c|c|c|c|c|}
\hline & (1) & (2) & (3) & (4) \\
\hline OCP Performance & $\begin{array}{c}0.014 \\
(0.010)\end{array}$ & & & \\
\hline OCP Performance X Low Competition (Tenure) & & $\begin{array}{c}0.033^{* * *} \\
(0.011)\end{array}$ & & \\
\hline OCP Performance X High Competition (Tenure) & & $\begin{array}{c}0.004 \\
(0.011)\end{array}$ & & \\
\hline OCP Performance X Low Competition (1-Pr Rate) & & & $\begin{array}{c}0.032^{* *} \\
(0.016)\end{array}$ & \\
\hline OCP Performance X High Competition (1-Pr Rate) & & & $\begin{array}{c}0.009 \\
(0.011)\end{array}$ & \\
\hline OCP Performance X Low Competition (Both) & & & & $\begin{array}{c}0.031 \\
(0.059)\end{array}$ \\
\hline OCP Performance X High Competition (Both) & & & & $\begin{array}{c}0.011 \\
(0.011)\end{array}$ \\
\hline Log GDP & $\begin{array}{c}0.201^{* * *} \\
(0.058)\end{array}$ & $\begin{array}{c}0.201^{* * *} \\
(0.056)\end{array}$ & $\begin{array}{c}0.199^{* * *} \\
(0.056)\end{array}$ & $\begin{array}{c}0.200^{* * *} \\
(0.059)\end{array}$ \\
\hline $\mathrm{N}$ & 1,597 & 1,597 & 1,597 & 1,597 \\
\hline $\mathrm{R}^{2}$ & 0.57 & 0.57 & 0.57 & 0.57 \\
\hline Year FE & $\mathrm{Y}$ & $\mathrm{Y}$ & $\mathrm{Y}$ & $\mathrm{Y}$ \\
\hline Person FE & $\mathrm{Y}$ & $\mathrm{Y}$ & $\mathrm{Y}$ & $\mathrm{Y}$ \\
\hline City FE & $\mathrm{Y}$ & $\mathrm{Y}$ & $\mathrm{Y}$ & $\mathrm{Y}$ \\
\hline Prefecture-year controls & Y & $\mathrm{Y}$ & Y & Y \\
\hline
\end{tabular}

(b) 2SLS Estimates

\begin{tabular}{|c|c|c|c|c|}
\hline & (1) & 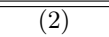 & (3) & (4) \\
\hline OCP Performance & $\begin{array}{l}0.028^{*} \\
(0.017)\end{array}$ & & & \\
\hline OCP Performance X Low Competition (Tenure) & & $\begin{array}{c}0.049^{* *} \\
(0.025)\end{array}$ & & \\
\hline OCP Performance X High Competition (Tenure) & & $\begin{array}{c}0.004 \\
(0.042)\end{array}$ & & \\
\hline OCP Performance X Low Competition (1-Pr Rate) & & & $\begin{array}{c}0.104^{* * *} \\
(0.030)\end{array}$ & \\
\hline OCP Performance X High Competition (1-Pr Rate) & & & $\begin{array}{c}-0.036 \\
(0.028)\end{array}$ & \\
\hline OCP Performance X Low Competition (Both) & & & & $\begin{array}{c}0.057^{* * *} \\
(0.019)\end{array}$ \\
\hline OCP Performance X High Competition (Both) & & & & $\begin{array}{c}0.002 \\
(0.025)\end{array}$ \\
\hline Log GDP & $\begin{array}{c}0.179^{* * *} \\
(0.051)\end{array}$ & $\begin{array}{c}0.167^{* * *} \\
(0.055)\end{array}$ & $\begin{array}{c}0.158^{* *} \\
(0.065)\end{array}$ & $\begin{array}{c}0.175^{* * *} \\
(0.057)\end{array}$ \\
\hline $\mathrm{N}$ & 1,519 & 1,519 & 1,519 & 1,519 \\
\hline Year FE & $\mathrm{Y}$ & $\mathrm{Y}$ & $\mathrm{Y}$ & $\mathrm{Y}$ \\
\hline Person FE & $\mathrm{Y}$ & $\mathrm{Y}$ & $\mathrm{Y}$ & $\mathrm{Y}$ \\
\hline City FE & $\mathrm{Y}$ & $\mathrm{Y}$ & $\mathrm{Y}$ & $\mathrm{Y}$ \\
\hline Prefecture-year controls & Y & $\mathrm{Y}$ & $\mathrm{Y}$ & $\mathrm{Y}$ \\
\hline
\end{tabular}

Notes: In this table, OCP Performance is interacted with indicator variables for High and Low levels of competition using the tenure, 1-promotion rate, as well as a joint, or "both" measure. Low competitiveness is defined as being in the lowest tercile of the distribution for the tenure and 1-promotion rate measures, while the "both" measure assigns a province to the low competition group if the province qualifies as low competition under either of the two definitions. In each case, we instrument for OCP Performance X Low Competition and OCP Performance X High Competition using interactions of decreases in targets with the indicators for High and Low competition. Tenure fixed effects and migration controls are included in all regressions. Prefecture-year controls include $\log ($ population), percentage of urban population and $\log$ (government investment). Standard errors are clustered at the province level and are bootstrapped. $*$ significant at $10 \%$ level; ${ }^{* *}$ significant at $5 \%$ level; ${ }^{* * *}$ significant at $1 \%$ level. 
Table A.13: Determinants of the Province-Level Birth Rate Target

\begin{tabular}{|c|c|c|c|c|c|c|}
\hline & \multicolumn{6}{|c|}{ Birth Rate Target (Province-Year) } \\
\hline & (1) & (2) & (3) & (4) & (5) & (6) \\
\hline $\operatorname{Ln}($ number of women aged $15-45)$ & $\begin{array}{c}12.693^{* * *} \\
(3.145)\end{array}$ & $\begin{array}{c}13.946^{* * *} \\
(3.089)\end{array}$ & $\begin{array}{c}12.266^{* * *} \\
(3.162)\end{array}$ & $\begin{array}{c}13.837^{* * *} \\
(3.175)\end{array}$ & $\begin{array}{l}6.713^{*} \\
(3.480)\end{array}$ & $\begin{array}{c}4.818 \\
(3.509)\end{array}$ \\
\hline Fraction of rural women & & $\begin{array}{l}29.275^{* *} \\
(12.035)\end{array}$ & & $\begin{array}{l}28.338^{* *} \\
(13.313)\end{array}$ & $\begin{array}{l}22.594^{*} \\
(13.104)\end{array}$ & $\begin{array}{c}19.506 \\
(13.183)\end{array}$ \\
\hline Fraction of women in ethnic minority & & & $\begin{array}{c}20.381 \\
(18.050)\end{array}$ & $\begin{array}{c}3.289 \\
(19.371)\end{array}$ & $\begin{array}{c}14.875 \\
(18.349)\end{array}$ & $\begin{array}{c}21.416 \\
(18.199)\end{array}$ \\
\hline Fraction of promoted mayors in the future & & & & & $\begin{array}{c}7.299 \\
(5.562)\end{array}$ & $\begin{array}{c}7.743 \\
(5.456)\end{array}$ \\
\hline Herfindahl-Hirschman Index & & & & & & $\begin{array}{l}-5.365 \\
(6.383)\end{array}$ \\
\hline Share of Province Population & & & & & & $\begin{array}{c}0.973 \\
(6.730)\end{array}$ \\
\hline Observations & 107 & 107 & 107 & 107 & 78 & 78 \\
\hline $\mathrm{R}^{2}$ & 0.70 & 0.73 & 0.71 & 0.73 & 0.85 & 0.87 \\
\hline Year FE & $\bar{Y}$ & $\mathrm{Y}$ & $\bar{Y}$ & $\mathrm{Y}$ & $\bar{Y}$ & $\bar{Y}$ \\
\hline Province FE & Y & Y & Y & Y & Y & Y \\
\hline
\end{tabular}

Notes: Data on the number of women aged 15-45, the fraction of rural women, and the fraction of women in ethnic minority are from the 1982, 1990 and 2000 population censuses. * significant at $10 \%$ level; ** significant at $5 \%$ level; $* * *$ significant at $1 \%$ level. 


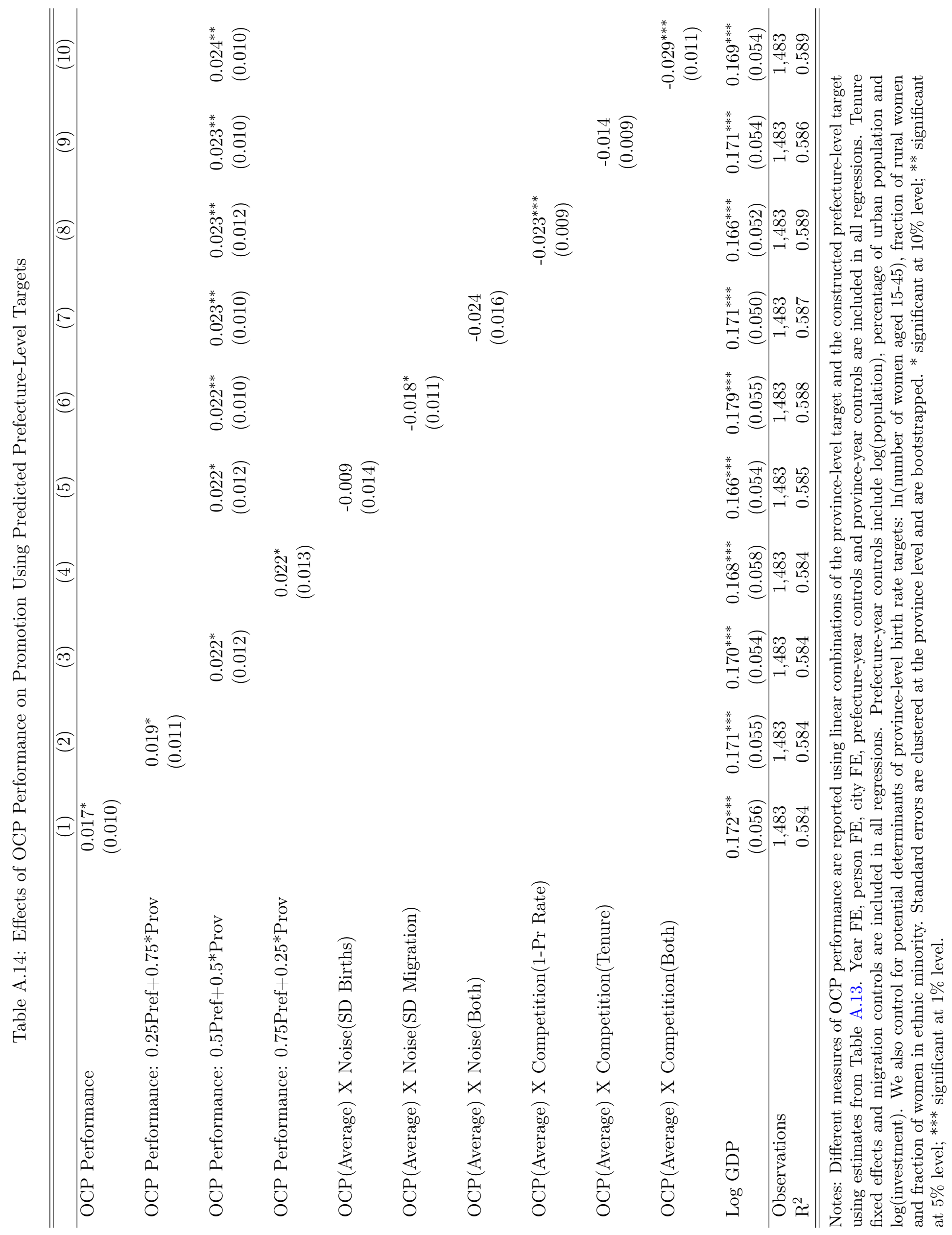


Table A.15: The Effect of Promotion on Reported OCP Performance is Robust to Mayor Dominance

\begin{tabular}{lcccc}
\hline \hline & \multicolumn{4}{c}{ Promotion =1 } \\
\cline { 2 - 5 } & $(1)$ & $(2)$ & $(3)$ & $(4)$ \\
\hline OCP Performance Reported & $0.017^{*}$ & $0.018^{*}$ & $0.019^{*}$ & $0.017^{*}$ \\
& $(0.010)$ & $(0.011)$ & $(0.010)$ & $(0.010)$ \\
OCP Performance from Census & -0.002 & -0.005 & -0.005 & -0.002 \\
& $(0.005)$ & $(0.004)$ & $(0.005)$ & $(0.005)$ \\
& & & & \\
Log GDP & $0.172^{* * *}$ & $0.163^{* *}$ & $0.165^{* * *}$ & $0.168^{* * *}$ \\
& $(0.056)$ & $(0.063)$ & $(0.061)$ & $(0.056)$ \\
Herfindahl-Hirschman Index & & & & 0.188 \\
& & & & $(0.618)$ \\
Share of Province Population & & & & -0.310 \\
& & & & $(0.503)$ \\
\hline Observations & 1,483 & 1,271 & 1,296 & 1,483 \\
$\mathrm{R}^{2}$ & 0.58 & 0.59 & 0.60 & 0.58 \\
Test $\beta^{\text {Reported }}>\beta^{\text {Census }}$ (p-val) & 0.08 & 0.04 & 0.04 & 0.08 \\
\hline \hline
\end{tabular}

Notes: OCP performance reported is the target for the rate of natural increase minus the reported rate of natural increase. Tenure fixed effects and migration controls are included in all regressions. Prefecture-year controls include $\log$ (population), percentage of urban population and $\log$ (government investment). Standard errors are clustered at province level. The Herfindahl-Hirschman Index captures the concentration of population within a province. Column (2) excludes mayors that represent more than $25 \%$ of a province's population and column (3) excludes relatively more concentrated provinces (those with an $\mathrm{HHI}$ above $33 \%$ ). ${ }^{*}$ significant at $10 \%$ level; ${ }^{* *}$ significant at $5 \%$ level; ${ }^{* * *}$ significant at $1 \%$ level. 

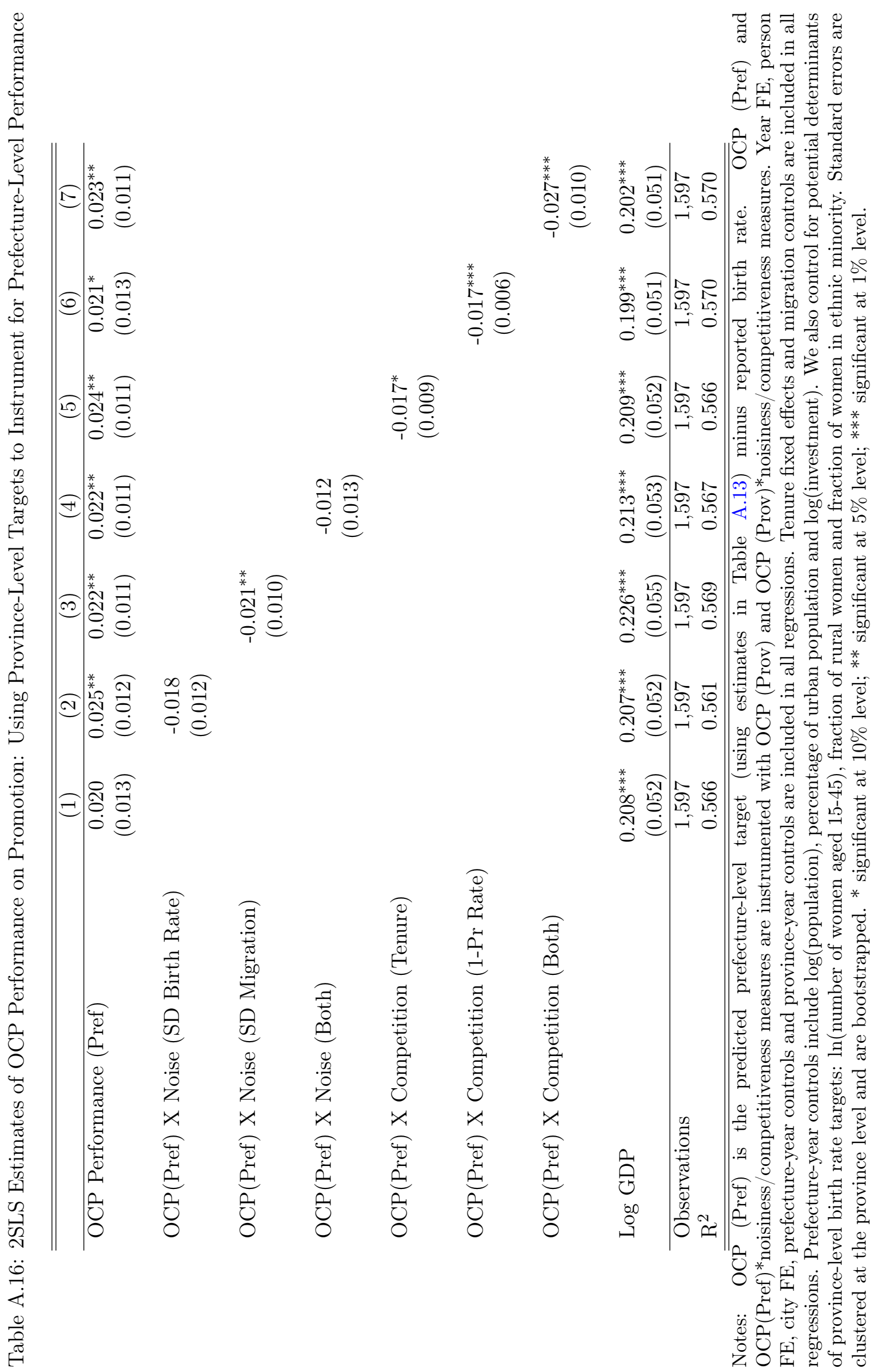

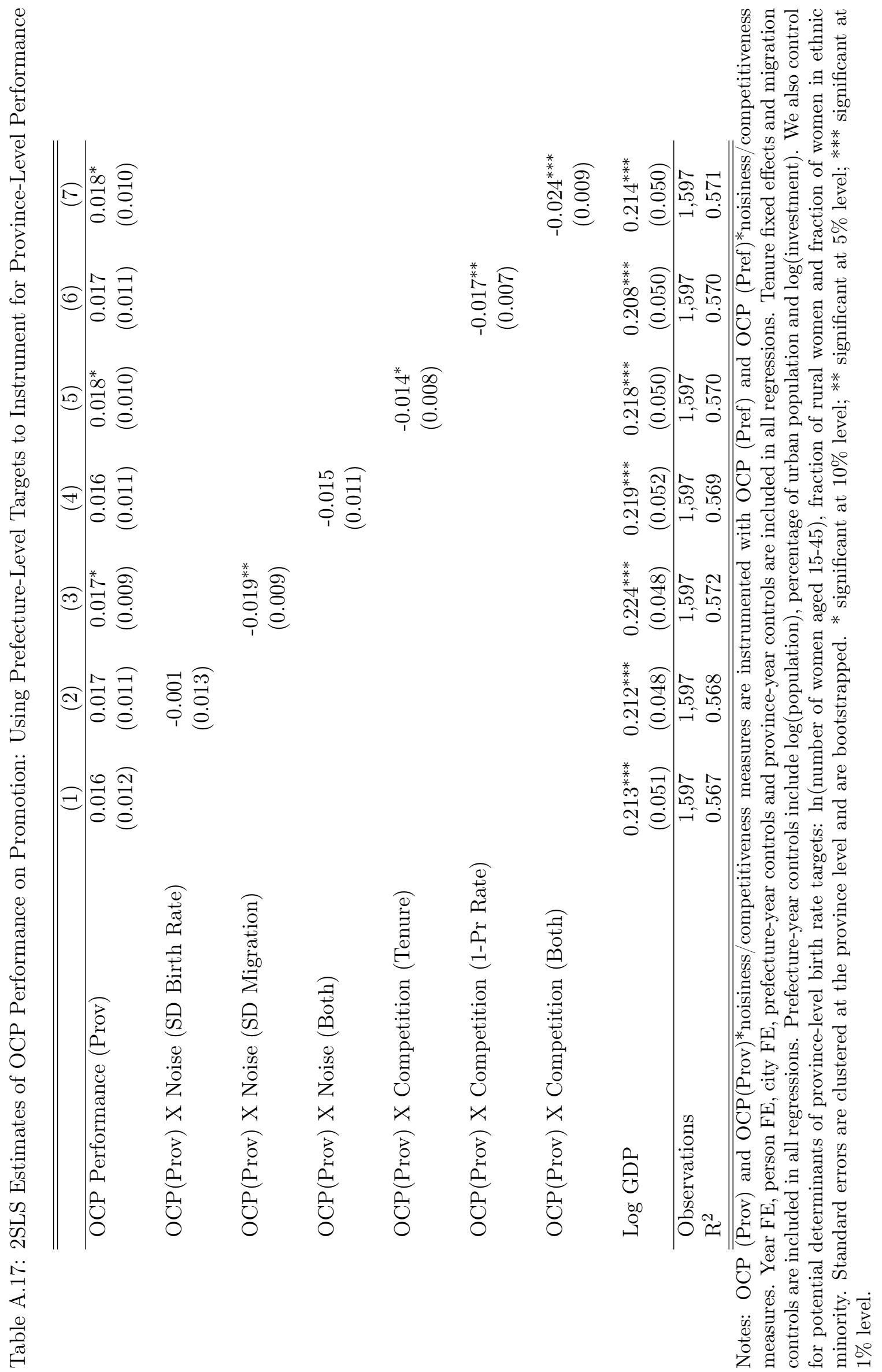
Table A.18: Lagged OCP Performance and Promotion

\begin{tabular}{lcccc}
\hline \hline & \multicolumn{4}{c}{ Promotion $=1$} \\
\cline { 2 - 5 } & $(1)$ & $(2)$ & $(3)$ & $(4)$ \\
\hline OCP Performance Reported & $0.017^{*}$ & $0.017^{*}$ & $0.018^{*}$ & $0.018^{*}$ \\
& $(0.010)$ & $(0.010)$ & $(0.009)$ & $(0.010)$ \\
OCP Performance Reported Lagged 1 & 0.002 & 0.002 & 0.003 & 0.003 \\
& $(0.002)$ & $(0.003)$ & $(0.003)$ & $(0.003)$ \\
OCP Performance Reported Lagged 2 & & 0.001 & 0.001 & 0.001 \\
& & $(0.003)$ & $(0.003)$ & $(0.003)$ \\
OCP Performance Reported Lagged 3 & & & $0.005^{* *}$ & $0.005^{* *}$ \\
& & & $(0.002)$ & $(0.002)$ \\
OCP Performance Reported Lagged 4 & & & & -0.001 \\
& & & & $(0.003)$ \\
Log GDP & & & & \\
& $0.168^{* * *}$ & $0.167^{* * *}$ & $0.170^{* * *}$ & $0.170^{* * *}$ \\
Observations & $(0.057)$ & $(0.055)$ & $(0.054)$ & $(0.057)$ \\
$\mathrm{R}^{2}$ & 1,482 & 1,481 & 1,480 & 1,480 \\
\hline Year FE & 0.58 & 0.58 & 0.59 & 0.59 \\
Person FE & $\mathrm{Y}$ & $\mathrm{Y}$ & $\mathrm{Y}$ & $\mathrm{Y}$ \\
City FE & $\mathrm{Y}$ & $\mathrm{Y}$ & $\mathrm{Y}$ & $\mathrm{Y}$ \\
Prefecture-year controls & $\mathrm{Y}$ & $\mathrm{Y}$ & $\mathrm{Y}$ & $\mathrm{Y}$ \\
\hline OCP perfomap & $\mathrm{Y}$ & $\mathrm{Y}$ & $\mathrm{Y}$ & $\mathrm{Y}$ \\
\hline
\end{tabular}

Notes: $\overline{\overline{\text { OCP performance reported is the target for the rate of natural increase minus the report }}}$ ed rate of natural increase. Tenure fixed effects and migration controls are included in all regressions. Prefecture-year controls include $\log$ (population), percentage of urban population and $\log$ (government investment). Standard errors are clustered at the province level and are bootstrapped. ${ }^{*}$ significant at $10 \%$ level; ${ }^{* *}$ significant at $5 \%$ level; *** significant at $1 \%$ level. 


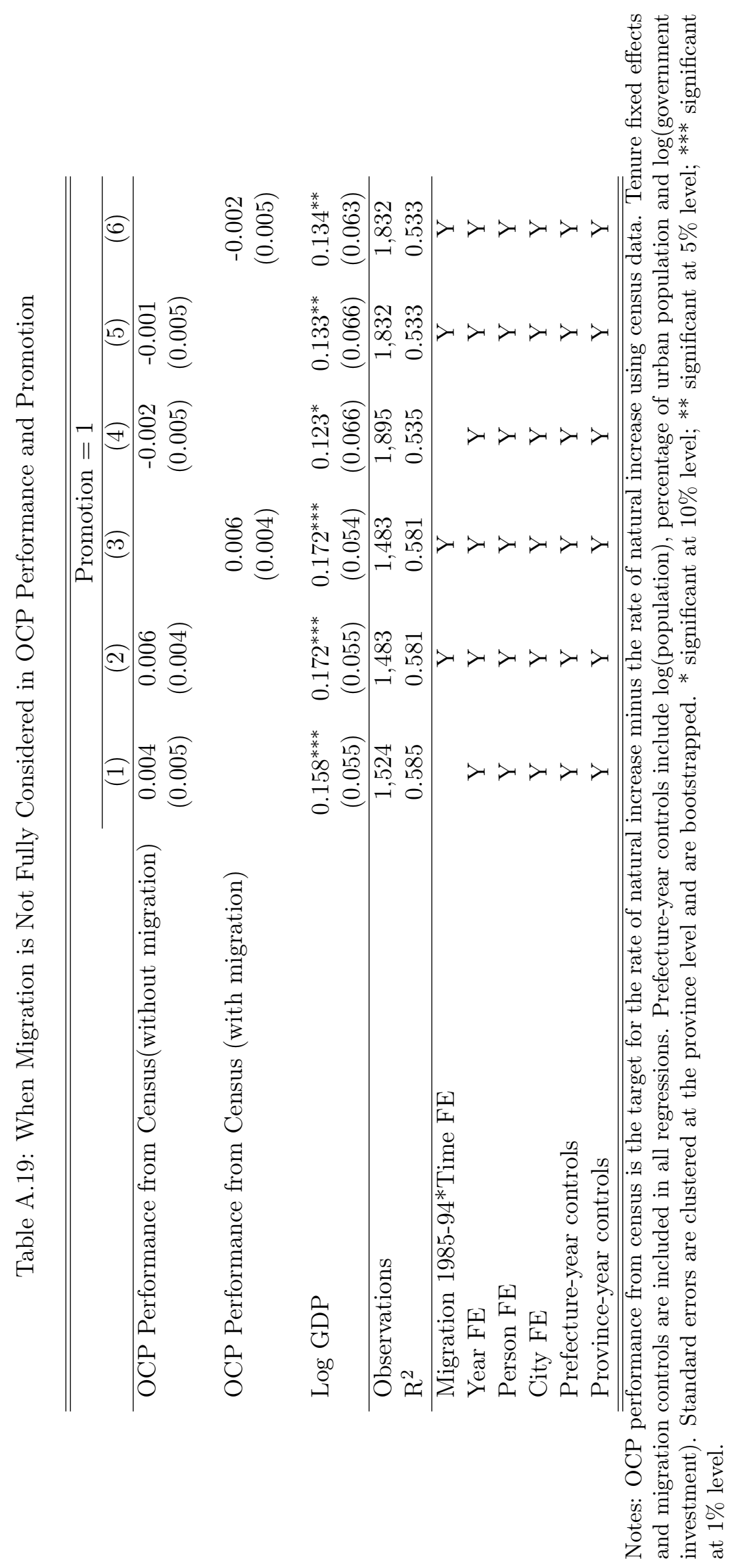




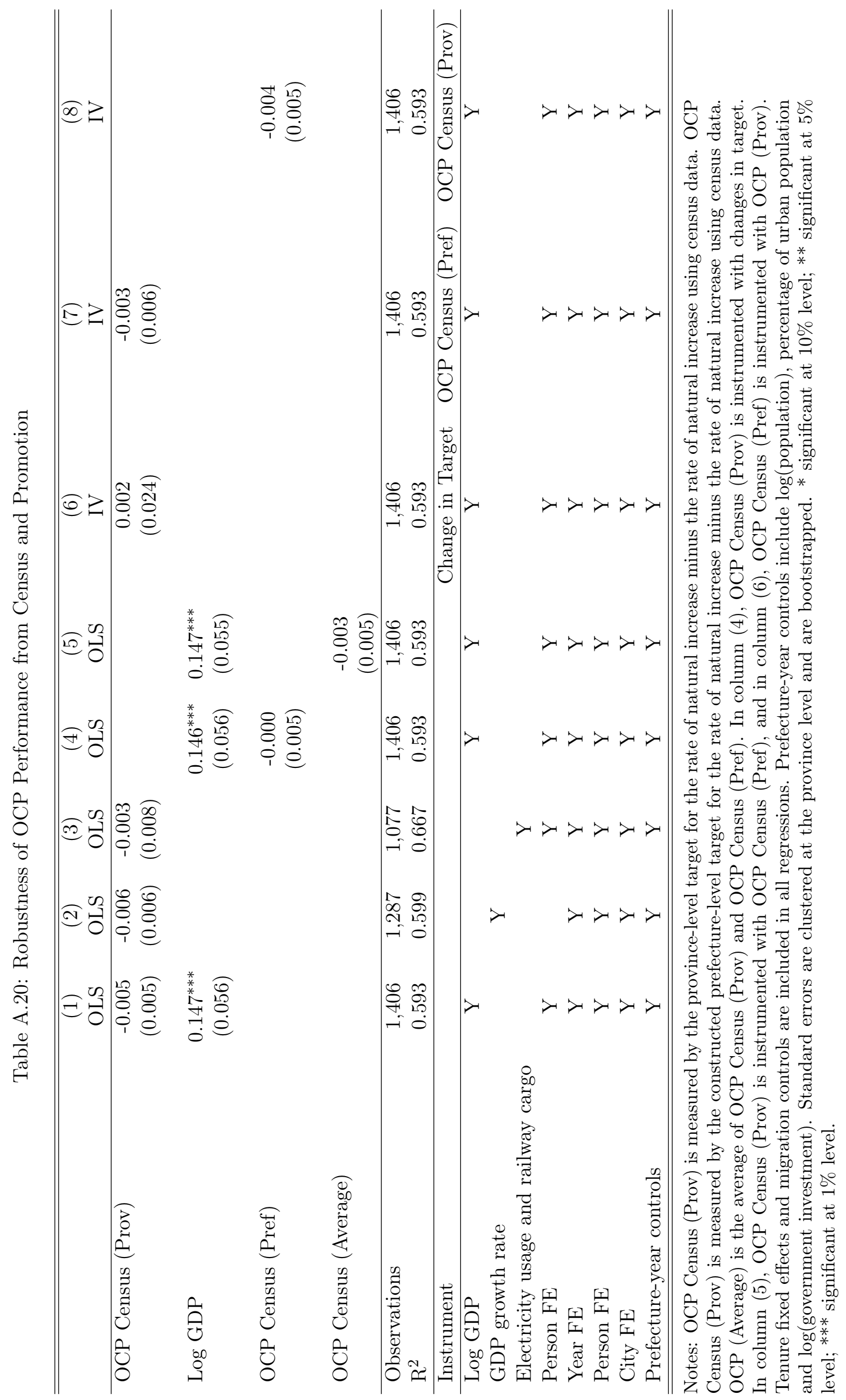


Table A.21: Effect of Being Above Target on Level of Misreporting

\begin{tabular}{lcccc}
\hline \hline & \multicolumn{4}{c}{ Misreporting } \\
\cline { 2 - 5 } Above Target & $(1)$ & $(2)$ & $(3)$ & $(4)$ \\
\cline { 2 - 5 } & $-1.284^{* * *}$ & $-2.394^{* * *}$ & $-2.394^{* * *}$ & $-2.415^{* * *}$ \\
& $(0.339)$ & $(0.384)$ & $(0.390)$ & $(0.377)$ \\
Log GDP & & & & \\
& -0.406 & -0.552 & -0.552 & -0.867 \\
& $(0.368)$ & $(0.584)$ & $(0.599)$ & $(0.674)$ \\
\hline Observations & 1,832 & 1,832 & 1,832 & 1,832 \\
$\mathrm{R}^{2}$ & 0.36 & 0.82 & 0.82 & 0.82 \\
\hline \hline
\end{tabular}

Notes: Misreporting is measured as the difference: Census - Reported Birth Rates. Tenure fixed effects and migration controls are included in all regressions. Prefecture-year controls include log(population), percentage of urban population and $\log$ (government investment). Standard errors are clustered at the province level and are bootstrapped. ${ }^{*}$ significant at $10 \%$ level; ${ }^{* *}$ significant at $5 \%$ level; ${ }^{* * *}$ significant at $1 \%$ level.

Table A.22: Effect of Being Above Target on Likelihood of Misreporting

\begin{tabular}{lcccc}
\hline \hline & \multicolumn{4}{c}{ Misreporting $=1$} \\
\cline { 2 - 5 } Above Target & $(1)$ & $(2)$ & $(3)$ & $(4)$ \\
\cline { 2 - 5 } & $-0.130^{* * *}$ & $-0.153^{* * *}$ & $-0.153^{* * *}$ & $-0.157^{* * *}$ \\
& $(0.034)$ & $(0.033)$ & $(0.034)$ & $(0.033)$ \\
Log GDP & & & & \\
& -0.014 & -0.070 & -0.070 & $-0.129^{*}$ \\
\hline Observations & $10.033)$ & $(0.066)$ & $(0.064)$ & $(0.075)$ \\
$\mathrm{R}^{2}$ & 0.29 & 1,972 & 1,972 & 1,972 \\
\hline \hline
\end{tabular}

Notes: We define incidence of misreporting as an indicator for Census $>$ Reported Birth Rates. Tenure fixed effects and migration controls are included in all regressions. Prefecture-year controls include log(population), percentage of urban population and $\log$ (government investment). Standard errors are clustered at the province level and are bootstrapped. ${ }^{*}$ significant at $10 \%$ level; ${ }^{* *}$ significant at $5 \%$ level; ${ }^{* * *}$ significant at $1 \%$ level.

Table A.23: Effects of Population Audits for Mayors Above Target

\begin{tabular}{lcccc}
\hline \hline & $(1)$ & $(2)$ & $(3)$ & $(4)$ \\
\hline & Misreporting & $\begin{array}{c}\text { Reported } \\
\text { Birth Rate }\end{array}$ & $\begin{array}{c}\text { Census } \\
\text { Birth Rate }\end{array}$ & Log GDP \\
\hline Audit Year & -0.134 & $-0.908^{*}$ & -1.043 & $0.232^{* * *}$ \\
& $(1.158)$ & $(0.498)$ & $(1.116)$ & $(0.049)$ \\
\hline Observations & 371 & 371 & 371 & 371 \\
$\mathrm{R}^{2}$ & 0.90 & 0.89 & 0.94 & 0.99 \\
\hline \hline
\end{tabular}

Notes: Misreporting is measured as the difference: Census - Reported Birth Rates. Audit years include the year before the census year in 1990 and 1995, and the year before the national fertility survey in 1988, 1992, and 1997. Tenure fixed effects and migration controls are included in all regressions. Prefecture-year controls include $\log$ (population), percentage of urban population and $\log$ (government investment). Standard errors are clustered at the province level and are bootstrapped. ${ }^{*}$ significant at $10 \%$ level; ${ }^{* *}$ significant at $5 \%$ level; $* * *$ significant at $1 \%$ level. 
Table A.24: OCP Performance and Promotion in a Sub-sample of Mayors in Position for More Than Two Years

\begin{tabular}{|c|c|c|c|c|}
\hline \multirow{4}{*}{ OCP Performance Reported } & \multicolumn{4}{|c|}{ Promotion $=1$} \\
\hline & (1) & (2) & (3) & (4) \\
\hline & 0.005 & $0.016^{*}$ & $0.016^{*}$ & $0.016^{*}$ \\
\hline & $(0.006)$ & $(0.009)$ & $(0.009)$ & $(0.009)$ \\
\hline OCP Performance from Census & 0.002 & -0.004 & -0.004 & -0.003 \\
\hline & $(0.003)$ & $(0.006)$ & $(0.005)$ & $(0.005)$ \\
\hline Log GDP & -0.011 & $0.148^{* *}$ & $0.148^{* *}$ & $0.180^{* * *}$ \\
\hline & $(0.012)$ & $(0.066)$ & $(0.069)$ & $(0.066)$ \\
\hline Observations & 1,304 & 1,304 & 1,304 & 1,304 \\
\hline $\mathrm{R}^{2}$ & 0.09 & 0.49 & 0.49 & 0.50 \\
\hline Test $\beta^{\text {Reported }}>\beta_{\text {Census }}(\mathrm{p}$-val) & 0.34 & 0.06 & 0.06 & 0.06 \\
\hline Year FE & $\bar{Y}$ & $\bar{Y}$ & $\mathrm{Y}$ & $\mathrm{Y}$ \\
\hline Person FE & & Y & Y & Y \\
\hline City FE & & & Y & Y \\
\hline Prefecture-year controls & & & & Y \\
\hline
\end{tabular}

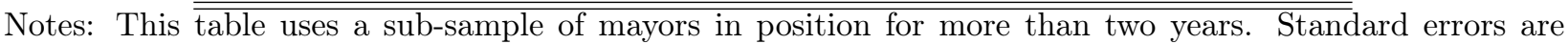
clustered at the province level and are bootstrapped. * significant at $10 \%$ level; ${ }^{* *}$ significant at $5 \%$ level; *** significant at $1 \%$ level. 